\title{
Pessaries (mechanical devices) for managing pelvic organ prolapse in women (Review)
}

Bugge C, Adams EJ, Gopinath D, Stewart F, Dembinsky M, Sobiesuo P, Kearney R

Bugge C, Adams EJ, Gopinath D, Stewart F, Dembinsky M, Sobiesuo P, Kearney R.

Pessaries (mechanical devices) for managing pelvic organ prolapse in women.

Cochrane Database of Systematic Reviews 2020, Issue 11. Art. No.: CD004010.

DOI: 10.1002/14651858.CD004010.pub4.

www.cochranelibrary.com 
TABLE OF CONTENTS

HEADER

ABSTRACT

PLAIN LANGUAGE SUMMARY

SUMMARY OF FINDINGS

BACKGROUND

OBJECTIVES

METHODS

RESULTS

Figure 1.

Figure 2.

Figure 3.

Figure 4.

DISCUSSION

AUTHORS' CONCLUSIONS

ACKNOWLEDGEMENTS

REFERENCES

CHARACTERISTICS OF STUDIES

DATA AND ANALYSES

Analysis 1.1. Comparison 1: Any pessary versus control, waiting list or no active treatment, Outcome 1: Women's perceived improvement in prolapse symptoms: POP score of Australian Pelvic Floor Questionnaire at 12 months (range 0-10, higher score = worse symptoms)

Analysis 1.2. Comparison 1: Any pessary versus control, waiting list or no active treatment, Outcome 2: Site-specific grading of prolapse - anterior - (measured with POP-Q) at 12 months

Analysis 1.3. Comparison 1: Any pessary versus control, waiting list or no active treatment, Outcome 3: Site-specific grading of prolapse - posterior - (measured with POP-Q) at 12 months

Analysis 1.4. Comparison 1: Any pessary versus control, waiting list or no active treatment, Outcome 4: Cure or improvement of bladder problems at 12 months (measured with bladder score of Australian Pelvic Floor Questionnaire, range 0-10, higher score $=$ worse symptoms)

Analysis 1.5. Comparison 1: Any pessary versus control, waiting list or no active treatment, Outcome 5: Cure or improvement of bowel problems at 12 months (measured with bowel score of Australian Pelvic Floor Questionnaire, range 0-10, higher score = worse symptoms)

Analysis 1.6. Comparison 1: Any pessary versus control, waiting list or no active treatment, Outcome 6: Cure or improvement of sexual problems at 12 months (measured with sex score of Australian Pelvic Floor Questionnaire, range 0-10, higher score = worse symptoms)

Analysis 2.1. Comparison 2: Any pessary versus PFMT, Outcome 1: Women's perceived improvement of prolapse symptoms at 12 months (measured with PFDI-20; range: 0-300, higher score = worse symptoms)

Analysis 2.2. Comparison 2: Any pessary versus PFMT, Outcome 2: Women's perceived improvement of prolapse symptoms at 24 months (measured with PFDI-20; range: 0-300, higher score = worse symptoms)

Analysis 2.3. Comparison 2: Any pessary versus PFMT, Outcome 3: Women's perceived improvement of prolapse symptoms at 12 months (measured with POPDI-6; range: 0-100, higher score = worse symptoms)

Analysis 2.4. Comparison 2: Any pessary versus PFMT, Outcome 4: Women's perceived improvement of prolapse symptoms at 24 months (POPDI-6; range: 0-100, higher score = worse symptoms)

Analysis 2.5. Comparison 2: Any pessary versus PFMT, Outcome 5: Women's perceived improvement of prolapse symptoms at 24 months

Analysis 2.6. Comparison 2: Any pessary versus PFMT, Outcome 6: Prolapse-specific quality of life at 12 months (measured with PFIQ-7, range: 0-300, higher score $=$ worse QoL)

Analysis 2.7. Comparison 2: Any pessary versus PFMT, Outcome 7: Prolapse-specific quality of life at 24 months (measured with PFIQ-7, range: 0-300, higher score $=$ worse $Q \mathrm{QL})$

Analysis 2.8. Comparison 2: Any pessary versus PFMT, Outcome 8: Quality of life at 12 months (measured with PCS-12, range: $0-100$, higher score $=$ better health status)

Analysis 2.9. Comparison 2: Any pessary versus PFMT, Outcome 9: Quality of life at 24 months (measures with PCS-12, range: 0 -100, higher score $=$ better health status)

Analysis 2.10. Comparison 2: Any pessary versus PFMT, Outcome 10: Quality of life at 12 months (measured with MCS-12, range: $0-100$, higher score $=$ better health status) 
Analysis 2.11. Comparison 2: Any pessary versus PFMT, Outcome 11: Quality of life at 24 months (measured with MCS-12, range: 0-100, higher score $=$ better health status)

Analysis 2.12. Comparison 2: Any pessary versus PFMT, Outcome 12: Cure or improvement of bladder problems at 12 months (measured with UDI-6, range: 0-100, higher score = worse symptoms)

Analysis 2.13. Comparison 2: Any pessary versus PFMT, Outcome 13: Cure or improvement of bladder problems at 24 month (measured with UDI-6, range: 0-100, higher score = worse symptoms)

Analysis 2.14. Comparison 2: Any pessary versus PFMT, Outcome 14: Cure or improvement of bowel problems at 12 months (measured with CRADI-8, range: 0-100, higher score = worse symptoms)

Analysis 2.15. Comparison 2: Any pessary versus PFMT, Outcome 15: Cure or improvement of bowel problems at 24 months (measured with CRADI-8, range: 0-100, higher score = worse symptoms)

Analysis 2.16. Comparison 2: Any pessary versus PFMT, Outcome 16: Cure or improvement of sexual problems at 12 months (measured with PISQ-12, range: 0-48, higher score = better sexual functioning)

Analysis 2.17. Comparison 2: Any pessary versus PFMT, Outcome 17: Cure or improvement of sexual problems at 24 months (measured with PISQ-12, range: 0-48, higher score = better sexual functioning)

Analysis 2.18. Comparison 2: Any pessary versus PFMT, Outcome 18: Number of women with adverse events

Analysis 3.1. Comparison 3: Any pessary plus PFMT versus PFMT alone, Outcome 1: Perceived improvement of prolapse symptoms at 12 months

Analysis 3.2. Comparison 3: Any pessary plus PFMT versus PFMT alone, Outcome 2: Cure or improvement of bladder problems - SUI

Analysis 3.3. Comparison 3: Any pessary plus PFMT versus PFMT alone, Outcome 3: Cure or improvement of bladder problems - UUI

Analysis 3.4. Comparison 3: Any pessary plus PFMT versus PFMT alone, Outcome 4: Cure or improvement of bladder problems - voiding difficulty

Analysis 3.5. Comparison 3: Any pessary plus PFMT versus PFMT alone, Outcome 5: Number of women with adverse events abnormal vaginal bleeding

Analysis 3.6. Comparison 3: Any pessary plus PFMT versus PFMT alone, Outcome 6: Number of women with adverse events de novo voiding difficulty

APPENDICES

WHAT'S NEW

HISTORY

CONTRIBUTIONS OF AUTHORS

DECLARATIONS OF INTEREST

SOURCES OF SUPPORT

DIFFERENCES BETWEEN PROTOCOL AND REVIEW

INDEX TERMS 
[Intervention Review]

\section{Pessaries (mechanical devices) for managing pelvic organ prolapse in women}

Carol Bugge ${ }^{1}$, Elisabeth J Adams², Deepa Gopinath ${ }^{3}$, Fiona Stewart ${ }^{4}$, Melanie Dembinsky ${ }^{1}$, Pauline Sobiesuo ${ }^{5}$, Rohna Kearney 6

1School of Health Sciences and Sport, University of Stirling, Stirling, UK. 2Department of Urodynamics, Liverpool Women's Hospital, Liverpool, UK. ${ }^{3}$ Department of Obstetrics and Gynaecology, Cairns Hospital, Cairns, Australia. ${ }^{4}$ C/o Cochrane Incontinence, Population Health Sciences Institute, Newcastle University, Newcastle upon Tyne, UK. ${ }^{5}$ Population Health Sciences Institute, Newcastle University, Newcastle upon Tyne, UK. ${ }^{6}$ The Warrell Unit, Department of Gynaecology, St Mary's Hospital, Manchester University Foundation NHS Trust, Manchester, UK

Contact address: Carol Bugge, carol.bugge@stir.ac.uk.

Editorial group: Cochrane Incontinence Group.

Publication status and date: New search for studies and content updated (conclusions changed), published in Issue 11, 2020.

Citation: Bugge C, Adams EJ, Gopinath D, Stewart F, Dembinsky M, Sobiesuo P, Kearney R. Pessaries (mechanical devices) for managing pelvic organ prolapse in women. Cochrane Database of Systematic Reviews 2020, Issue 11. Art. No.: CD004010. DOI: 10.1002/14651858.CD004010.pub4.

Copyright @ 2020 The Cochrane Collaboration. Published by John Wiley \& Sons, Ltd.

\section{A B S T R A C T}

\section{Background}

Pelvic organ prolapse is a common problem in women. About $40 \%$ of women will experience prolapse in their lifetime, with the proportion expected to rise in line with an ageing population. Women experience a variety of troublesome symptoms as a consequence of prolapse, including a feeling of 'something coming down' into the vagina, pain, urinary symptoms, bowel symptoms and sexual difficulties. Treatment for prolapse includes surgery, pelvic floor muscle training (PFMT) and vaginal pessaries. Vaginal pessaries are passive mechanical devices designed to support the vagina and hold the prolapsed organs back in the anatomically correct position. The most commonly used pessaries are made from polyvinyl-chloride, polythene, silicone or latex. Pessaries are frequently used by clinicians with high numbers of clinicians offering a pessary as first-line treatment for prolapse.

This is an update of a Cochrane Review first published in 2003 and last published in 2013.

\section{Objectives}

To assess the effects of pessaries (mechanical devices) for managing pelvic organ prolapse in women; and summarise the principal findings of relevant economic evaluations of this intervention.

\section{Search methods}

We searched the Cochrane Incontinence Specialised Register which contains trials identified from the Cochrane Central Register of Controlled Trials (CENTRAL), MEDLINE, MEDLINE In-Process, MEDLINE Epub Ahead of Print, ClinicalTrials.gov, WHO ICTRP and handsearching of journals and conference proceedings (searched 28 January 2020). We searched the reference lists of relevant articles and contacted the authors of included studies.

\section{Selection criteria}

We included randomised and quasi-randomised controlled trials which included a pessary for pelvic organ prolapse in at least one arm of the study. 


\section{Data collection and analysis}

Two review authors independently assessed abstracts, extracted data, assessed risk of bias and carried out GRADE assessments with arbitration from a third review author if necessary.

\section{Main results}

We included four studies involving a total of 478 women with various stages of prolapse, all of which took place in high-income countries. In one trial, only six of the 113 recruited women consented to random assignment to an intervention and no data are available for those six women. We could not perform any meta-analysis because each of the trials addressed a different comparison. None of the trials reported data about perceived resolution of prolapse symptoms or about psychological outcome measures. All studies reported data about perceived improvement of prolapse symptoms.

Generally, the trials were at high risk of performance bias, due to lack of blinding, and low risk of selection bias. We downgraded the certainty of evidence for imprecision resulting from the low numbers of women participating in the trials.

Pessary versus no treatment: at 12 months' follow-up, we are uncertain about the effect of pessaries compared with no treatment on perceived improvement of prolapse symptoms (mean difference (MD) in questionnaire scores $-0.03,95 \%$ confidence interval (CI) -0.61 to 0.55; 27 women; 1 study; very low-certainty evidence), and cure or improvement of sexual problems (MD $-0.29,95 \% \mathrm{Cl}-1.67$ to $1.09 ; 27$ women; 1 study; very low-certainty evidence). In this comparison we did not find any evidence relating to prolapse-specific quality of life or to the number of women experiencing adverse events (abnormal vaginal bleeding or de novo voiding difficulty).

Pessary versus pelvic floor muscle training (PFMT): at 12 months' follow-up, we are uncertain if there is a difference between pessaries and PFMT in terms of women's perceived improvement in prolapse symptoms (MD -9.60, 95\% Cl -22.53 to 3.33; 137 women; low-certainty evidence), prolapse-specific quality of life (MD $-3.30,95 \% \mathrm{Cl}-8.70$ to $15.30 ; 1$ study; 116 women; low-certainty evidence), or cure or improvement of sexual problems (MD -2.30, 95\% -5.20 to 0.60; 1 study; 48 women; low-certainty evidence). Pessaries may result in a large increase in risk of adverse events compared with PFMT (RR 75.25, 95\% Cl 4.70 to 1205.45; 1 study; 97 women; low-certainty evidence). Adverse events included increased vaginal discharge, and/or increased urinary incontinence and/or erosion or irritation of the vaginal walls.

Pessary plus PFMT versus PFMT alone: at 12 months' follow-up, pessary plus PFMT probably leads to more women perceiving improvement in their prolapse symptoms compared with PFMT alone (RR 2.15, 95\% Cl 1.58 to 2.94; 1 study; 260 women; moderate-certainty evidence). At 12 months' follow-up, pessary plus PFMT probably improves women's prolapse-specific quality of life compared with PFMT alone (median (interquartile range (IQR)) POPIQ score: pessary plus PFMT 0.3 (0 to 22.2); 132 women; PFMT only 8.9 (0 to 64.9 ); 128 women; $\mathrm{P}=0.02$; moderate-certainty evidence). Pessary plus PFMT may slightly increase the risk of abnormal vaginal bleeding compared with PFMT alone (RR $2.18,95 \% \mathrm{Cl} 0.69$ to $6.91 ; 1$ study; 260 women; low-certainty evidence). The evidence is uncertain if pessary plus PFMT has any effect on the risk of de novo voiding difficulty compared with PFMT alone (RR 1.32, 95\% Cl 0.54 to 3.19; 1 study; 189 women; lowcertainty evidence).

\section{Authors' conclusions}

We are uncertain if pessaries improve pelvic organ prolapse symptoms for women compared with no treatment or PFMT but pessaries in addition to PFMT probably improve women's pelvic organ prolapse symptoms and prolapse-specific quality of life. However, there may be an increased risk of adverse events with pessaries compared to PFMT. Future trials should recruit adequate numbers of women and measure clinically important outcomes such as prolapse specific quality of life and resolution of prolapse symptoms.

The review found two relevant economic evaluations. Of these, one assessed the cost-effectiveness of pessary treatment, expectant management and surgical procedures, and the other compared pessary treatment to PFMT.

\section{PLAIN LANGUAGE SUMMARY}

\section{Pessaries (mechanical devices) for managing pelvic organ prolapse in women}

\section{Review question}

How effective are pessaries (mechanical devices) for managing pelvic organ prolapse in women?

\section{Background}

Pelvic organs, such as the uterus, bladder or bowel, may protrude into the vagina because of weakness in the tissues that normally support them. This protrusion is known as pelvic organ prolapse. Women who experience prolapse report a wide variety of symptoms that affect their quality of life. The choice of treatment options for pelvic organ prolapse symptoms is dictated largely by patient choice, as the interventions of lifestyle changes, pelvic floor muscle training (PFMT), pessary and surgery are very different with different complication risks. Vaginal pessaries are one treatment option for prolapse that are commonly used to restore the prolapsed organs to their normal position and hence relieve symptoms. A vaginal pessary can be used to treat all four prolapse stages. 


\section{How up-to-date is this review?}

We searched for studies published up to 28 January 2020.

\section{Study characteristics}

We found four studies involving 478 women with various stages of prolapse. All four studies were carried out in high-income countries.

\section{Key results}

None of the studies reported whether or not the women's prolapse symptoms were completely resolved. We are uncertain about the effect of pessaries compared with no treatment on perceived improvement of prolapse symptoms, and cure or improvement of sexual problems. We did not find any evidence relating to the risk of vaginal bleeding or difficulty urinating in the studies comparing pessaries with no treatment.

We are uncertain if pessaries have any effect on improving women's prolapse symptoms when pessary is compared with PFMT. The evidence is also very uncertain about the effect of pessaries compared with PFMT on prolapse-specific quality of life and on sexual problems. Pessaries may result in a greater risk of adverse events, including vaginal discharge, increased urinary incontinence and erosion of the vaginal walls, compared with PFMT.

Pessary plus PFMT probably leads to more women perceiving improvement in their prolapse symptoms and in their prolapse-specific quality of life compared with PFMT alone. Compared with PFMT alone, pessary plus PFMT may slightly increase the risk of abnormal vaginal bleeding and the risk of having difficulty urinating, for women who did not have this problem before starting prolapse treatment, but the evidence is very uncertain.

\section{Certainty of the evidence}

We assessed the evidence relating to pessary compared with no treatment as very low certainty because of the low numbers of women participating in the study and because of problems with the way the trial was conducted. We assessed the evidence relating to pessary compared with PFMT, and pessary plus PFMT compared with PFMT alone, as low- to moderate-certainty because of the low numbers of women involved in the studies.

\section{Authors' conclusions}

Each of these trials contain small numbers of women, reducing the certainty of our conclusions. We are uncertain if pessaries improve pelvic organ prolapse symptoms for women compared with no treatment or when compared to another active treatment like PFMT, but pessaries in addition to PFMT probably improve women's symptoms and prolapse-specific quality of life. However, there may be an increased risk of adverse events with pessaries compared to no treatment or PFMT.

The review found two economic evaluation studies that compared pessary treatment to alternative interventions (PFMT, expectant management and surgical procedures). 


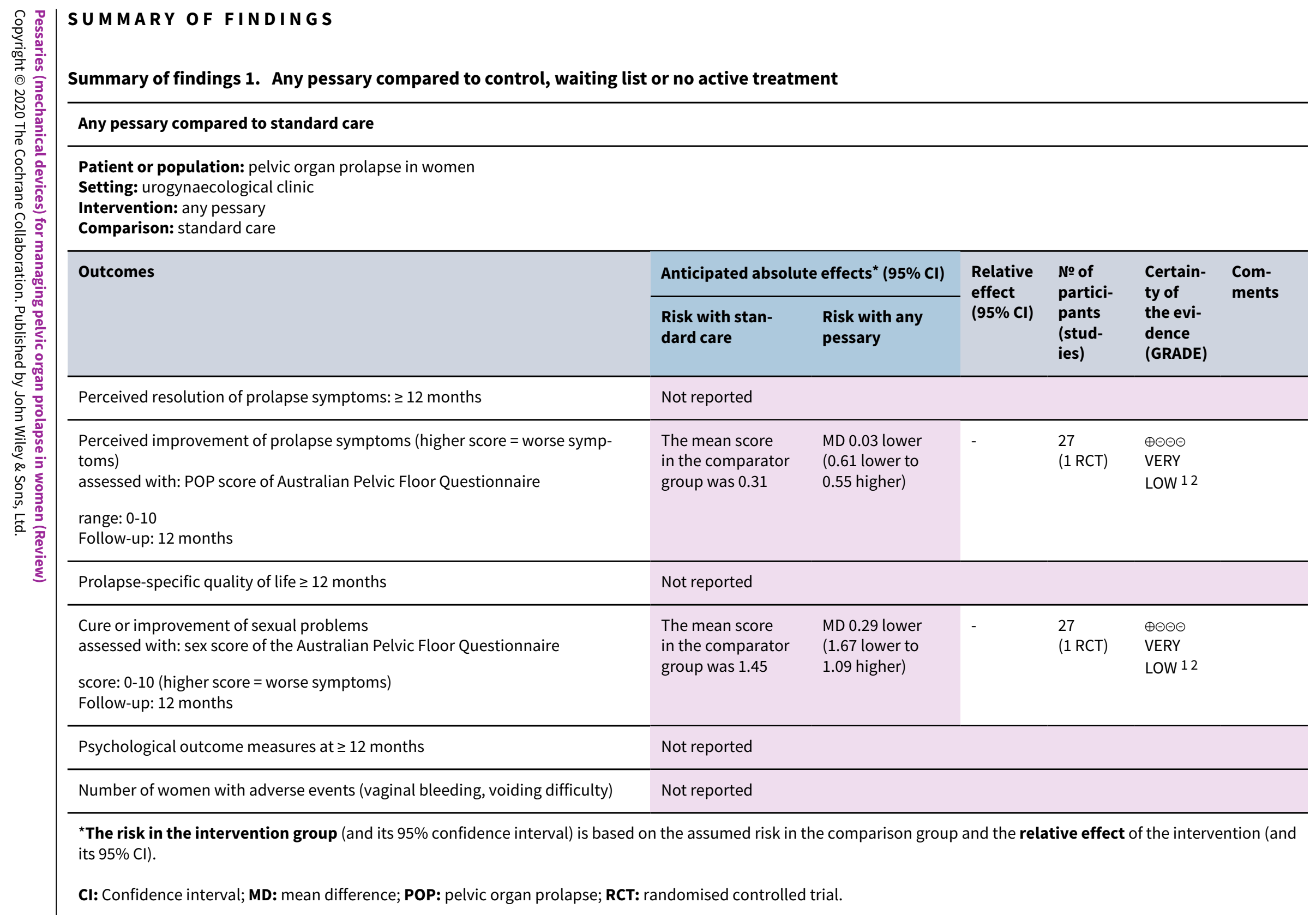

\section{GRADE Working Group grades of evidence}

High certainty: we are very confident that the true effect lies close to that of the estimate of the effect. 
Moderate certainty: we are moderately confident in the effect estimate; the true effect is likely to be close to the estimate of the effect, but there is a possibility that it is substantially different.

Low certainty: our confidence in the effect estimate is limited; the true effect may be substantially different from the estimate of the effect.

Very low certainty: we have very little confidence in the effect estimate; the true effect is likely to be substantially different from the estimate of effect.

1 Downgraded one level for risk of bias (performance and attrition bias)

2 Downgraded two levels for imprecision (few participants and wide $95 \% \mathrm{Cl}$ crossing the line of no effect)

\section{Summary of findings 2. Any pessary compared to pelvic floor muscle training (PFMT) for pelvic organ prolapse in women}

\section{Any pessary compared to PFMT or pelvic organ prolapse in women}

Patient or population: pelvic organ prolapse in women

Setting: urogynaecological clinic

Intervention: any pessary

Comparison: PFMT

\begin{tabular}{|c|c|c|c|c|c|c|}
\hline \multirow[t]{2}{*}{ Outcomes } & \multicolumn{2}{|c|}{ Anticipated absolute effects ${ }^{\star}(95 \% \mathrm{Cl})$} & \multirow{2}{*}{$\begin{array}{l}\text { Relative } \\
\text { effect } \\
(95 \% \mathrm{CI})\end{array}$} & \multirow{2}{*}{$\begin{array}{l}\text { № of } \\
\text { partici- } \\
\text { pants } \\
\text { (stud- } \\
\text { ies) }\end{array}$} & \multirow{2}{*}{$\begin{array}{l}\text { Certain- } \\
\text { ty of } \\
\text { the evi- } \\
\text { dence } \\
\text { (GRADE) }\end{array}$} & \multirow{2}{*}{$\begin{array}{l}\text { Com- } \\
\text { ments }\end{array}$} \\
\hline & Risk with PFMT & Risk with pessary & & & & \\
\hline Perceived resolution of prolapse symptoms $\geq 12$ months & Not reported & & & & & \\
\hline $\begin{array}{l}\text { Women's perceived improvement of prolapse symp- } \\
\text { toms (higher score = worse symptoms) } \\
\text { assessed with: POPDI- } 6 \\
\text { Scale from: } 0 \text { to } 100 \\
\text { Follow-up: } 12 \text { months }\end{array}$ & $\begin{array}{l}\text { The mean POPDI- } 6 \text { score in the } \\
\text { PFMT group was } 16.4\end{array}$ & $\begin{array}{l}\text { MD } 3.60 \text { lower } \\
\text { (8.73 lower to } 1.53 \text { higher) }\end{array}$ & - & $\begin{array}{l}117 \\
(1 \mathrm{RCT})\end{array}$ & $\begin{array}{l}\oplus \oplus \ominus \ominus \\
\text { LOW } 1\end{array}$ & \\
\hline $\begin{array}{l}\text { Prolapse-specific quality of life (higher score = worse } \\
\text { QoL) } \\
\text { assessed with: PFIQ-7 } \\
\text { Scale from: } 0 \text { to } 300 \\
\text { Follow-up: } 12 \text { months }\end{array}$ & $\begin{array}{l}\text { The mean PFIQ- } 7 \text { score in the } \\
\text { PFMT group was } 15.8\end{array}$ & $\begin{array}{l}\text { MD } 3.3 \text { higher } \\
\text { (8.70 lower to } 15.30 \text { higher) }\end{array}$ & - & $\begin{array}{l}116 \\
(1 \mathrm{RCT})\end{array}$ & $\begin{array}{l}\oplus \oplus \ominus \ominus \\
\text { LOW } 1\end{array}$ & \\
\hline
\end{tabular}




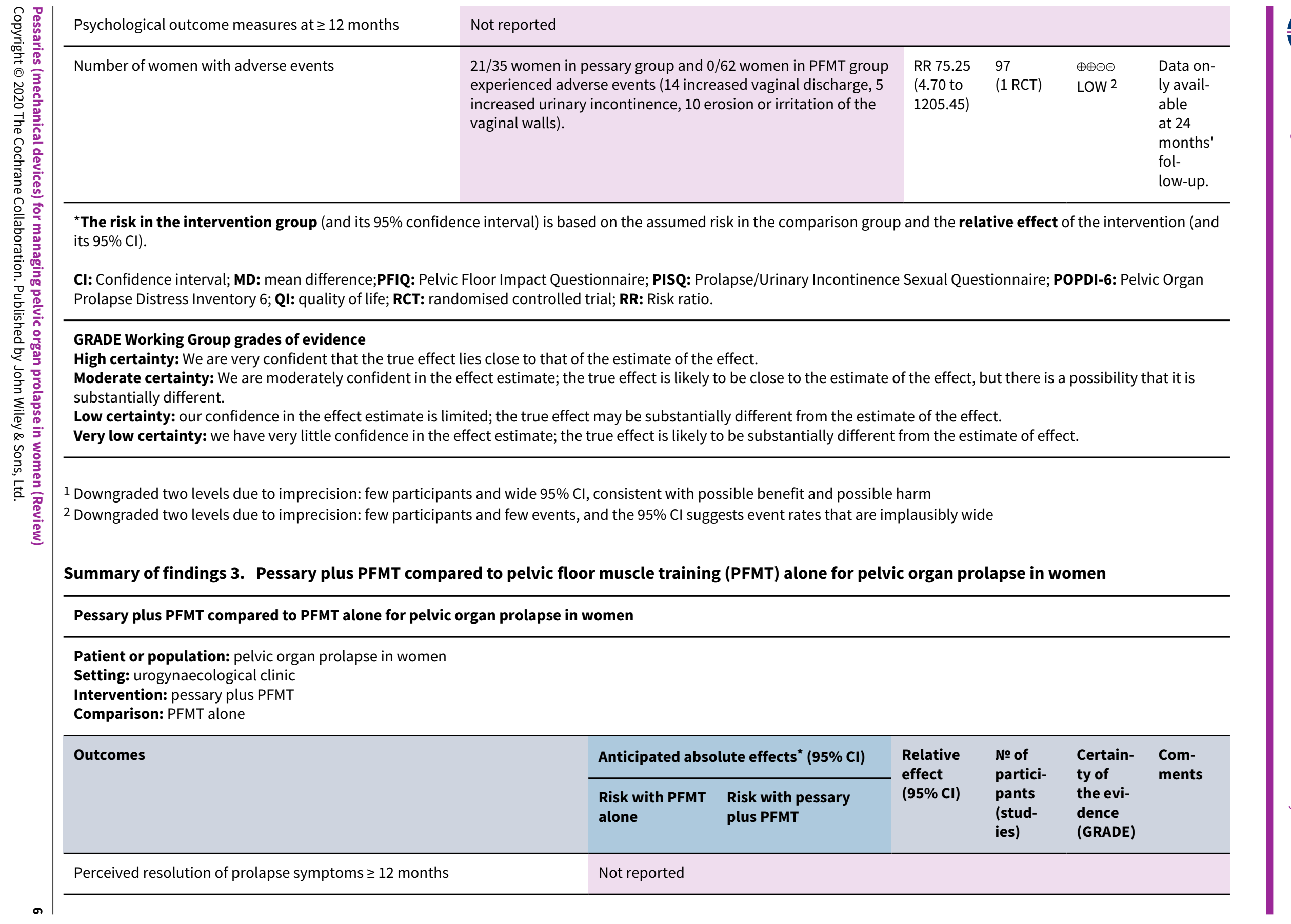




\begin{tabular}{|c|c|c|c|c|c|c|}
\hline 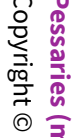 & $\begin{array}{l}\text { Perceived improvement of prolapse symptoms } \\
\text { Follow-up: } 12 \text { months }\end{array}$ & 281 per 1000 & $\begin{array}{l}605 \text { per } 1000 \\
(444 \text { to } 827)\end{array}$ & $\begin{array}{l}\text { RR } 2.15 \\
(1.58 \text { to } \\
2.94)\end{array}$ & $\begin{array}{l}260 \\
(1 \mathrm{RCT})\end{array}$ & $\begin{array}{l}\oplus \oplus \oplus \ominus \\
\text { MODER- } \\
\text { ATE } 1\end{array}$ \\
\hline 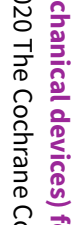 & $\begin{array}{l}\text { Prolapse-specific quality of life } \\
\text { assessed with: POPIQ (higher score = worse quality of life) (scale: 0-100 } \\
\text { Follow-up: } 12 \text { months }\end{array}$ & \multicolumn{2}{|c|}{ 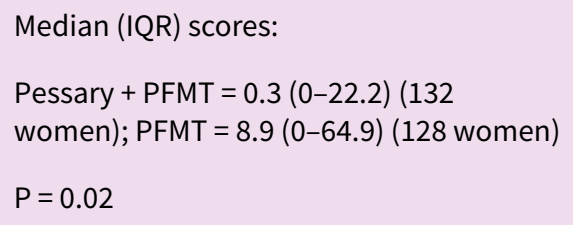 } & - & $\begin{array}{l}260 \\
(1 \mathrm{RCT})\end{array}$ & $\begin{array}{l}\oplus \oplus \oplus \ominus \\
\text { MODER- } \\
\text { ATE } 1\end{array}$ \\
\hline 3 & Cure or improvement of sexual problems $\geq 12$ months & \multicolumn{5}{|l|}{ Not reported } \\
\hline$\stackrel{0.90}{=}$ & Psychological outcome measures at $\geq 12$ months & \multicolumn{5}{|l|}{ Not reported } \\
\hline 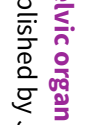 & $\begin{array}{l}\text { Number of women with adverse events - abnormal vaginal bleeding } \\
\text { Follow-up: } 12 \text { months }\end{array}$ & 31 per 1000 & $\begin{array}{l}68 \text { per } 1000 \\
\text { (22 to } 216)\end{array}$ & $\begin{array}{l}\text { RR } 2.18 \\
(0.69 \text { to } \\
6.91)\end{array}$ & $\begin{array}{l}260 \\
(1 \mathrm{RCT})\end{array}$ & $\begin{array}{l}\oplus \oplus \odot \ominus \\
\text { LOW } 2\end{array}$ \\
\hline 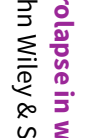 & $\begin{array}{l}\text { Number of women with adverse events - de novo voiding difficulty } \\
\text { Follow-up: } 12 \text { months }\end{array}$ & 82 per 1000 & $\begin{array}{l}109 \text { per } 1000 \\
(45 \text { to } 263)\end{array}$ & $\begin{array}{l}\text { RR } 1.32 \\
(0.54 \text { to } \\
3.19)\end{array}$ & $\begin{array}{l}189 \\
(1 \mathrm{RCT})\end{array}$ & $\begin{array}{l}\oplus \oplus \ominus \ominus \\
\text { LOW } 2\end{array}$ \\
\hline 垔. & \multicolumn{6}{|c|}{$\begin{array}{l}{ }^{*} \text { The risk in the intervention group (and its } 95 \% \text { confidence interval) is based on the assumed risk in the comparison group and the relative effect of the intervention (and } \\
\text { its } 95 \% \mathrm{Cl} \text { ). }\end{array}$} \\
\hline & \multicolumn{6}{|c|}{$\begin{array}{l}\text { GRADE Working Group grades of evidence } \\
\text { High certainty: we are very confident that the true effect lies close to that of the estimate of the effect. } \\
\text { Moderate certainty: we are moderately confident in the effect estimate; the true effect is likely to be close to the estimate of the effect, but there is a possibility that it is } \\
\text { substantially different. } \\
\text { Low certainty: our confidence in the effect estimate is limited; the true effect may be substantially different from the estimate of the effect. } \\
\text { Very low certainty: we have very little confidence in the effect estimate; the true effect is likely to be substantially different from the estimate of effect. }\end{array}$} \\
\hline
\end{tabular}

1 Downgraded one level for imprecision: few participants

2 Downgraded two levels for imprecision: few participants and wide $95 \% \mathrm{Cl}$ spanning possible harm and possible benefit 


\section{B A C K G R O U N D}

\section{Description of the condition}

Pelvic organ prolapse is the descent of some part, or parts, of the female pelvic organs (uterus, bladder and rectum) from their normal anatomical position into the vagina. It affects about $40 \%$ of women aged over 40 (Hendrix 2002), with the prevalence expected to increase as the population ages ( $\mathrm{Wu}$ 2011). Pelvic organ prolapse includes anterior vaginal wall prolapse (cystocoele, urethrocoele), posterior vaginal wall prolapse (enterocoele, rectocoele, perineal deficiency), and uterine or vaginal vault prolapse. Women can present with prolapse in one or more of these sites. The International Continence Society has standardised the naming of the condition using the POP-Q (Pelvic Organ Prolapse Quantification) evaluation (Bump 1996), but in this review we have also used the descriptive terms above as these are compatible with literature searches.

The cause of pelvic organ prolapse is complex and multifactorial. Various risk factors have been proposed, including pregnancy, childbirth, hereditary factors, denervation or weakness of the pelvic floor, ageing, menopause, and factors associated with chronically raised intra-abdominal pressure (such as obesity, coughing and heavy lifting) (Bump 1998; Dietz 2008; Gyhagen 2015; Jelovsek 2018; MacLennan 2000).

Women with prolapse may have a variety of pelvic floor symptoms (Barber 2001; Hagen 2009; Jelovsek 2006; Lone 2011). Women experience symptoms of 'something coming down', pelvic heaviness, a dragging sensation in the vagina, a bulge, lump or protrusion coming down from the vagina and backache. Women can also experience symptoms related to the movement of the pelvic organs and their protrusion into the vagina, which include urinary symptoms, bowel symptoms and sexual difficulties. Symptoms, and perceived bother of symptoms, may negatively affect a woman's body image, quality of life and mental health, as well as their ability to perform day to day activities (Jelovsek 2006; Lowder 2011; Pakbaz 2010).

\section{Description of the intervention}

Prolapse treatment may be dependent on a number of factors, including the severity of prolapse, the bother of the associated symptoms, the woman's general health and the woman's treatment preference (Basu 2011; Kapoor 2009). Various treatment options exist for women who have pelvic organ prolapse and these can be split into surgical and conservative options. Approximately $9.5 \%$ of women will undergo prolapse surgery in their lifetime (Abdel-Fattah 2011). A US-based study forecast that approximately 9.2 million women will be affected by pelvic organ prolapse by 2050 (Wu 2009), and about 300,000 women undergo pelvic organ prolapse surgery in the USA every year costing over 1 billion US dollars (the cost year was unclear) (Enemchukwu 2019; Subak 2001). The NHS spent over $£ 45$ million on the treatment of prolapse between 2017 and 2018 (Primary Care Women's Health Forum 2019).

Vaginal pessaries are passive mechanical devices that are worn internally and designed to support the vaginal walls and apex. An extensive range of pessaries have been described for treating prolapse (Oliver 2011; Poma 2000). These consist mainly of PVC, latex or silicone pessaries, which are shaped devices inserted into and left inside the vagina to support the prolapsed pelvic organs. Two main groups of pessaries are used: support pessaries (e.g. ring pessary or ring pessary with support) and space filling pessaries (e.g. Gellhorn or cube) (Dwyer 2019; Oliver 2011). Support pessaries are inserted into the vagina and are positioned between the pubic bone and posterior vaginal fornix, providing support to descending organs. They do not prohibit vaginal intercourse and are easier to remove and replace. Space filling pessaries provide support by filling the vaginal space to prevent prolapse descent, creating a suction effect around the pessary which thereby increases the likelihood of retention. They are not compatible with vaginal intercourse and are more difficult to remove and replace (Dwyer 2019). Studies suggest that ring pessaries are the most commonly used in practice (Bugge 2013a; Cundiff 2000).

Recently published NICE guidance suggests considering pessary treatment (alone or with: pelvic floor muscle training (PFMT)) when women have symptomatic prolapse (NICE 2019). Surveys suggest that $87 \%$ to $98 \%$ of clinicians report using pessaries in their clinical practice (Bugge 2013a; Cundiff 2000; Gorti 2009; Pott-Grinstein 2001), while $77 \%$ of gynaecologists report using pessaries as a firstline treatment for prolapse (Cundiff 2000). Health professionals $(87.6 \%)$ report that they are most likely to fit pessaries in women aged 60 or older and $98.8 \%$ would use a pessary for treatment when a woman is unfit for surgery (Bugge 2013a). Evidence from observational studies suggests that about $76 \%$ of women who try a pessary continue to use it for at least four weeks and, of those women who continue pessary use for more than four weeks, $86 \%$ continued to use the pessary for over five years (Lone 2011). Furthermore, observational studies have shown that pessaries may improve symptoms for women (Lamers 2011; Manchana 2012).

\section{How the intervention might work}

Pessaries are used in pelvic organ prolapse in order to physically support the vaginal walls and the pelvic organs behind them. The pessary is inserted into the vagina with a view to holding the prolapsed organs, supporting the pelvic structures, and relieving pressure on the bladder and bowel (Dumoulin 2017). Using a pessary in the management of pelvic organ prolapse aims to prevent the prolapse from becoming worse, as well as helping to decrease the frequency or severity of symptoms of prolapse, and averting or delaying the need for surgery (Oliver 2011).

\section{Why it is important to do this review}

The effectiveness of surgical treatment options for prolapse are reported in other Cochrane Reviews (Baessler 2018; Maher 2016a; Maher 2016b; Maher 2016c; Mowat 2018). Conservative treatment options that are currently used are pelvic floor muscle training (PFMT), vaginal pessaries and lifestyle advice. The effectiveness of PFMT and lifestyle advice is reported in one review (Hagen 2011a). The remaining conservative option, vaginal pessaries, is the focus of this review.

The majority of evidence for the use of pessaries comes from nonrandomised studies (e.g. Brazell 2014; Clemons 2004b; Clemons 2004a; Clemons 2004c; Hanson 2006; Kapoor 2009; Lamers 2011; Lone 2011; Manchana 2012). As such, the effectiveness of pessaries for managing pelvic organ prolapse still needs to be clearly established. There is a lack of consensus as to the optimal treatment for women. Provided that sufficient numbers of trials of adequate quality have been conducted, the most reliable evidence 
is likely to come from consideration of randomised controlled trials (RCTs), which is the basis for the current review. The aim is to help identify optimal practice and highlight where there is a need for further research.

Given that different costs are associated with the alternative interventions included in this review, it is important to conduct a brief economic commentary (BEC) to find available evidence (if any) on the costs of the interventions relative to their effectiveness.

\section{O B JECT IVES}

To assess the effects of pessaries (mechanical devices) for managing pelvic organ prolapse in women; and summarise the principal findings of relevant economic evaluations of this intervention.

\section{METHODS}

\section{Criteria for considering studies for this review}

\section{Types of studies}

We included randomised trials (RCTs) and quasi-randomised trials in which at least one arm was a pessary for pelvic organ prolapse. We excluded cross-over studies.

\section{Types of participants}

We included studies focusing on adult women who were seeking treatment for pelvic organ prolapse. Participants could have prolapse with any POP-Q staging (Bump 1996), and prolapse of any type: anterior vaginal wall prolapse (cystocoele, urethrocoele); posterior vaginal wall prolapse (enterocoele, rectocoele, perineal deficiency); and uterine or vaginal vault prolapse. We included trials where women were seeking treatment for urinary incontinence (UI) or prolapse if the data for women with prolapse (including women with prolapse and $\mathrm{UI}$ ) were considered, or available separately.

\section{Types of interventions}

We included studies where one arm involved allocation to a pessary aiming to provide support for pelvic organ prolapse. Thus, we excluded studies where the pessary was used for exercise (and not support) or where pessaries were only used to deliver drug treatments (such as oestrogen). Pessaries could be of any type and made of any material. The types of devices included support pessaries (e.g. ring, ring with support) and space-filling devices (e.g. shelf, Gellhorn, cube).

We considered the following comparisons and planned to present 'Summary of findings' tables for the first three.

- Any pessary versus control, waiting list or no active treatment.

- Any pessary versus another treatment (lifestyle interventions, oestrogen treatment, physical interventions such as pelvic floor muscle training, surgery).

- Any pessary plus another treatment versus the other treatment alone.

- One pessary versus another pessary.

\section{Types of outcome measures}

\section{Primary outcomes}

- Women's perceived resolution of prolapse symptoms

- Women's perceived improvement in prolapse symptoms (assessed using validated symptom questionnaires such as the Pelvic Floor Disability Index (PFDI) (Barber 2001; Barber 2005), or the Pelvic Organ Symptom Score (POP-SS) (Hagen 2009))

\section{Secondary outcomes}

- Patient-reported satisfaction with pessary treatment

- Grade of prolapse (i.e. the compartment that has the most descent, e.g. using Pelvic Organ Prolapse-Quantification (POPQ) classification (Bump 1996))

- Site-specific grading of prolapse (i.e. the descent in each of the specific anterior, apical or posterior compartments, e.g. using POP-Q (Bump 1996))

- Prolapse-specific quality of life (measured with validated instrument, e.g. the Pelvic Floor Impact Questionnaire (PFIQ), Barber 2001; Barber 2005)

- Quality of life measured with generic quality of life or health status measures (e.g. SF-36, Ware 1993)

- Psychological outcome measures (e.g. Hospital Anxiety and Depression Scale (HADS), Zigmond 1983)

- Cure or improvement of bladder problems (including urinary incontinence, occult incontinence and relief of voiding difficulty)

- Cure or improvement of bowel problems (including relief of obstructed defecation)

- Cure or improvement of sexual problems (including acceptability of device to both partners)

- Number of women with adverse events (vaginal bleeding, voiding difficulty)

\section{Timing of outcome assessment}

We considered all outcomes at $\geq 12$ months.

\section{Main outcomes for 'Summary of findings' tables}

These outcomes have been informed by a recent priority-setting exercise for pessary use (Lough 2018).

- Woman's perceived resolution of prolapse symptoms at $\geq 12$ months

- Woman's perceived improvement in prolapse symptoms assessed using a validated symptom questionnaire at $\geq 12$ months

- Prolapse-specific quality of life (e.g. PFIQ) at $\geq 12$ months

- Cure or improvement of sexual problems at $\geq 12$ months

- Psychological outcome measures at $\geq 12$ months

- Number of women with adverse events (vaginal bleeding, voiding difficulty)

\section{Search methods for identification of studies}

We did not impose any language or other restrictions on any of the searches detailed below. 


\section{Electronic searches}

\section{Search for clinical effectiveness studies}

We identified relevant trials from the Cochrane Incontinence Specialised Register. For more details of the search methods used to build the Specialised Register, please see the Group's webpages where details of the Register's development (from inception) and the most recent searches performed to populate the Register can be found. To summarise, the Register contains trials identified from the Cochrane Central Register of Controlled Trials (CENTRAL), MEDLINE, MEDLINE In-Process, MEDLINE Epub Ahead of Print, ClinicalTrials.gov, WHO ICTRP, Be Part of Research and handsearching of journals and conference proceedings. Many of the trials in the Cochrane Incontinence Specialised Register are also contained in CENTRAL.

The terms used to search the Cochrane Incontinence Group Specialised Register are given in Appendix 1. The date of the most recent search of the Register for this review: 28 January 2020.

The search methods and strategies used for some of the previous versions of this review are given in Appendix 2.

\section{Search for economic evaluations}

We performed additional searches for the brief economic commentary (BEC). We searched the following.

- The NHS Economic Evaluation Database (NHS EED) on the Centre for Reviews and Dissemination (CRD) website (covering from the earliest record in NHS EED, dating from 1968, up to and including 31 December 2014 when their coverage ended). Date of search: 13 February 2020.

As NHS EED is no longer actively updated, we performed additional searches of the following databases to identify eligible studies added to these databases from 1 January 2015 onwards (date of search: 13 February 2020):

- MEDLINE on OvidSP (covering 1 January 1946 to January February 12020$)$; and

- Embase (on OvidSP) (covering 1 January 1974 to 2020 Week 06).

Details of the searches that were performed can be found in Appendix 3.

\section{Searching other resources}

We searched the reference lists of relevant articles for other possibly relevant trials. We also contacted the authors of included abstracts.

\section{Data collection and analysis}

We conducted data collection and analysis in accordance with methods specified in the Cochrane Handbook for Systematic Reviews of Interventions (Higgins 2019).

\section{Selection of studies}

Two review authors independently screened all potentially eligible abstracts from the search ( $C B$ and DG or MD). We nominated a third review author to arbitrate in the event of disagreement (EJA). We excluded any studies which were not relevant at this stage. We then obtained the full-text articles of relevant studies. If there was any uncertainty on the eligibility of the studies based on title and abstract, we obtained the full paper, which was reviewed by the same two review authors.

\section{Data extraction and management}

Two review authors independently undertook data extraction using a predefined data extraction form (from CB, RK and FS). We then made comparisons to ensure accuracy. We resolved any discrepancies by discussion with, or referral to, a third party (EJA).

\section{Assessment of risk of bias in included studies}

We assessed the risk of bias within studies as part of the data extraction. We used the methods outlined in the Cochrane Handbook to assess risk of bias in the following domains (Higgins 2011): random sequence generation (selection bias); allocation concealment (selection bias); blinding of participants and personnel (detection bias); blinding of outcome assessors (performance bias); incomplete outcome data (attrition bias); selective reporting (reporting bias); other bias not considered under other domains. Two review authors assessed the included studies for risk of bias and any discrepancies were resolved by discussion and referred to a third author where necessary.

\section{Measures of treatment effect}

For binary outcomes, we have reported risk ratios (RR) and 95\% confidence intervals $(\mathrm{Cl})$. For continuous outcomes, we reported mean differences (MDs) with $95 \% \mathrm{Cls}$.

\section{Unit of analysis issues}

The primary analysis was per woman randomised. Had data allowed, we would have analysed each pair of arms in multi-arm studies as a separate comparison. To avoid double-counting where the same study with three treatment arms is included twice in the same meta-analysis, we planned to divide the number of women and events by two in the group that appears twice in the analysis.

\section{Dealing with missing data}

We contacted study authors to obtain missing data in order to be able to conduct intention-to-treat analysis wherever possible. Where randomised data were not available, we have reported data from per protocol analyses as presented in the study publications. We have clearly indicated in the Effects of interventions where we have used per protocol data.

\section{Assessment of heterogeneity}

We intended to combine studies in meta-analysis where clinical and methodological heterogeneity was low; that is, studies had to be broadly similar in terms of participant characteristics, interventions, study design and outcomes in order to be pooled. Had data allowed, we would have assessed statistical heterogeneity in meta-analyses as follows, taking into account the magnitude and direction of effects as well as the $P$ value and/or confidence interval for $\mathrm{I}^{2}$ :

- $0 \%$ to $40 \%$ : heterogeneity might not be important

- $30 \%$ to $60 \%$ might represent moderate heterogeneity

- $50 \%$ to $90 \%$ might represent substantial heterogeneity

- $75 \%$ to $100 \%$ represents considerable heterogeneity 


\section{Assessment of reporting biases}

Using the data extraction form, we assessed for data that could have been collected but was not reported. Where there were 10 or more studies in the same meta-analysis and where data allowed, we would have investigated reporting biases (such as publication bias) using funnel plots. If funnel plot asymmetry was suggested by a visual assessment, we would have performed exploratory analyses to investigate it.

\section{Data synthesis}

Had data allowed, we would have used a fixed-effect metaanalysis for combining data if it was reasonable to assume that the studies were estimating the same underlying treatment effect (i.e. where trials were examining the same intervention, and the trials' populations and methods were judged sufficiently similar). If there was clinical heterogeneity sufficient to expect that the underlying treatment effects differed between trials, or if substantial statistical heterogeneity was detected, we would have used a random-effects meta-analysis to produce an overall summary.

\section{Subgroup analysis and investigation of heterogeneity}

Had data allowed, we planned to carry out subgroup analysis according to different prolapse stages or compartments.

\section{Sensitivity analysis}

Had data allowed, we would have conducted sensitivity analyses to examine the effect of studies with high risk of bias on the results. We would have repeated the main meta-analyses without studies judged to be at high risk and compare those results to the main analyses with all studies included.

\section{Incorporating economics evidence}

Once the search outlined in the Search methods for identification of studies was performed, we developed a brief economic commentary (BEC) to summarise the availability and principal findings of the full economic evaluations that compared pessaries with alternative treatment interventions for pelvic organ prolapse in women (Shemilt 2019). This BEC encompassed full economic evaluations (i.e. cost-effectiveness analyses, cost-utility analyses and cost-benefit analyses), conducted alongside or based on one or more studies included in the main review of intervention effects, or model-based economic evaluations.

\section{Summary of findings and assessment of the certainty of the evidence}

We prepared 'Summary of findings' tables using the GRADEpro GDT software for the comparisons pre-stated in the Types of interventions.

We used the GRADE approach to assess the certainty of evidence related to the outcomes listed in the 'Main outcomes for 'Summary of findings' tables' in the Types of outcome measures (Schünemann 2019). We used the five GRADE considerations (study limitations, consistency of effect, imprecision, indirectness and publication bias) to assess the certainty of the body of evidence for the prespecified outcomes. We justified all decisions to downgrade the certainty of studies using footnotes.

\section{RE S U L T S}

\section{Description of studies}

\section{Results of the search}

We reviewed 182 abstracts, of which 25 full-text reports (from 17 trials) were retrieved and assessed. Twelve reports of eleven trials were subsequently excluded, which are detailed in the Characteristics of excluded studies. Eleven reports of four studies were included in the review. Additionally several studies were identified within the search from their registration on clinical trial databases, and from these we identified a further two studies that, if completed, look likely to be included in future versions of this review. These studies are reported in the Characteristics of ongoing studies. The flow of literature through the assessment process for the update of this review is shown in Figure 1. 
Figure 1. PRISMA study flow diagram - search for clinical effectiveness studies

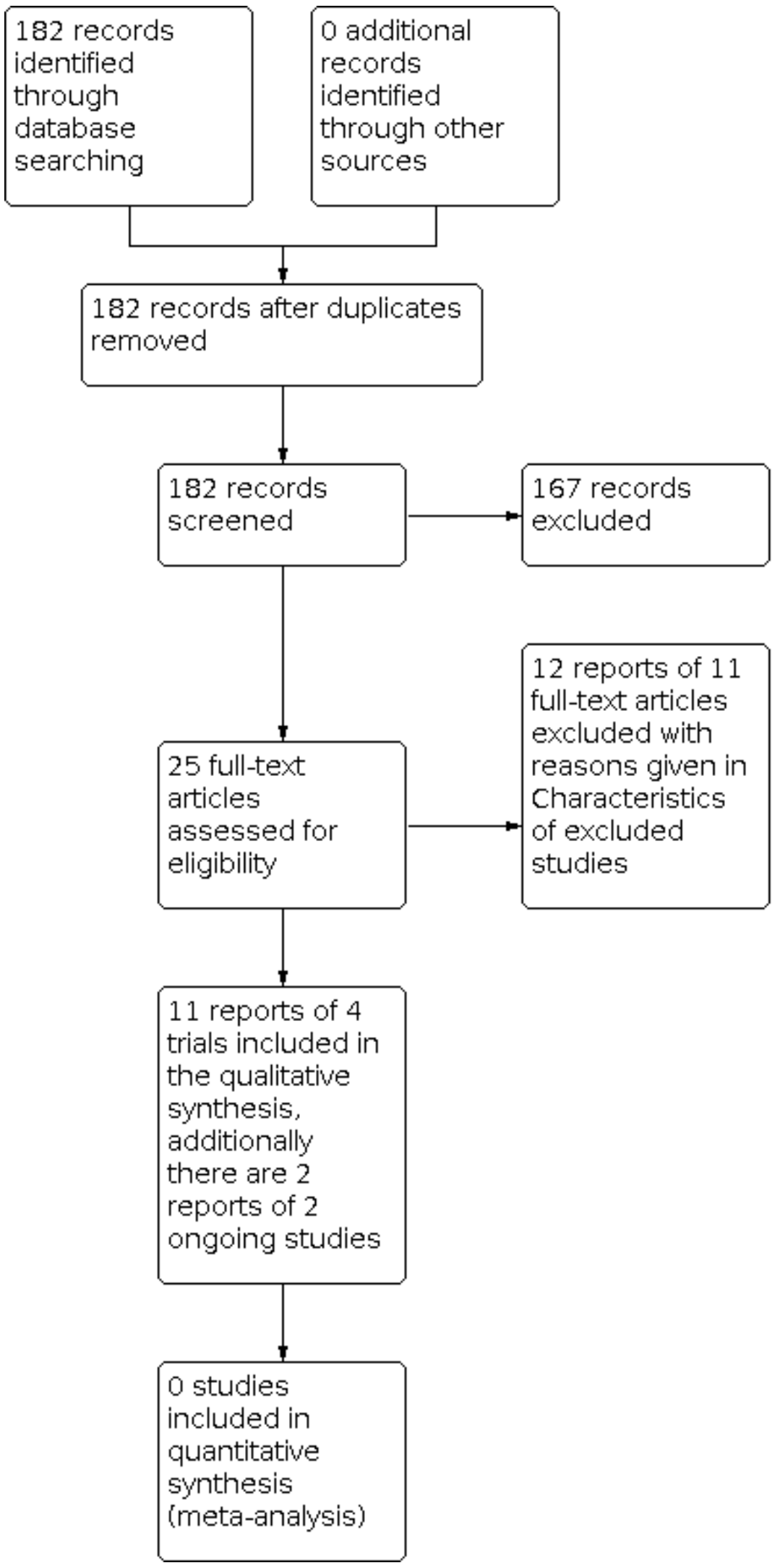


This is the second review update. In the first version of the review, no relevant randomised controlled trials (RCTs) were identified (Adams 2004). In the first update (Bugge 2013b), we included one cross-over study (Cundiff 2007), which we have now excluded because the cross-over study design means that we cannot tell what the true effects of the pessary are.
Searches for economic evaluations to inform the development of the brief economic commentary (BEC) produced 479 unique records after removal of duplicates. We retrieved the full-text of seven articles that appeared to meet our eligibility criteria but found that three of these did not include the correct population and were therefore excluded; the remaining four reports of two economic evaluations were included in this BEC. The flow of literature through the assessment process is shown in Figure 2. 
Figure 2. PRISMA study flow diagram - search for economic evaluations for the BEC

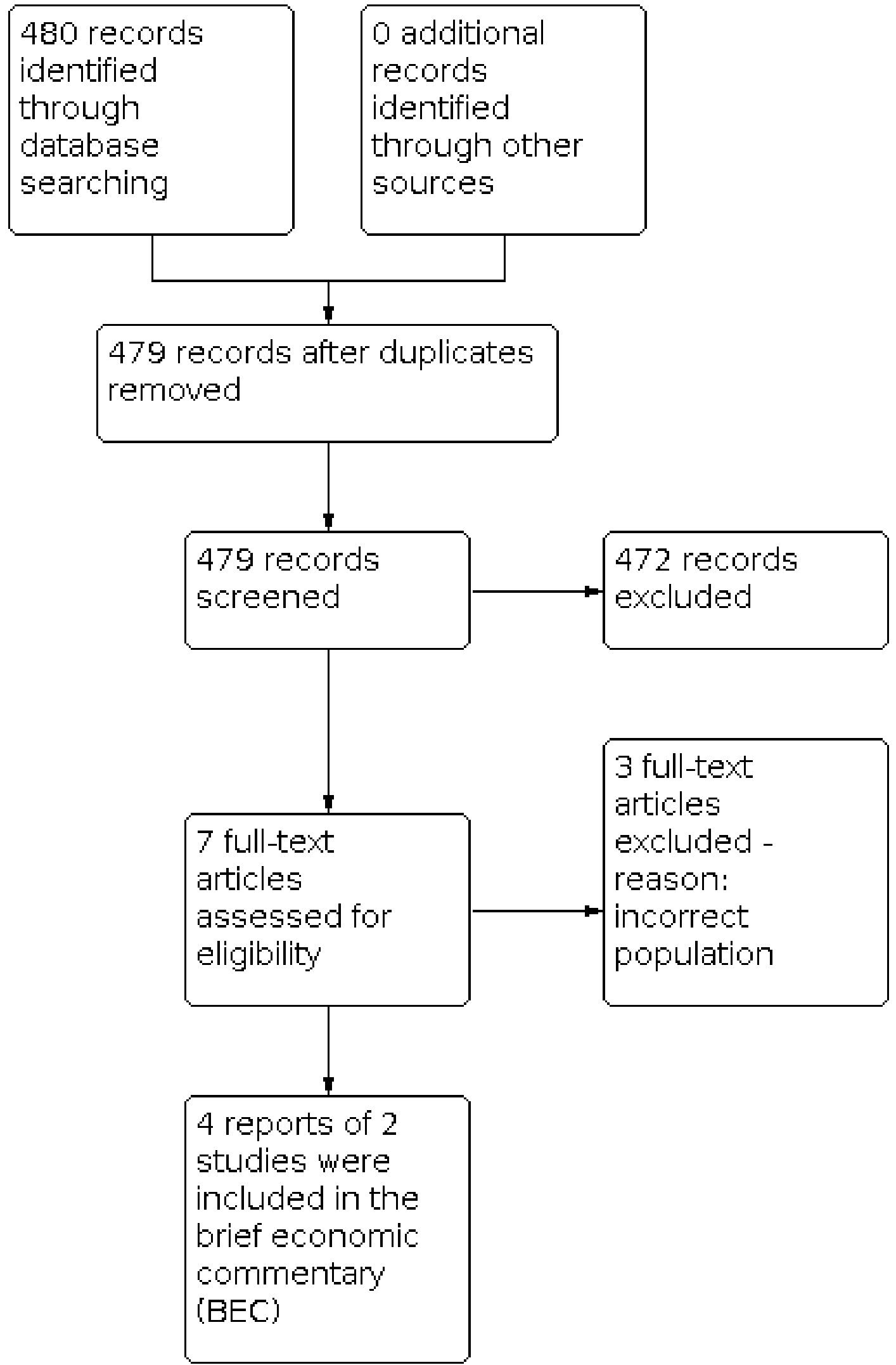




\section{Included studies}

Four trials met the inclusion criteria. Full details are included in the Characteristics of included studies.

\section{Design}

All four included trials were RCTs. In one trial only six women were randomised before patient preference took priority and data were not reported per randomised group (Coolen 2018). The data were therefore not usable in the review.

\section{Sample size}

Sample sizes ranged from 34 (Baessler 2019) to 276 (Cheung 2016).

\section{Setting}

The included trials took place in the Netherlands (Coolen 2018; Panman 2016), Hong Kong (Cheung 2016), and Germany (Baessler 2019).

\section{Participants}

The trials included 478 women and the mean age ranged from 30.4 (Baessler 2019) to 65.6 years (Panman 2016). The trials included women with: stage I to III POP-Q symptomatic prolapse (Cheung 2016); stage II or greater symptomatic prolapse (Coolen 2018; Baessler 2019); and prolapse at or beyond the hymen (Panman 2016). One trial included women who were in the immediate postpartum period (Baessler 2019).

\section{Length of follow-up}

Follow-up in included trials ranged from six weeks (Baessler 2019) to two years (Panman 2016).

\section{Interventions}

One trial compared pessary with standard care (no interventions for six weeks postpartum) (Baessler 2019). Two trials compared pessary with another treatment: one compared pessary with pelvic floor muscle training (PFMT) (Panman 2016), while another compared pessary with surgery (Coolen 2018). One trial compared pessary plus PFMT versus PFMT alone (Cheung 2016).

\section{Outcomes}

None of the included trials reported the primary outcome of resolution of prolapse symptoms. Three trials reported the primary outcome of perceived improvement of prolapse symptoms (Baessler 2019; Cheung 2016; Panman 2016).

The secondary outcomes reported in the trials were as follows.

- Grade of prolapse (Baessler 2019; Coolen 2018; Panman 2016)

- Site-specific grading of prolapse (Baessler 2019; Coolen 2018; Panman 2016)

- Prolapse-specific quality of life (Baessler 2019; Cheung 2016; Coolen 2018; Panman 2016)

- Quality of life measured with generic quality of life or health status measures (Coolen 2018; Panman 2016)

- Cure or improvement of bladder problems (Baessler 2019; Cheung 2016; Coolen 2018; Panman 2016)

- Cure or improvement of bowel symptoms (Baessler 2019; Cheung 2016; Panman 2016)

- Cure or improvement of sexual problems (Baessler 2019; Coolen 2018; Panman 2016)

- Number of women with adverse events (Baessler 2019; Cheung 2016; Coolen 2018; Panman 2016)

None of the included studies reported data on patient-reported satisfaction with pessary treatment or psychological outcome measures.

\section{Excluded studies}

Eleven studies were excluded (see the Characteristics of excluded studies). Of these, two were excluded because it was not possible to separate the data for the women with prolapse from the data for women with urinary incontinence (Meriwether 2015; Taege 2017). A further seven trials were excluded because they investigated pessary plus another treatment compared with pessary alone (Chou 2013; Hagen 2011b; McDermott 2012; Propst 2015; Sanker 2013; Tontivuthikul 2016; Viravaidya 2012). These studies would address the effectiveness of adding the other treatment to pessary, but it would not be evidence of the effectiveness of the pessary itself. Two studies were excluded because they did not use eligible study designs (Cundiff 2007; Danandeh 2019).

\section{Risk of bias in included studies}

See Figure 3 and Figure 4 for visual representations of the risk of bias in the included trials. Risk of bias for each included study is further detailed in the Characteristics of included studies. 
Figure 3. 'Risk of bias' summary: review authors' judgements about each risk of bias item for each included study.

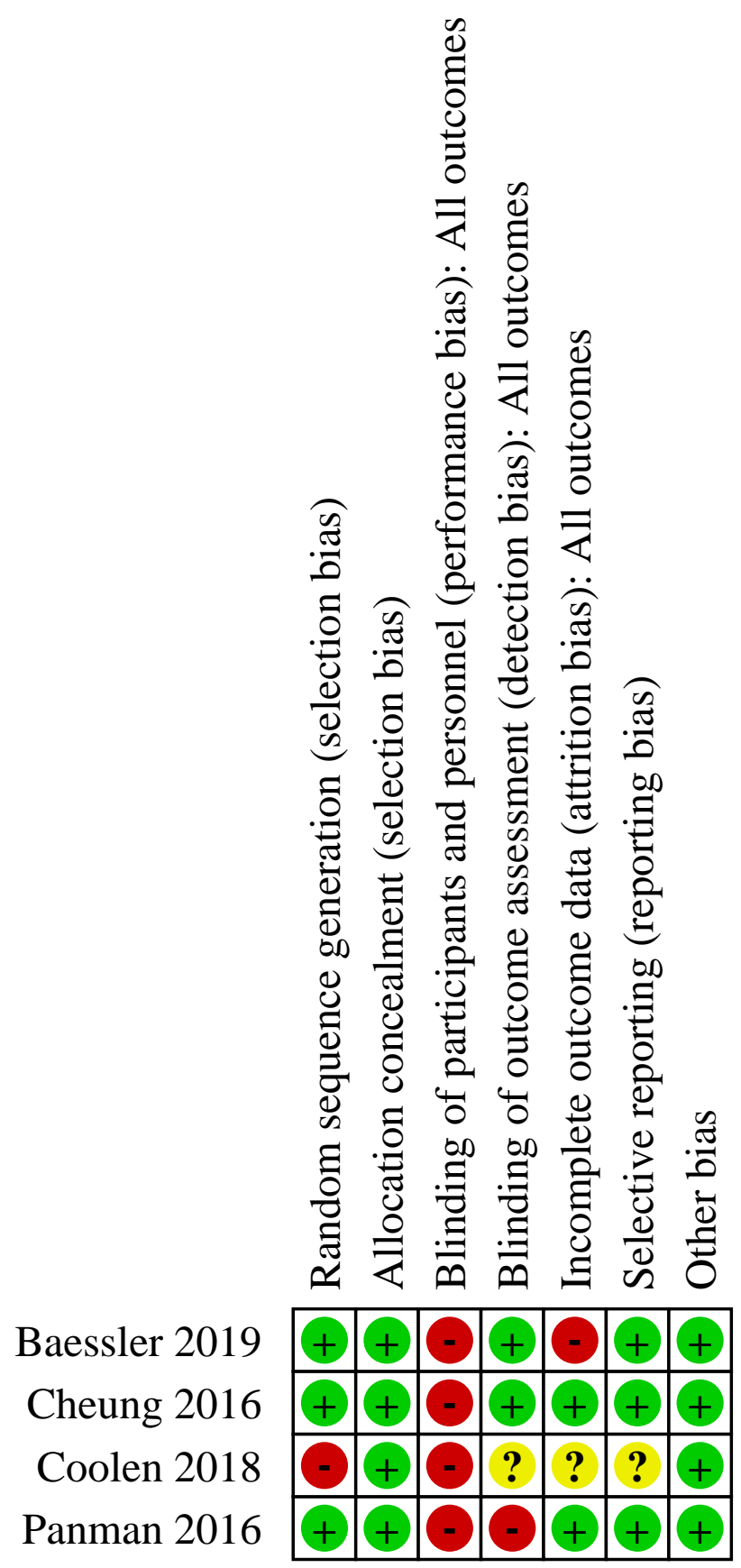


Figure 4. 'Risk of bias' graph: review authors' judgements about each risk of bias item presented as percentages across all included studies.

$\begin{array}{r}\text { Random sequence generation (selection bias) } \\ \text { Allocation concealment (selection bias) } \\ \text { Blinding of participants and personnel (performance bias): All outcomes } \\ \text { Blinding of outcome assessment (detection bias): All outcomes } \\ \text { Incomplete outcome data (attrition bias): All outcomes } \\ \text { Selective reporting (reporting bias) } \\ \text { Other bias } \\ \hline \text { Low risk of bias }\end{array}$

\section{Allocation}

\section{Random sequence generation}

Three trials had a low risk of bias for random sequence generation as they utilised remote computerised systems for randomisation (Baessler 2019; Cheung 2016; Panman 2016). Coolen 2018 had a high risk of bias as only $6 / 113$ women in the study were randomised. For the remaining women in this study, the patients' treatment preference took priority.

\section{Allocation concealment}

All four trials had a low risk of bias for allocation concealment, as they used remote systems and in blocks of variable size, hence blinding the researchers to the possible treatment allocation (Baessler 2019; Cheung 2016; Coolen 2018; Panman 2016).

\section{Blinding}

\section{Blinding of participants and personnel}

All trials were unable to blind participants given the nature of the interventions in use (pessaries, PFMT and surgery) (Baessler 2019; Cheung 2016; Coolen 2018; Panman 2016). We therefore judged them to be at high risk of performance bias since knowledge of their assignment could influence their subjective assessment of their prolapse symptoms.

\section{Blinding of outcome assessment}

We assessed two trials as low risk of detection bias (Baessler 2019; Cheung 2016) because assessors were blinded to group allocation. One trial was judged to be at an unclear risk of bias for this domain (Coolen 2018). One trial was judged at high risk of detection bias because the outcome assessors were not blinded to group allocation (Panman 2016). In all cases where it was reported, attempts were made to blind the assessors to previous measurements.

\section{Incomplete outcome data}

One trial was assessed as high risk of attrition bias because of the substantially higher withdrawal rate in the control group (Baessler 2019). Two trials were assessed to be at a low risk of attrition bias because there was no differential attrition and the trialists conducted intention-to-treat analysis (Cheung 2016;
Panman 2016). In one trial, the risk of attrition bias was unclear due to a lack of information (Coolen 2018).

\section{Selective reporting}

Three trials were assessed as having a low risk of reporting bias as all outcomes were reported across all the published material (Baessler 2019; Cheung 2016 Panman 2016). The fourth trial did not provide sufficient information to judge the risk of reporting bias and so was judged to be at unclear risk of bias (Coolen 2018).

\section{Other potential sources of bias}

There were no indications of any other kind of bias in the included trials, so all four were judged to be at low risk of bias (Baessler 2019; Cheung 2016; Coolen 2018; Panman 2016).

\section{Effects of interventions}

See: Summary of findings 1 Any pessary compared to control, waiting list or no active treatment; Summary of findings 2 Any pessary compared to pelvic floor muscle training (PFMT) for pelvic organ prolapse in women; Summary of findings 3 Pessary plus PFMT compared to pelvic floor muscle training (PFMT) alone for pelvic organ prolapse in women

\section{Any pessary versus control, waiting list or no active treatment}

One trial compared a ring pessary versus standard care (defined as no treatment for six weeks postpartum) for women who had stage II prolapse one to three days postpartum (Baessler 2019). In this trial, 13 women were randomised to pessary care and 21 to standard care.

\section{Primary outcomes}

Women's perceived resolution of prolapse symptoms

Not reported.

\section{Women's perceived improvement in prolapse symptoms}

Baessler 2019 measured improvement in prolapse symptoms using the Australian Pelvic Floor Questionnaire (Baessler 2009). We are uncertain if pessaries have any effect on women's perceived improvement in prolapse symptoms compared to standard care (mean difference (MD) $-0.03,95 \%$ confidence interval $(\mathrm{Cl})-0.61$ to 0.55 ; 1 study; 27 women; very low-certainty evidence; Summary of findings 1; Analysis 1.1). 


\section{Secondary outcomes}

\section{Patient-reported satisfaction with pessary treatment}

Not reported.

\section{Grade of prolapse}

Not reported.

\section{Site-specific grading of prolapse}

Baessler 2019 measured site-specific grading of prolapse using the POP-Q. After the pessary has been removed for a period of time, we are uncertain if it has any effect on the anatomical measurement of prolapse compared with standard care (anterior compartment: MD $0.10,95 \% \mathrm{Cl}-0.73$ to $0.93 ; 1$ study, 27 women; Analysis 1.2; posterior compartment $(0.10,95 \% \mathrm{Cl}-0.49$ to $0.69 ; 1$ study, 27 women; Analysis 1.3).

\section{Prolapse-specific quality of life}

Not reported.

Quality of life measured with generic quality of life or health status measures

Not reported.

\section{Psychological outcome measures}

Not reported.

\section{Cure or improvement of bladder problems}

Baessler 2019 measured bladder problems using the bladder score of the Australian Pelvic Floor Questionnaire. We are uncertain if pessaries have any effect on bladder problems compared with standard care (MD $-0.15,95 \% \mathrm{Cl}-0.55$ to $0.25 ; 1$ study, 27 women; Analysis 1.4).

\section{Cure or improvement of bowel problems}

Baessler 2019 measured bladder problems using the bowel score of the Australian Pelvic Floor Questionnaire. We are uncertain if pessaries have any effect on bowel problems compared with standard care (MD $0.00,95 \% \mathrm{Cl}-0.60$ to $0.60 ; 1$ study, 27 women; Analysis 1.5).

\section{Cure or improvement of sexual problems}

Baessler 2019 measured bladder problems using the sex score of the Australian Pelvic Floor Questionnaire. We are uncertain if pessaries have any effect on curing or improving sexual problems compared with standard care (MD $-0.29,95 \% \mathrm{Cl}-1.67$ to 1.09 ; 1 study; 27 women; very low-certainty evidence; Summary of findings 1; Analysis 1.6).

\section{Number of women with adverse events (vaginal bleeding, voiding} difficulty)

The adverse events of vaginal bleeding and voiding difficulty were not reported.

\section{Any pessary versus another treatment}

One trial compared a pessary with pelvic floor muscle training (PFMT) (Panman 2016). In this trial, 82 women received a pessary and 80 women received PFMT. Another trial compared a pessary with surgery (Coolen 2018). However, of the 113 women recruited to the trial only six consented to the randomisation process (two were randomised to pessary and four to surgery). The data were presented for the whole study population as a prospective cohort and therefore were not usable for this review.

\section{Primary outcomes}

Women's perceived resolution of prolapse symptoms

Not reported.

\section{Women's perceived improvement in prolapse symptoms}

Panman 2016 measured improvement in prolapse symptoms using the Pelvic Floor Disability Index (PFDI-20) (Barber 2005), and also the subscale of the PFDI measure on specific prolapse symptoms (Pelvic Organ Prolapse Distress Inventory 6 (POPDI-6)). According to POPDI-6 scores, we are uncertain if pessaries have any effect on women's prolapse symptoms compared with PFMT at 12 months (MD -3.60, 95\% Cl-8.73 to 1.53; 117 women; Analysis 2.3; lowcertainty evidence Summary of findings 2), or at 24 months (MD $-4.20,95 \% \mathrm{Cl}-9.03$ to $0.63 ; 141$ women; Analysis 2.4 ). According to PFDI-20 scores at 12 months, we are uncertain if pessaries have any effect on women's prolapse symptoms compared with PFMT (MD $-9.60,95 \% \mathrm{Cl}-22.53$ to $3.33 ; 137$ women; Analysis 2.1 ). At 24 months the MD PFDI-20 was $-12.10(95 \% \mathrm{Cl}-25.33$ to $1.13 ; 138$ women; Analysis 2.2).

Panman 2016 reported the number of women self-reporting 'better' or 'much better' symptoms. At 24 months, we are uncertain if pessaries have any effect on women's perceived improvement in prolapse symptoms compared with PFMT because the certainty of evidence is low and the $95 \% \mathrm{Cl}$ spans possible harm and possible benefit (risk ratio (RR) $1.01,95 \% \mathrm{Cl} 0.64$ to $1.59 ; 1$ study; 142 women; Analysis 2.5).

\section{Secondary outcomes}

Patient-reported satisfaction with pessary treatment

Not reported.

\section{Grade of prolapse}

Not reported.

\section{Site-specific grading of prolapse}

Not reported.

\section{Prolapse-specific quality of life}

Panman 2016 measured prolapse-specific quality of life using the PFIQ-7. At 12 months' follow-up, we are uncertain if pessaries have any effect on prolapse-specific quality of life compared to PFMT because the evidence is low certainty and the wide $95 \% \mathrm{Cl}$ is consistent with possible harm and possible benefit (MD -3.30, $95 \% \mathrm{Cl}-8.70$ to $15.30 ; 1$ study; 116 women; low-certainty evidence; Summary of findings 2; Analysis 2.6)

At 24 months' follow-up it is still uncertain if pessaries have any effect on prolapse-specific quality of life compared with PFMT (MD $-3.00,95 \% \mathrm{Cl}-12.72$ to $6.72 ; 133$ women; Analysis 2.7 ).

\section{Quality of life measured with generic quality of life or health status} measures

Panman 2016 measured general quality of life using the two subscales of the SF-12 (Ware 1996) (physical health score (PCS-12); mental health score (MCS-12)). The MD between groups for the 
PCS-12 at 12 months was $1.20(95 \% \mathrm{Cl}-2.45$ to $4.85 ; 108$ women; Analysis 2.8). The MD between groups for the PCS-12 at 24 months was $2.30(95 \% \mathrm{Cl}-1.01$ to $5.61 ; 130$ women; Analysis 2.9$)$. The MD between groups for the MCS- 12 at 12 months was -1.90 (95\% Cl -5.58 to $1.78 ; 108$ women; Analysis 2.10$)$ and -1.70 at 24 months $(95 \% \mathrm{Cl}$ -4.67 to $1.27 ; 130$ women; Analysis 2.11 ).

\section{Psychological outcome measures}

Not reported.

\section{Cure or improvement of bladder problems}

Panman 2016 measured bladder symptoms using the Urinary Distress Index (UDI-6) (a subscale of the PFDI-20). The MD between groups at 12 months was $-2.70(95 \% \mathrm{Cl}-9.45$ to $4.05 ; 115$ women; Analysis 2.12). At 24 months, the MD between groups was -2.20 (95\% $\mathrm{Cl}-8.33$ to 3.93 ; 140 women; Analysis 2.13).

\section{Cure or improvement of bowel problems}

Panman 2016 measured bowel problems using the Colorectal-Anal Distress Inventory-8 (CRADI-8) (a subscale of the PFDI-20). The MD between groups at 12 months was $-3.50(95 \% \mathrm{Cl}-8.61$ to $1.61 ; 114$ women; Analysis 2.14). At 24 months, the MD between groups was $-4.50(95 \% \mathrm{Cl}-9.38$ to $0.38 ; 141$ women; Analysis 2.15$)$.

\section{Cure or improvement of sexual problems}

Panman 2016 measured sexual function using PISQ-12. At 12 months' follow-up, pessaries may have a slightly detrimental effect on women's sexual function compared with PFMT (MD -2.30, 95\% -5.20 to 0.60 ; 1 study; 48 women; low-certainty evidence; Summary of findings 2; Analysis 2.16).

At 24 months, we are uncertain if pessaries have any effect on women's sexual function compared with PFMT (MD $-1.00,95 \% \mathrm{Cl}$ -3.49 to 1.49 ; 58 women; Analysis 2.17 ).

\section{Number of women with adverse events (vaginal bleeding, voiding} difficulty)

Data on complications in one study were only available as part of the per protocol analysis (Panman 2016). Pessaries may substantially increase the risk of adverse events compared with PFMT (RR 75.25, 95\% Cl 4.70 to 1205.45; 1 study; 97 women; lowcertainty evidence; Summary of findings 2; Analysis 2.18). There were no reported complications for the PFMT group. Of the 35 women who persisted with a pessary until 24 months, $60 \%$ ( $n=$ 21) reported pessary-related side effects. These were: increased vaginal discharge $(n=14)$; increased urinary incontinence $(n=5)$; and irritation or erosions of the vaginal wall $(n=10)$.

Panman 2016 also reported reasons for pessary device removal. For 34 women, the initial pessary fit was unsuccessful, with a further seven women then also experiencing unsuccessful fit. Twelve women discontinued pessary treatment for the following reasons: increased incontinence $(n=4)$; vaginal erosion $(n=2)$; pessary treatment too burdensome $(n=2)$; no effect of pessary treatment ( $n$ $=1)$; discomfort during intercourse $(n=1)$; and other reasons $(n=3)$.

\section{Any pessary plus another treatment versus the other treatment alone}

One trial compared pelvic floor muscle training (PFMT) plus a pessary with PFMT alone (Cheung 2016). A total of 276 women were randomised in this trial: 137 received PFMT treatment and 139 received PFMT treatment plus a vaginal pessary.

\section{Primary outcomes}

Women's perceived resolution of prolapse symptoms

Not reported.

\section{Women's perceived improvement in prolapse symptoms}

At 12 months, pessary plus PFMT probably leads to more women perceiving improvement in their prolapse symptoms compared with PFMT alone (RR 2.15, 95\% Cl 1.58 to 2.94; 1 study; 260 women; moderate-certainty evidence; Summary of findings 3; Analysis 3.1). With pessary plus PFMT, 32.3\% more women will probably feel that their symptoms have improved compared with pessary alone ( $16.3 \%$ more to $54.6 \%$ more).

Cheung 2016 also measured perceived improvement in prolapse symptoms using the PFDI questionnaire (and the POPDI subscale - prolapse-specific symptoms; Barber 2001). In the intention-totreat ( ITT) analysis, there was a difference at 12 months for the POPDI subscale of the PFDI for women undertaking PFMT plus pessary (median score 32.1, interquartile range (IQR) 12.5 to 78.6 ; 139 women) compared to those in the PFMT-only group (median score 49.4, IQR 21.4 to 95.2; 137 women; $P=0.04$ ), which further suggests that a pessary may improve prolapse symptoms when added to PFMT.

\section{Secondary outcomes}

Patient-reported satisfaction with pessary treatment

Not reported.

\section{Grade of prolapse}

Not reported.

\section{Site-specific grade of prolapse}

Not reported.

\section{Prolapse-specific quality of life}

In Cheung 2016, at 12 months the women's prolapse-specific quality of life was measured using the POPIQ subscale of the PFIQ (higher score = worse quality of life; Barber 2001). On POPIQ score, pessary plus PFMT probably improves women's prolapse-specific quality of life (median 0.3 , IQR 0 to $22.2 ; 132$ women, in comparison to the PFMT-only group (median 8.9, IQR 0 to $64.9,128$ women; $\mathrm{P}=$ 0.02 ; moderate-certainty evidence; Summary of findings 3 ).

\section{Quality of life measured with generic quality of life or health status} measures

Not reported.

\section{Psychological outcome measures}

Not reported.

\section{Cure or improvement of bladder problems}

Cheung 2016 reported the number of women with pre-existing bladder problems who reported their symptoms had improved. Compared with PFMT alone, more women in the pessary plus PFMT group perceived cure or improvement of stress urinary incontinence (SUI) (19/82 and 15/70 respectively; RR $1.08,95 \% \mathrm{CI}$ 
0.60 to 1.96; 152 women; Analysis 3.2) and cure or improvement of voiding difficulty $(25 / 40$ and $11 / 31$ respectively; RR $1.76,95 \% \mathrm{Cl}$ 1.03 to 3.00; 71 women; Analysis 3.4). Fewer women in the pessary plus PFMT group perceived cure or improvement in urgency urinary incontinence compared with PFMT alone 17/59 and 18/44 respectively; (RR 0.70, 95\% $\mathrm{Cl} 0.41$ to $1.20 ; 103$ women; Analysis 3.3).

In the 12-month ITT analysis, Cheung 2016 also measured urinary symptoms using the UDI and associated quality of life using the Urinary Impact Questionnaire (UIQ).

- Median (IQR) UDI score: pessary plus PFMT 39.4 (16.9 to 74.7), 132 women; PFMT-only 37.5 (16.7 to 67.5), 128 women; $P=0.57$

- Median (IQR) UIQ score: pessary plus PFMT13.3 (0 to 40.3), 132 women; PFMT-only 9.7 (0 to 54.8), 128 women; $P=0.71$

\section{Cure or improvement of bowel problems}

In the 12-month ITT analysis, Cheung 2016 measured bowel symptoms using the CRADI and associated quality of life using the CRAIQ.

- Median (IQR) CRADI score: pessary plus PFMT 32.1 (15.8 to 75.5), 132 women; PFMT-only 32.1 (14.9 to 68.0), 128 women; $P=0.80$

- Median (IQR) CRAIQ score: pessary plus PFMT 0 (0 to 5.6), 132 women; PFMT-only 0 (0 to 5.6), 128 women; $P=0.77$

\section{Cure or improvement of sexual problems}

Not reported.

\section{Number of women with adverse events (vaginal bleeding, voiding difficulty)}

Pessary plus PFMT may slightly increase the risk of abnormal vaginal bleeding compared with PFMT alone (RR 2.18, 95\% Cl 0.69 to 6.91 ; 1 study; 260 women; low-certainty evidence; Summary of findings 3; Analysis 3.5). Pessary plus PFMT may lead to 3.7\% more women having abnormal vaginal bleeding compared with PFMT alone ( $1 \%$ fewer to $18 \%$ more).

We are less certain if pessary plus PFMT has any effect on the risk of de novo voiding difficulty because the $95 \% \mathrm{Cls}$ are wide and span possible harm and possible benefit (RR 1.32, 95\% $\mathrm{Cl} 0.54$ to $3.19 ; 1$ study; 189 women; low-certainty evidence; Analysis 3.6; Summary of findings 3 ).

\section{One pessary versus another pessary}

No trials were identified for this comparison.

\section{DISCUSSION}

\section{Summary of main results}

Four trials involving a total of 478 women were included in this updated review. None of the included trials reported our primary outcome of women's perception of cure of prolapse symptoms. Due to the varied nature of the comparisons, it was not possible to pool data.

The evidence is very uncertain about the effect of pessaries compared with standard care on perceived improvement of prolapse symptoms, prolapse-specific quality of life, and cure or improvement of sexual problems (Summary of findings 1 ). We did not find any evidence about the risk of adverse events compared with standard care (no treatment).

We are uncertain whether pessaries have any effect on women's perceived improvement in prolapse symptoms compared with pelvic floor muscle training (PFMT). We are also uncertain whether pessaries have any effect on prolapse-specific quality of life measured with the Pelvic Floor Impact Questionnaire-7 (PFIQ-7), or on cure or improvement of sexual problems measured with the Pelvic Organ Prolapse/Urinary Incontinence Sexual Questionnaire (PISQ-12) compared with PFMT (low-certainty evidence). However, pessaries may result in a large increase in risk of adverse events compared with PFMT (low-certainty evidence). Adverse events included increased vaginal discharge, increased urinary incontinence and erosion or irritation of the vaginal walls (Summary of findings 2).

Pessary plus PFMT probably leads to more women perceiving improvement in their prolapse symptoms and in their prolapsespecific quality of life compared with PFMT alone (moderatecertainty evidence). However, pessary plus PFMT may slightly increase the risk of abnormal vaginal bleeding compared with PFMT alone (low-certainty evidence). We are less certain if pessary plus PFMT has any effect on the risk of de novo voiding dysfunction because the $95 \% \mathrm{Cls}$ are wide and span possible harm and possible benefit (Summary of findings 3 ).

\section{Overall completeness and applicability of evidence}

We identified no studies comparing different types of pessaries. The studies included here are small and do not report several of our outcomes of interest. In particular, we identified no evidence regarding the effect of pessaries on women's perceived resolution of prolapse symptoms. However, the women included in the studies are largely representative of the wider population of women with pelvic organ prolapse in that they represent women with prolapse of different types, stages and across a range of ages.

Although the evidence base about vaginal pessary use for pelvic organ prolapse in women is growing, the available trials offer limited answers to the primary question regarding the effectiveness of pessaries in resolving or improving women's prolapse symptoms. In addition, we do not have adequate evidence to be certain regarding the effect of pessaries on quality of life, or their complications and adverse effects.

\section{Quality of the evidence}

Overall, we judged the studies to have a low risk of bias in most domains. Given that it was not possible to blind participants to their treatment allocation in any of the studies, and given that our primary outcome is subjectively reported, we judged the studies to have a high risk of performance bias. Due to imbalanced attrition and missing outcome data, we also judged some studies to have a high risk of attrition bias.

With regard to the outcomes presented in the 'Summary of findings' tables, we made decisions to downgrade the certainty of evidence because of the extent of risk of bias. Additionally, we downgraded all outcomes for imprecision due to the small sample sizes in the studies. 


\section{Potential biases in the review process}

We made every attempt to reduce bias in the review as far as possible, with broad inclusion criteria and a comprehensive search strategy not limited by language or publication type. We also ensured data extraction and 'Risk of bias' assessments were carried out independently by two review authors.

\section{Brief economic commentary}

In addition to the main review, we searched for economic evaluations that compared pessaries with either surgical procedures or conservative management, or both. From searches conducted in February 2020, we identified two economic evaluation studies (Hullfish 2011 and Panman 2016). We did not subject these identified economic evaluations to critical appraisal and we do not attempt to draw any firm or general conclusions regarding the relative costs or efficiency of pessaries in treating pelvic organ prolapse.

Hullfish 2011 conducted a model-based cost-utility analysis (CUA) comparing expectant management, placement of a pessary and surgical procedures (vaginal reconstructive surgery (VRS), traditional/open abdominal sacrocolpopexy, and robotic-assisted abdominal sacrocolpopexy) for post-hysterectomy pelvic organ prolapse. The study was conducted in the USA. A Markov model was developed to link potential health states and probabilistic events that follow from each treatment strategy. The model inputs include event probabilities, costs and utilities for outcomes at "a baseline case of a healthy 65 year old, post-hysterectomy female with $\geq$ stage III apical prolapse of the vagina, who wishes to preserve coital function". Event probabilities were mainly obtained from a review of published literature but expert knowledge was used to derive missing estimates. Due to the unavailability of health-related quality of life utility scores for pelvic organ prolapse, the authors used relative utility values that were developed based on clinical researchers' opinions. The model structure allows individuals to exist in one of seven health states during any given month over a 12-month period. These health states include pelvic organ prolapse with no complications, with presenting complications (voiding dysfunction); pessary with no complications, pessary with complication (vaginal erosion); repaired pelvic organ prolapse without late/postoperative complications (urinary tract infection); and repaired pelvic organ prolapse with major late complications (i.e. reoperation). Only direct medical costs of each treatment alternative were estimated from a number of sources for the analysis. The currency and price year are US \$ and 2007 respectively. At baseline, only pessary and VRS were found to be cost-effective: pessary use yielded about 10.4 quality-adjusted months at a cost of $\$ 10,000$ per patient and the VRS alternative obtained 11.4 quality-adjusted months at a cost of approximately $\$ 15,000$ per patient.

In a deterministic sensitivity analysis, expectant management with VRS was efficient when baseline probability of pelvic organ prolapse complications was decreased. Pessary alternative was no longer efficient after the probability of pelvic organ prolapse complications was reduced to 0.12 and the probability of surgery following pessary use was increased to 0.17 . Monte Carlo simulation results indicated that pessary use was an optimal alternative below $\$ 5600$ 'Willingness to Pay' (WTP) per qualityadjusted life month threshold and VRS was the optimal strategy above that threshold. The authors concluded that their model demonstrated that pessary use and VRS are both cost-effective alternatives for treating hysterectomy vaginal prolapse given the context of their study.

Panman 2016 conducted both a CUA and a cost-effectiveness analysis (CEA) to compare pessary treatment with pelvic floor muscle training (PFMT) using RCT data (three follow-ups within two years) from 20 primary care practices in the Netherlands (Wiegersma 2014). Participants included all women aged at least 55 years registered with their primary care practice. The outcome used in the CEA was distress measured by Pelvic Floor Distress Inventory-20 (PFDI-20; Barber 2005), while quality-adjusted lifeyears (QALYS) were measured in the CUA based on EQ-5D utility values using the UK population tariff (Dolan 1995). Only direct medical costs were included in the analysis, with a time horizon of two years. The main costs of the intervention included pessaries and pessary-related visits, costs of physical therapy, consultations with GPs and medical specialists, use of absorbent pads, medication and costs of operative procedures. Both costs and health benefits were recorded and estimated on an individual participant basis, and then the mean differences of effects and costs between the two treatment groups were estimated. The costs were valued in Euros at 2014 price level and later converted to US dollars based on the November 242015 exchange rate (1 Euro $=1.0657$ dollars). Results of the analysis were summarised in incremental cost-effectiveness ratio (ICER) and incremental cost-utility ratio (ICUR) for the CEA and CUA respectively. However, the focus is on the results of the cost-effectiveness planes which, as indicated below, show the likelihood that an intervention was less costly but more effective.

The costs per person were $\$ 309$ in the pessary group and $\$ 437$ in the PFMT group. The mean difference was $\$ 128$ (95\% $\mathrm{Cl} 27$ to 236), with costs dependent on the primary treatment. Costs for pessaries and pessary-related visits were higher in the pessary group ( $\$ 202$ per person compared with $\$ 0.5$ in the PFMT group), whereas costs for physical therapy were higher in the PFMT group ( $\$ 324$ per person for the PFMT group compared with $\$ 2$ in the pessary group).

In the CUA, both treatment groups lost QALYs over the study period, with slightly less lost in the pessary group $(0.024$ in the pessary group and 0.065 in the PFMT group). In total, $71 \%$ of the 5000 replications in the bootstrap simulation indicated better outcomes and lower costs for the pessary group.

The authors stated that there was no difference in change in pelvic floor symptoms between pessary treatment and PFMT in women aged 55 years or older recruited by screening. Although pessary treatment led to a statistically significant greater improvement in typical prolapse symptoms compared with PFMT, the difference was small and the clinical relevance doubtful.

The authors reported that their study was the first to investigate the cost-effectiveness of pessary treatment and PFMT from such a trial and that there were no significant differences between pessary treatment and PFMT in the reduction of pelvic floor symptoms but women with apex prolapse symptoms benefited more from pessary treatment than from PFMT. Pessary treatment was preferable to PFMT in the cost-effectiveness analysis, with PFMT being more expensive but no more effective.

The interventions compared in one of the economic evaluation studies match interventions compared in Summary of findings 
2 (Panman 2016). It would therefore be useful to compare the findings of the economic evaluation with data in Summary of findings 2 .

End users of this review will need to assess the extent to which results of identified economic evaluations may be applicable (or transferable) to their own setting.

\section{Agreements and disagreements with other studies or reviews}

The previous version of this review (Bugge 2013b), the most recent review for the International Continence Society monograph (Dumoulin 2017), and the current review have all reached similar conclusions. All conclude that there is insufficient evidence on which to guide clinical practice surrounding prolapse management using vaginal pessaries.

\section{AUTHORS' CONCLUSIONS}

\section{Implications for practice}

The evidence from randomised controlled trials (RCTs) on which to base the treatment of women with pelvic organ prolapse using vaginal pessaries remains very limited. The research base is growing but more trials are needed in order for data to be pooled in a way that will allow for greater certainty in recommendations for treatment. Clinical staff may wish to read this review alongside the surgical Cochrane Reviews (Baessler 2018; Maher 2016a; Maher 2016b; Maher 2016c; Mowat 2018) and the Cochrane Review of conservative and lifestyle measures (Hagen 2011a).

In the postpartum period, one small trial compared pessary versus standard care (no treatment for six weeks), and across the available comparisons the certainty of evidence was very low, making recommendations for practice in the postpartum period difficult. Panman 2016 compared pessary versus pelvic floor muscle training (PFMT), and it was uncertain if pessary had an effect on women's perceived improvement in prolapse symptoms in comparison to PFMT. Both PFMT and pessary are active treatments and, as such, it is not known if improvements were greater than if no treatment had been given. Cheung 2016 added a pessary to PFMT and probably led to more women perceiving an improvement in prolapse symptoms. It may be that practitioners consider the added benefit of a pessary for women with prolapse who are receiving PFMT.

There was some evidence of an increase in adverse events with pessary use. However, the clinical significance of these adverse events is unknown but may be argued to be low. Specifically, increased vaginal bleeding and discharge may be adverse events a woman is willing to accept if she experiences a decrease in prolapse symptoms. De novo stress urinary incontinence (SUI) may be a more problematic adverse event for women, but the evidence surrounding the effects of pessary on de novo SUI are not certain. While some evidence is suggestive of an increase in adverse events for women who use a pessary for prolapse, the extent to which these events are bothersome for women requires further investigation before recommendations can be made for practice.

\section{Implications for research}

Adequately-powered trials measuring clinically-important outcomes are urgently needed to guide international practice. The comparison between pessary and no active treatment is perhaps difficult as there is observational evidence suggesting benefit of pessary and other conservative treatments, making a no active treatment group possibly unacceptable to women or policy makers (Hagen 2011a; Lamers 2011).

Across the other comparisons more research is needed, specifically: pessary versus another active treatment; pessary as an adjunct to other treatments; and comparison between pessary types. It is important that future trials measure women's perceived resolution of prolapse symptoms. Qualitative research about the bothersomeness of adverse events of pessary use would also support the understanding of adverse event reporting in the trials. As the evidence base evolves, it will also be helpful to explore the effectiveness of pessary for different stages and types of prolapse.

This review identified only two relevant economic evaluations, which highlights both the lack of economic evidence and the need to conduct more economic evaluations on prolapse interventions that includes pessaries.

\section{ACK N OWLEDGEMENTS}

We are grateful to Chantale Dumoulin and Durhane Wong-Rieger for their valuable comments on drafts of the review, along with a health economist who provided feedback on the brief economic commentary. We thank Sheila Wallace for assistance with searches for this review and Muhammad Imran Omar, Lindsey Elstub and Eugenie Johnson for advice on undertaking and reporting the review.

We acknowledge the contributions of Suzanne Hagen, who was an author on the original review, and Fiona Reid, who was an author on the first revision of the review. 


\section{RE F E R E N C E S}

\section{References to studies included in this review}

\section{Baessler 2019 \{published and unpublished data\}}

Baessler K, Heihoff-Klose A, Boelke S, Stupin J, Junginger B. Does an early postpartum pessary treatment lead to remission of pelvic organ prolapse after vaginal birth? A pilot study. Female Pelvic Medicine and Reconstructive Surgery 2019;25(Suppl 15S):S302. [Abstract number: Poster 294] [srincont78490]

\section{Cheung 2016 \{published data only\}}

Cheung RY, Chan SS, Lee LL, Lee JH. 12 months outcome of women with symptomatic pelvic organ prolapse: vaginal ring pessary versus conservative treatment. In: 45th Annual Meeting of the International Continence Society (ICS), 2015 Oct 6-9, Montreal, Canada. 2015. [Abstract number 397] [CUHK_CCT00302] [sr-incont68811]

Cheung RY, Chan SS, Lee LL, Lee JH. Changes in urinary symptom in women treated with vaginal pessary with symptomatic pelvic organ prolapse - a randomized controlled trial. In: 45th Annual Meeting of the International Continence Society (ICS), 2015 Oct 6-9, Montreal, Canada. 2015. [Abstract number 377] [CUHK_CCT00302] [sr-incont68810]

* Cheung RY, Lee JH, Lee LL, Chung TK, Chan SS. Vaginal pessary in women with symptomatic pelvic organ prolapse: a randomized controlled trial. Obstetrics and Gynecology 2016;128(1):73-80. [DOI: 10.1097/AOG.0000000000001489] [CUHK_CCT00302] [ChiCTR-TRC-11001796] [sr-incont72969]

Lee HS, ChiCTR-TRC-11001796. Randomised controlled trial of vaginal ring pessary versus conservative management in women with pelvic organ prolapse. chictr.org/en/proj/ show.aspx?proj=2263 (first received 14 December 2011). [CUHK_CCT00302] [ChiCTR-TRC-11001796] [sr-incont65486]

Coolen 2018 \{published and unpublished data\}

Coolen AL, Troost S, Mol BW, Roovers JP, Bongers MY. Primary treatment of vaginal prolapse, pessary use versus prolapse surgery. International Urogynecology Journal and Pelvic Floor Dysfunction 2016;27(1 Suppl 1):S61-2. [Abstract number PP 44] [NTR2856] [sr-incont73917]

Coolen AL. Primary treatment of vaginal prolapse: pessary use versus prolapse surgery - ROK. trialregister.nl/trial/2719 (first received 17 April 2011). [NL2719 (NTR2856)] [Source ID: 0826] [TrialID.ROK] [sr-incont65492]

* Coolen AW, Troost S, Mol BW, Roovers JP, Bongers MY. Primary treatment of pelvic organ prolapse: pessary use versus prolapse surgery. International Urogynecology Journal 2018;29(1):99-107. [DOI: 10.1007/s00192-017-3372-x] [NTR2856] [sr-incont76942]

\section{Panman 2016 \{published data only\}}

Panman CM, Wiegersma M, Kollen BJ, Berger MY, Lisman-van Leeuwen Y, Dekker JH. Effects of pelvic floor muscle training and pessary treatment in women $\geq 55$ years with an advanced pelvic organ prolapse. International Urogynecology Journal and Pelvic Floor Dysfunction 2014;25(1 Suppl 1):S79-80. [Abstract number OP 004] [NTR2047 - POPPS2] [sr-incont67297]
* Panman CM, Wiegersma M, Kollen BJ, Berger MY, Lismanvan Leeuwen $\mathrm{Y}$, Vermeulen KM, et al. Effectiveness and costeffectiveness of pessary treatment compared with pelvic floor muscle training in older women with pelvic organ prolapse: 2-year follow up of a randomised controlled trial in primary care. Menopause 2016;23(12):1307-18. [NTR2047 - POPPS2] [srincont73042]

Wiegersma M, Panman CM, Kollen BJ, Vermeulen KM, Schram AJ, Messelink EJ, et al. Pelvic floor muscle training versus watchful waiting or pessary treatment for pelvic organ prolapse (POPPS): design and participant baseline characteristics of two parallel pragmatic randomized controlled trials in primary care. Maturitas 2014;77(2):168-73. [NTR2047 POPPS2] [sr-incont50409]

\section{References to studies excluded from this review}

\section{Chou 2013 \{published data only\}}

Chou Q, Leong Y, Cordick J, NCT01843166. Vaginal estrogen with pessary treatment [Use of vaginal estrogen with pessary treatment of pelvic organ prolapse and urinary incontinence]. clinicaltrials.gov/show/NCT01843166 (date received 30 April 2013). [NCT01843166] [sr-incont60025]

\section{Cundiff 2007 \{published data only\}}

Cundiff GN, Amundsen CL, Bent AE, Coates KW, Schaffer JI, Strohbehn K, et al. The PESSRI study: symptom relief outcomes of a randomized crossover trial of the ring and Gellhorn pessaries. American Journal of Obstetrics and Gynecology 2007;196(4):405.e1-8. [sr-incont23081] [PMID: 17403437]

Danandeh 2019 \{published data only\}

Danandeh Osgui N, Bastani P. Improvement of concomitant symptoms of pelvic organ prolapsed with applied pessary. Clinical and Experimental Obstetrics \& Gynecology 2019;46(1):42-4.

\section{Hagen 2011b \{published data only\}}

Bugge C, Williams B, Hagen S, Logan J, Glazener C, Pringle S, et al. A process for Decision-making after Pilot and feasibility Trials (ADePT): development following a feasibility study of a complex intervention for pelvic organ prolapse. Trials 2013;14:353.

* Hagen S, Sinclair L, Glazener C, Stark D, Pringle S, Logan J. A feasibility study for a randomised controlled trial of pelvic floor muscle training combined with vaginal pessary for women with pelvic organ prolapse. In: 41st Annual Meeting of the International Continence Society (ICS), 2011 Aug 29 to Sept 2, Glasgow, Scotland. 2011. [Abstract number 616] [srincont42224]

\section{McDermott 2012 \{published data only\}}

McDermott, C, Lennox G, NCT01644214. Timing of pessary follow-up for pelvic organ prolapse: patient preference and complication rates [Extended Pessary Interval for Care (EPIC Study): patient preference for 3 verus 6 month follow-up]. clinicaltrials.gov/show/NCT01644214 (first received 19 July 2012). [NCT01644214] [sr-incont65517] 
Meriwether 2015 \{published data only\}

Meriwether KV, Rogers RG, Craig E, Peterson SD, Gutman RE, Iglesia $\mathrm{CB}$. The effect of hydroxyquinoline-based gel on pessaryassociated bacterial vaginosis:a multicenter randomized controlled trial. American Journal of Obstetrics and Gynecology 2015;213(5):729.e1-9. [NCT01471457] [sr-incont69208]

Propst 2015 \{published data only\}

Propst K, NCT02371083. Timing of pessary care. clinicaltrials.gov/show/NCT02371083 (first received 25 February 2015). [HHC-2014-0112] [NCT02371083] [sr-incont66664]

Sanker 2013 \{published data only\}

Sanker V, Suvarna S. A clinical trial to study the effects of traditional treatments in patients with pelvic organ prolapse [A controlled prospective open labelled study to evaluate the traditional management of pelvic organ prolapse]. ctri.nic.in/ Clinicaltrials/pmaindet2.php?trialid=6069 (first received 17 April 2013). [CTRI/2013/04/003563] [sr-incont65481]

\section{Taege 2017 \{published data only\}}

Taege SK, Adams W, Mueller ER, Brubaker L, Fitzgerald CM, Brincat C. A randomized, double blind, placebo controlled trial of topical anesthetic use in pessary management: the TAP study. Neurourology and Urodynamics 2017;36(S1):S53-4. [(Abstract number: Poster \#M44)]

\section{Tontivuthikul 2016 \{published data only\}}

Tontivuthikul P, Sanmee U, Wongtra-Ngan S, Pongnarisorn C. Effect of local estrogen cream on vaginal health after pessary use for prolapsed pelvic organ: a randomized controlled trial. Journal of the Medical Association of Thailand 2016;99(7):757-63.

\section{Viravaidya 2012 \{published data only\}}

Viravaidya S, Manonai J, Sarit-Apirak S, Wattanayingcharoenchai R. Effects of topical antiseptic agent on vaginal symptoms, $\mathrm{pH}$ and infection in postmenopausal women using pessary for pelvic organ prolapse. International Urogynecology Journal 2012;23(Suppl 2):s131-2. [Abstract number 84] [sr-incont49142]

\section{References to ongoing studies}

\section{Cornish 2018 \{published data only\}}

Cornish A, Yong CH, Carey M, ACTRN12618000416291. Polyvinyl chloride ring pessary versus silicon irregular hexagon pessary for pelvic organ prolapse: a randomised trial comparing treatment success. anzctr.org.au/ACTRN12618000416291.aspx (first received 4 March 2018). [ACTRN12618000416291] [srincont77835]

\section{van de Waarsenburg 2014 \{published data only\}}

Van de Waarsenburg MK, van der Vaart CH. Pessary or prolapse surgery for symptomatic pelvic organ prolapse. trialregister.nl/trial/4756 (first received 18 November 2014). [NL4756 (NTR4883)] [sr-incont65472]

\section{Additional references}

\section{Abdel-Fattah 2011}

Abdel-Fattah M, Familusi A, Fielding S, Ford J, Bhattacharya S. Primary and repeat surgical treatment for female pelvic organ prolapse and incontinence in parous women in the UK: a register linkage study. BMJ Open 2011;1:e000206.

\section{Baessler 2009}

Baessler K, O'Neill SM, Maher CF, Battistutta D. Australian pelvic floor questionnaire: a validated interviewer-administered pelvic floor questionnaire for routine clinic and research. International Urogynecology Journal and Pelvic Floor Dysfunction 2009;20(2):149-58.

\section{Baessler 2018}

Baessler K, Christmann-Schmid C, Maher C, Haya N, Crawford TJ, Brown J. Surgery for women with pelvic organ prolapse with or without stress urinary incontinence. Cochrane Database of Systematic Reviews 2018, Issue 8. Art. No: CD013108. [DOI: 10.1002/14651858.CD013108]

\section{Barber 2001}

Barber MD, Kuchibhatla MN, Pieper CF, Bump RC. Psychometric evaluation of 2 comprehensive condition-specific quality of life instruments for women with pelvic floor disorders. American Journal of Obstetrics and Gynecology 2001;185(6):1388-95.

\section{Barber 2005}

Barber MD, Walters MD, Bump RC. Short forms of two conditionspecific quality-of-life questionnaires for women with pelvic floor disorders (PFDI-20 and PFIQ-7). American Journal of Obstetrics and Gynecology 2005;193(1):103-13.

\section{Basu 2011}

Basu M, Wise B, Duckett J. A qualitative study of women's preferences for treatment of pelvic floor disorders. BJOG 2011;118(3):338-44.

\section{Brazell 2014}

Brazell HD, Patel M, O'Sullivan DM, Mellen C, LaSala CA. The impact of pessary use on bowel symptoms: one-year outcomes. Female Pelvic Medicine \& Reconstructive Surgery 2014;20(2):95-8.

\section{Bugge 2013a}

Bugge C, Hagen S, Thakar R. Vaginal pessaries for pelvic organ prolapse and urinary incontinence: a multiprofessional survey of practice. International Urogynecology Journal 2013;24(6):1017-24.

\section{Bugge 2020 [pers comm]}

Bugge C. Your RCT comparing pessary and surgery [personal communication]. Email to: A-L Coolen 4 March 2020.

\section{Bump 1996}

Bump RC, Mattiasson A, Bø K, Brubaker LP, DeLancey JO, Klarskov $P$, et al. The standardisation of terminology of female pelvic organ prolapse and pelvic floor dysfunction. American Journal of Obstetrics and Gynecology 1996;175(1):10-7. 


\section{Bump 1998}

Bump R, Norton P. Epidemiology and natural history of pelvic floor dysfunction. Obstetrics and Gynecology Clinics of North America 1998;25(4):723-46.

\section{Clemons 2004a}

Clemons JL, Aguilar VC, Tillinghast TA, Jackson ND, Myers DL. Risk factors associated with an unsuccessful pessary fitting trial in women with pelvic organ prolapse. American Journal of Obstetrics and Gynecology 2004;190(2):345-50.

\section{Clemons 2004b}

Clemons JL, Aguilar VC, Tillinghast TA, Jackson ND, Myers DL. Patient satisfaction and changes in prolapse and urinary symptoms in women who were fitted successfully with a pessary for pelvic organ prolapse. American Journal of Obstetrics and Gynecology 2004;190(4):1025-9.

\section{Clemons 2004c}

Clemons JL, Aguilar VC, Sokol ER, Jackson ND, Myers DL. Patient characteristics that are associated with continued pessary use versus surgery after 1 year. American Journal of Obstetrics and Gynecology 2004;191(1):159-64.

\section{CRD 2015}

Centre for Reviews and Dissemination (CRD). CRD databases: search strategies. 2015. crd.york.ac.uk/crdweb/ (accessed 19 May 2020).

\section{Cundiff 2000}

Cundiff GW, Weidner AC, Visco AG, Bump RC, Addison WA A survey of pessary use by members of the American Urogynecologic Society. Obstetrics and Gynecology 2000;95(6 Pt 1):931-5.

\section{Dietz 2008}

Dietz HP. The aetiology of prolapse. International Urogynecology Journal and Pelvic Floor Dysfunction 2008;19(10):1323-9.

\section{Dolan 1995}

Dolan P, Gudex C, Kind P, Williams A. A social tariff for EuroQol: results from a UK general population survey.. York, UK: Centre for Health Economics, University of York; 1995.Working paper number: 138chedp. Avialable from www.york.ac.uk/media/ che/documents/papers/discussionpapers/CHE\%20Discussion \%20Paper\%20138.pdf (accessed 22 May 2020).

\section{Dumoulin 2017}

Dumoulin C, Adewuyi T, Booth J, Bradley C, Burgio K, Hagen S, et al. Adult conservative management. In: Abrams $P$, Cardozo L, Wagg A, Wein A, editors(s). Incontinence: 6th International Consultation on Incontinence, Tokyo, September 2016. 6th edition. Vol. 2. Bristol, UK: International Continence Society (ICS) and International Consultation on Urological Diseases (ICUD), 2017:1443-1628.

\section{Dwyer 2019}

Dwyer L, Kearney R, Lavender T. A review of pessary for prolapse practitioner training. British Journal of Nursing 2019;28(9):S18-24.

\section{EndNote 2018 [Computer program]}

EndNote. Version X8.2. Philadelphia (PA): Clarivate Analytics, 2018.

\section{Enemchukwu 2019}

Enemchukwu EA. Transvaginal suture-based repair. Urologic Clinics of North America 2019;46(1):97-102.

\section{Gorti 2009}

Gorti M, Hudelist G, Simons A. Evaluation of vaginal pessary management: a UK-based survey. Journal of Obstetrics and Gynaecology 2009;29(2):129-31.

\section{GRADEpro GDT [Computer program]}

McMaster University (developed by Evidence Prime) GRADEpro GDT. Version accessed 5 May 2020. Hamilton (ON): McMaster University (developed by Evidence Prime). Available at gradepro.org.

\section{Gyhagen 2015}

Gyhagen M, Åkervall S, Milsom I. Clustering of pelvic floor disorders 20 years after one vaginal or one cesarean birth. International Urogynecology Journal 2015;26(8):1115-21.

\section{Hagen 2009}

Hagen S, Glazener C, Sinclair L, Stark D, Bugge C. Psychometric properties of the Pelvic Organ Prolapse Symptom Score. BJOG 2009;116(1):25-31.

\section{Hagen 2011a}

Hagen S, Stark D. Conservative prevention and management of pelvic organ prolapse in women. Cochrane Database of Systematic Reviews 2011, Issue 12. Art. No: CD003882. [DOI: 10.1002/14651858.CD003882.pub4]

\section{Hanson 2006}

Hanson LM, Schulz JA, Flood CG, Cooley B, Tam F. Vaginal pessaries in managing women with pelvic organ prolapse and urinary incontinence:patient characteristics and factors contributing to success. International Urogynecology Journal and Pelvic Floor Dysfunction 2006;17(2):155-9.

\section{Hendrix 2002}

Hendrix SL, Clark A, Nygaard I, Aragaki A, Barnabei V, McTiernan A. Pelvic organ prolapse in the Women's Health Initiative: gravity and gravidity. American Journal of Obstetrics and Gynecology 2002;186(6):1160-6.

\section{Higgins 2011}

Higgins JP, Green S, editor(s). Cochrane Handbook for Systematic Reviews of Interventions Version 5.1.0 (updated March 2011). The Cochrane Collaboration, 2011. Available from handbook.cochrane.org.

\section{Higgins 2019}

Higgins JP, Thomas J, Chandler J, Cumpston M, Li T, Page MJ, et al (editors). Cochrane Handbook for Systematic Reviews of Interventions Version 6.0 (updated July 2019). Cochrane, 2019. Available from www.training.cochrane.org/handbook. 


\section{Hullfish 2011}

Hullfish KL, Trowbridge ER, Stukenborg GJ. Treatment strategies for pelvic organ prolapse: a cost-effectiveness analysis. International Urogynecology Journal 2011;22(5):507-15.

\section{Jelovsek 2006}

Jelovsek JE, Barber MD. Women seeking treatment for advanced pelvic organ prolapse have decreased body image and quality of life. American Journal of Obstetrics and Gynaecology 2006;194(5):1455-61.

\section{Jelovsek 2018}

Jelovsek JE, Chagin K, Gyhagen M, Hagen S, Wilson D, Kattan MW, et al. Predicting risk of pelvic floor disorders 12 and 20 years after delivery. American Journal of Obstetrics and Gynecology 2018;218(2):222.e1-19.

\section{Kapoor 2009}

Kapoor DS, Thakar R, Sultan AH, Oliver R. Conservative versus surgical management of prolapse: what dictates patient choice? International Urogynecology Journal and Pelvic Floor Dysfunction 2009;20(10):1157-61.

\section{Lamers 2011}

Lamers BH, Broekman BM, Milani AL. Pessary treatment for pelvic organ prolapse and health-related quality of life: a review. International Urogynaecology Journal 2011;22(6):637-44.

\section{Lone 2011}

Lone F, Thakar R, Sultan AH, Karamalis G. A 5-year prospective study of vaginal pessary use for pelvic organ prolapse. International Journal of Gynaecology and Obstetrics 2011;114(1):56-9.

\section{Lough 2018}

Lough K, Hagen S, McClurg D, Pollock A, JLA Pessary PSP Steering Group. Shared research priorities for pessary use in women with prolapse: results from a James Lind Alliance Priority Setting Partnership. BMJ Open 2018;8(4):e021276.

\section{Lowder 2011}

Lowder JL, Ghetti C, Nikolajski C, Oliphant SS, Zyczynski HM. Body image perceptions in women with pelvic organ prolapse: a qualitative study. American Journal of Obstetrics and Gynecology 2011;204(5):441.e1-5.

\section{MacLennan 2000}

MacLennan AH, Taylor AW, Wilson DH, Wilson D. The prevalence of pelvic floor disorders and their relationship to gender, age, parity and mode of delivery. BJOG 2000;107(12):1460-70. [MEDLINE: 21029149]

\section{Maher 2016a}

Maher C, Feiner B, Baessler K, Christmann-Schmid C, Haya N, Marjoribanks J. Transvaginal mesh or grafts compared with native tissue repair for vaginal prolapse. Cochrane Database of Systematic Reviews 2016, Issue 2. Art. No: CD012079. [DOI: 10.1002/14651858.CD012079]

\section{Maher 2016b}

Maher C, Feiner B, Baessler K, Christmann-Schmid C, Haya N, Brown J. Surgery for women with apical vaginal prolapse. Cochrane Database of Systematic Reviews 2016, Issue 10. Art. No: CD012376. [DOI: 10.1002/14651858.CD012376]

\section{Maher 2016c}

Maher C, Feiner B, Baessler K, Christmann-Schmid C, Haya N, Brown J. Surgery for women with anterior compartment prolapse. Cochrane Database of Systematic Reviews 2016, Issue 11. Art. No: CD004014. [DOI: 10.1002/14651858.CD004014.pub6]

\section{Manchana 2012}

Manchana T, Bunyavejchevin S. Impact on quality of life after ring pessary use for pelvic organ prolapse. International Urogynecological Journal 2012;23(7):873-7.

\section{Mowat 2018}

Mowat A, Maher D, Baessler K, Christmann-Schmid C, Haya N, Maher C. Surgery for women with posterior compartment prolapse. Cochrane Database of Systematic Reviews 2018, Issue 3. Art. No: CD012975. [DOI: 10.1002/14651858.CD012975]

\section{NICE 2019}

National Institute for Health and Care Excellence (NICE), National Guideline Alliance. Urinary incontinence and pelvic organ prolapse in women: management. NICE guideline [NG123]. London: National Institute for Health and Care Excellence (NICE); 2019. Available from nice.org.uk/guidance/ ng123 (accessed 30 April 2020).

\section{Oliver 2011}

Oliver R, Thakar R, Sultan AH. The history and usage of the vaginal pessary: a review. European Journal of Obstetrics, Gynecology, and Reproductive Biology 2011;156(2):125-30.

\section{Pakbaz 2010}

Pakbaz M, Persson M, Löfgren M, Mogren I. 'A hidden disorder until the pieces fall into place' - a qualitative study of vaginal prolapse. BMC Women's Health 2010;10:18. [DOI: 10.1186/1472-6874-10-18]

\section{Poma 2000}

Poma PA. Nonsurgical management of genital prolapse. A review and recommendations for clinical practice. Journal of Reproductive Medicine 2000;45(10):789-97. [PMID: 11077625]

\section{Pott-Grinstein 2001}

Pott-Grinstein E, Newcomer JR. Gynecologists' patterns of prescribing pessaries. Journal of Reproductive Medicine 2001;46(3):205-8. [PMID: 11304859]

\section{Primary Care Women's Health Forum 2019}

Primary Care Women's Health Forum. What is the cost of pelvic organ prolapse to the NHS? News: 28 August 2019. Available at pcwhf.co.uk/news/what-is-the-cost-of-pelvic-organ-prolapseto-the-nhs/ (accessed 24 July 2020).

\section{Schünemann 2019}

Schünemann HJ, Higgins JP, Vist GE, Glasziou P, Akl EA, Skoetz N, et al. Chapter 14: Completing 'Summary of findings' 
tables and grading the certainty of the evidence. In: Higgins JP, Thomas J, Chandler J, Cumpston M, Li T, Page MJ, et al editor(s). Cochrane Handbook for Systematic Reviews of Interventions Version 6.0 (updated July 2019). Cochrane, 2019. Available from www.training.cochrane.org/handbook.

\section{Shemilt 2019}

Shemilt I, Aluko P, Graybill E, Craig D, Henderson C, Drummond $\mathrm{M}$, et al, on behalf of the Campbell and Cochrane Economics Methods Group. Chapter 20: Economic evidence. In: Higgins JP, Thomas J, Chandler J, Cumpston M, Li T, Page MJ, et al, editor(s). Cochrane Handbook for Systematic Reviews of Interventions Version 6.0 (updated July 2019). Cochrane, 2019. Available from www.training.cochrane.org/handbook.

\section{Subak 2001}

Subak LL, Waetjen LE, van den Eeden S, Thom DH, Vittinghoff E, Brown JS. Cost of pelvic organ prolapse surgery in the United States. Obstretrics and Gynecology 2001;98(4):646-51.

\section{Ware 1993}

Ware JE. Measuring patients' views: the optimum outcome measure. SF36: a valid, reliable assessment of health from the patient's point of view. BMJ 1993;306(6890):1429-30.

\section{Ware 1996}

Ware J Jr, Kosinski M, Keller SD. A 12-Item Short-Form Health Survey: construction of scales and preliminary tests of reliability and validity. Medical Care 1996;34(3):220-33.

\section{Wiegersma 2014}

Wiegersma M, Panman CM, Kollen BJ, Vermeulen KM, Schram AJ, Messelink EJ, et al. Pelvic floor muscle training versus watchful waiting or pessary treatment for pelvic organ prolapse (POPPS): design and participant baseline characteristics of two parallel pragmatic randomized controlled trials in primary care. Maturitas 2014;77(2):168-73.

\section{CHARACTERISTICS OFSTUDIES}

Characteristics of included studies [ordered by study ID]

\section{Wu 2009}

Wu JM, Hundley AF, Fulton RG, Myers ER. Forecasting the prevalence of pelvic floor disorders in US Women: 2010 to 2050. Obstetrics and Gynecology 2009;114(6):1278-83.

\section{Wu 2011}

Wu JM, Kawasaki A, Hundley AF, Dieter AA, Myers ER, Sung VW. Predicting the number of women who will undergo incontinence and prolapse surgery, 2010 to 2050. American Journal of Obstetrics and Gynecology 2011;205(3):230.e1-5.

\section{Zigmond 1983}

Zigmond AS, Snaith RP. The Hospital Anxiety and Depression scale. Acta Psychiatrica Scandinavica 1983;67(6):361-70.

\section{References to other published versions of this review}

\section{Adams 2002}

Adams EJ, Thomson A, Maher C, Hagen S. Mechanical devices for pelvic organ prolapse in women. Cochrane Database of Systematic Reviews 2002, Issue 4. Art. No: CD004010. [DOI: 10.1002/14651858.CD004010]

\section{Adams 2004}

Adams EJ, Thomson AJ, Maher C, Hagen S. Mechanical devices for pelvic organ prolapse in women. Cochrane Database of Systematic Reviews 2004, Issue 2. Art. No: CD004010. [DOI: 10.1002/14651858.CD004010.pub2]

\section{Bugge 2013b}

Bugge C, Adams EJ, Gopinath D, Reid F. Pessaries (mechanical devices) for pelvic organ prolapse in women. Cochrane Database of Systematic Reviews 2013, Issue 2. Art. No: CD004010. [DOI: 10.1002/14651858.CD004010.pub3]

* Indicates the major publication for the study

Baessler 2019

\section{Study characteristics}

\begin{tabular}{ll}
\hline Methods & Design: two-arm parallel RCT \\
\hline Participants & Country: Germany \\
& Number of participants: 34 \\
& Mean age: pessary group 32 (SD 5.6); standard care 30.4 (SD 6.6) \\
& Prolapse staging: stage II \\
& Prolapse compartment: anterior and posterior
\end{tabular}

Inclusion criteria: women 18 and over, first vaginal delivery, stage 2 POP (examination or perineal ultrasound in standing position) 
Baessler 2019 (Continued)

Exclusion criteria: severe diseases of mother/child, previous pelvic surgery, neurological diseases, severe perineal post partum pain, high vaginal tears
Interventions

Group I ( $\mathbf{n}$ 13): vaginal ring pessary

Group II ( $\mathbf{n}=\mathbf{2 1}$ ): standard care (no interventions for six weeks postpartum)

Primary outcome: prolapse symptoms measured using the Australian Pelvic Floor Questionnaire (German version with validated postpartum module) at 12 months

Secondary outcomes: POP-Q, pelvic ultrasound for bladder neck and puborectalis at rest and on straining in standing

Funding source: not reported
Declarations of interest: J Stupin discloses Arabin GmbH: Consultant, all other authors state they
have noting to disclose.
$\begin{aligned} & \text { Trial stopped early due to poor recruitment and 'occasional pessary problems which were solved with } \\ & \text { pessary removal' }\end{aligned}$

\section{Risk of bias}

\begin{tabular}{|c|c|c|}
\hline Bias & Authors' judgement & Support for judgement \\
\hline $\begin{array}{l}\text { Random sequence genera- } \\
\text { tion (selection bias) }\end{array}$ & Low risk & $\begin{array}{l}\text { PC-generated randomisation list put into opaque envelopes. Preference was } \\
\text { permitted but data are available for randomised group only }\end{array}$ \\
\hline $\begin{array}{l}\text { Allocation concealment } \\
\text { (selection bias) }\end{array}$ & Low risk & Opaque envelopes opened after consent and examination for levator avulsion \\
\hline $\begin{array}{l}\text { Blinding of participants } \\
\text { and personnel (perfor- } \\
\text { mance bias) } \\
\text { All outcomes }\end{array}$ & High risk & Not possible to blind participant or caregiver. \\
\hline $\begin{array}{l}\text { Blinding of outcome as- } \\
\text { sessment (detection bias) } \\
\text { All outcomes }\end{array}$ & Low risk & Assessors blinded to group allocation. \\
\hline $\begin{array}{l}\text { Incomplete outcome data } \\
\text { (attrition bias) } \\
\text { All outcomes }\end{array}$ & High risk & $\begin{array}{l}\text { Some differential loss to follow-up ( } 1 / 13 \text { in pessary group, } 6 / 21 \text { in standard } \\
\text { care group). }\end{array}$ \\
\hline $\begin{array}{l}\text { Selective reporting (re- } \\
\text { porting bias) }\end{array}$ & Low risk & Data provided on measured outcomes. \\
\hline Other bias & Low risk & None \\
\hline
\end{tabular}

Cheung 2016

\section{Study characteristics}

Methods Design: parallel group RCT

Dates study conducted: December 2011 to November 2014 
Cheung 2016 (Continued)

Participants

Setting: Hong Kong, single centre

Number of participants: 276 women with pelvic organ prolapse stages I to III (POPQ)

Mean age: PFMT group 62.7 (SD 10.2); pessary group 62.5 (SD 9.1)

Prolapse staging:

PFMT group: stage I n = 14 (10\%); stage II n = 92 (67\%); stage III n = $31(23 \%)$

Pessary group: stage I $n=11(8 \%)$, stage II $n=96(69 \%)$ stage III $n=32(23 \%)$

\section{Prolapse compartment:}

PFMT group: anterior $n=91$ (61.4\%); apical $n=38(27.7 \%)$; posterior $n=8(5.8 \%)$

Pessary group: anterior $n=90(64.7 \%)$; apical $n=45(32.4 \%)$; posterior $n=4(2.9 \%)$

Inclusion criteria: symptomatic pelvic organ prolapse stage I to III (POP-Q), no previous treatment

Exclusion criteria: complications that arise from prolapse, confirmed urinary retention, vaginal erosion or ulcer that required active treatment, impaired mobility, cognitive impairment, language barrier that prevented questionnaire completion

Interventions

Group I ( $\mathbf{n}$ = 137): PFMT treatment alone

Group II ( $\mathbf{n}=\mathbf{1 3 9})$ : vaginal ring pessary plus conservative treatment

$\begin{array}{ll}\text { Outcomes } & \text { Primary outcome: PFDI and PFIQ plus subscales } \\ & \text { Secondary outcome: discomfort from prolapse symptoms (VAS score), desired treatment, complica- } \\ \text { tions }\end{array}$
tions

Notes $\quad$ Funding source: not reported

Declarations of interest: quote: "The authors did not report any potential conflicts of interest"

\section{Risk of bias}

\begin{tabular}{|c|c|c|}
\hline Bias & Authors' judgement & Support for judgement \\
\hline $\begin{array}{l}\text { Random sequence genera- } \\
\text { tion (selection bias) }\end{array}$ & Low risk & $\begin{array}{l}\text { Women randomised using random computer-generated numbers and allocat- } \\
\text { ed in serially numbered envelopes. }\end{array}$ \\
\hline $\begin{array}{l}\text { Allocation concealment } \\
\text { (selection bias) }\end{array}$ & Low risk & Allocated by random number series \\
\hline $\begin{array}{l}\text { Blinding of participants } \\
\text { and personnel (perfor- } \\
\text { mance bias) } \\
\text { All outcomes }\end{array}$ & High risk & $\begin{array}{l}\text { Participants not blinded to treatment. Investigator who took history and } \\
\text { recorded POP-Q blinded to group allocation. }\end{array}$ \\
\hline $\begin{array}{l}\text { Blinding of outcome as- } \\
\text { sessment (detection bias) } \\
\text { All outcomes }\end{array}$ & Low risk & $\begin{array}{l}\text { Primary outcome self-completion. Investigator who took history and recorded } \\
\text { POP-Q blinded to group allocation. }\end{array}$ \\
\hline $\begin{array}{l}\text { Incomplete outcome data } \\
\text { (attrition bias) } \\
\text { All outcomes }\end{array}$ & Low risk & $\begin{array}{l}\text { 135/139 in pessary group and 130/137 in PFMT alone group completed mea- } \\
\text { sures at } 12 \text { months. }\end{array}$ \\
\hline
\end{tabular}


Cheung 2016 (Continued)

Selective reporting (re- Low risk Not all outcomes listed in Trial registry and paper presented but main outporting bias) comes are presented and they have reported outcomes of interest to this review

Other bias Low risk None.

Coolen 2018

\section{Study characteristics}

Methods Design: parallel group RCT

Dates study conducted: June 2009 and July 2014

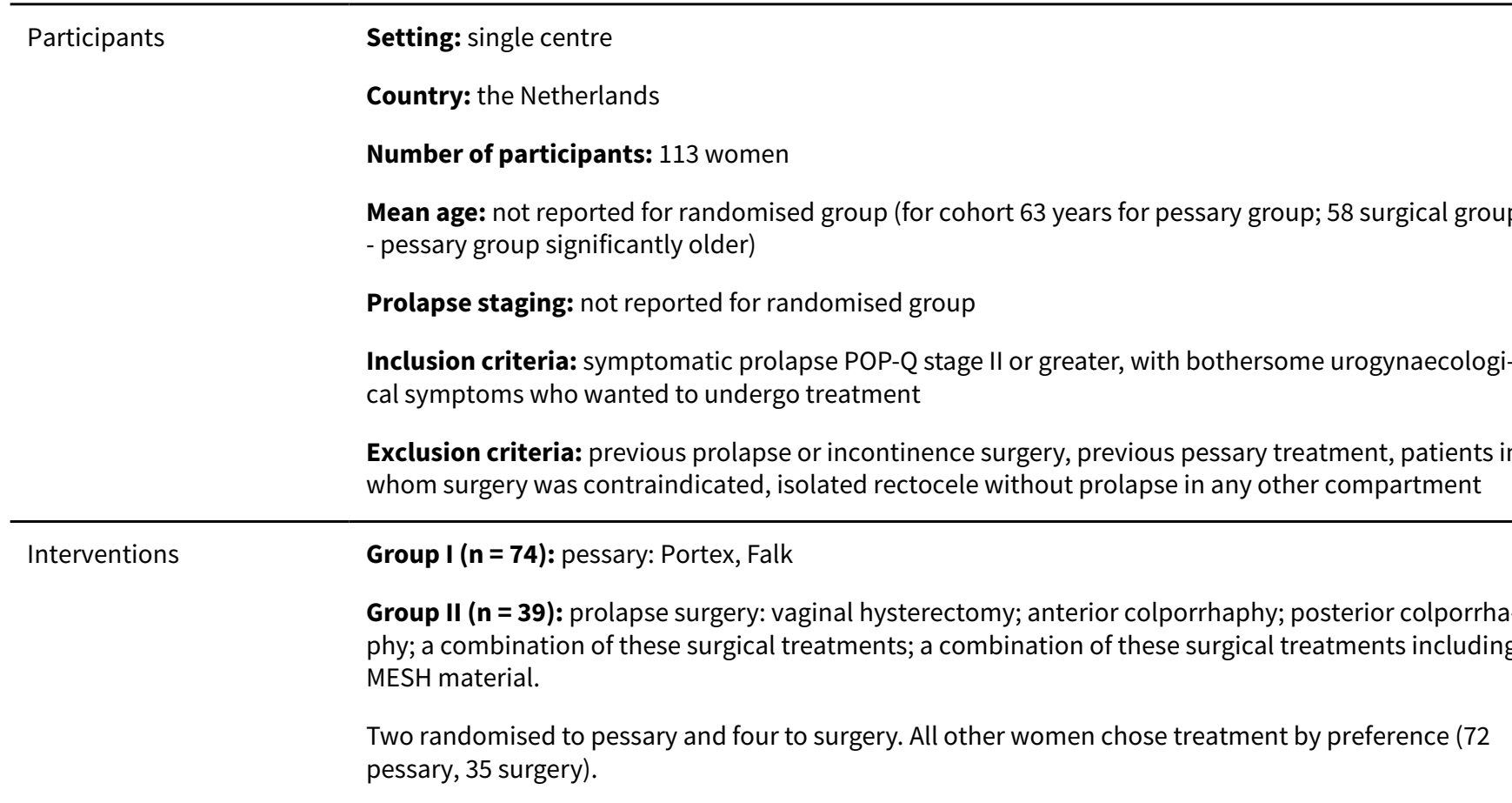

Outcomes

Primary outcome: disease-specific quality of life - prolapse domain of Urinary Distress Inventory (UDI)

Secondary outcomes: general quality of life (werkgroepbekkenbodem, EURQOL, SF36); successful continuous pessary treatment; anatomical outcome (POP-Q).

Funding source: not reported
Declarations of interest: not reported
Data on the six randomised women were not available in the published study reports. We were in com
munication with the trialists regarding obtaining these data but the global pandemic of 2020 meant
we had to pause this process - we will re-establish contact with the trialists for the next review update
(Bugge 2020 [pers comm].

\section{Risk of bias}

Bias Authors' judgement Support for judgement


Coolen 2018 (Continued)

Random sequence genera- High risk Only six women randomised, patient preference took priority. tion (selection bias)

\begin{tabular}{ll}
\hline $\begin{array}{l}\text { Allocation concealment } \\
\text { (selection bias) }\end{array}$ Low risk & Allocation in sealed opaque envelopes.
\end{tabular}

(selection bias)

Blinding of participants High risk Blinding not possible.

and personnel (perfor-

mance bias)

All outcomes

\begin{tabular}{lll}
\hline $\begin{array}{l}\text { Blinding of outcome as- } \\
\text { sessment (detection bias) } \\
\text { All outcomes }\end{array}$ & Unclear risk & Not reported \\
\hline $\begin{array}{l}\text { Incomplete outcome data } \\
\text { (attrition bias) } \\
\text { All outcomes }\end{array}$ & Unclear risk & Not known for randomised group \\
\hline $\begin{array}{l}\text { Selective reporting (re- } \\
\text { porting bias) }\end{array}$ & Unclear risk & Not known for randomised group \\
\hline Other bias & Low risk & None \\
\hline
\end{tabular}

\section{Panman 2016}

\section{Study characteristics}

Methods Design: parallel group RCT

Dates study conducted: October 2009 to December 2012

Participants

Setting: multicentre (women recruited from 20 general practices)

Country: the Netherlands

Number of participants: 162 women with prolapse at or beyond hymen (POP-Q measured)

Mean age: PFMT group 65.6 (SD 6.4); pessary group 64.9 (SD 7.4)

Prolapse staging:

PFMT group: stage II $77.5 \%(n=62)$; stage III 22.5\% $(n=18)$.

Pessary group: stage II 70.7\% ( $n=58)$; stage III 29.3\% ( $n=24)$.

\section{Prolapse compartment:}

PFMT group: anterior $31.3 \%(n=25)$, posterior $3.8 \%(n=3)$, apical $0 \%(n=0)$, anterior and posterior $32.5 \%(n=26)$, anterior and apical $10 \%(n=8)$, posterior and apical $2.5 \%(n=2)$, anterior and posterior and apical $20 \%(n=16)$

Pessary group: anterior $24.7 \%(n=20)$, posterior $0 \%(n=0)$, apical $0 \%(n=0)$, anterior and posterior $28.4 \%(n=23)$, anterior and apical $23.5 \%(n=19)$, posterior and apical $0 \%(n=0)$, anterior and posterior and apical $23.5 \%(\mathrm{n}=19)$

Inclusion criteria: women aged 55 years and older, GP registered, self-identified prolapse symptoms (using screening tool), prolapse at or beyond hymen using POP-Q 
Panman 2016 (Continued)

Exclusion criteria: current prolapse treatment (or within the last year for PFMT, pessary or surgery), current treatment for gynaecological or urological disorder, current gynaecological or urological malignancy, severe/terminal illness, inability to visit GP office, cognitive impairment, inability to understand complete Dutch questionnaires, stage IV prolapse

Interventions

Group I ( $\mathbf{n}=\mathbf{8 0}$ ): PFMT. Delivered by a registered pelvic physiotherapist registered with Dutch Pelvic Physio Association. Started with explanation of pelvic floor function, if unable to contract taught this first, women did exercises during physiotherapy contact and at home three to five times a week and two to three times a day. All participants started with same exercise regimen and then individual adaptation in line with normal practice (included being able to use electrical stimulation). All taught the knack. Attention paid to lifestyle and toileting habits. At three-month follow-up all PFMT group received a leaflet with information and advice on lifestyle and continuing PFMT.

Group II ( $\mathbf{n = 8 2}$ ): pessary. Fitted by quote: "trained research physician" $(n=4)$. Two-week trial of pessary with refit at two weeks if necessary (maximum of three refits); first ring, then ring with support and then Shaatz or Gellhorn (all silicone). Follow-up started as soon as successful fit achieved. Additional visits (to GP or research physician) to clean pessary and monitor side effects every three months. Topical oestrogen used for vaginal decubitus.

Outcomes Primary outcome: distress caused by pelvic floor symptoms measured by PFDI-20

Secondary outcomes: three subscales of PFDI-20, condition-specific and general quality of life, sexual function, pelvic floor muscle function, POP-Q, post void residual volume, patients' perception of improvement, costs

Notes

Funding source: quote: "funded by the Netherlands Organisation for Health Research and Development (ZonMw), project number 4201.1001"; "The funding organization had no role in the design and conduct of the study; the collection, management, analysis, and interpretation of the data; the preparation, review, or approval of the manuscript; or the decision to submit the manuscript for publication."

Declarations of interest: quote: "The authors declare no conflict of interest."

There is both the main paper that presented an intention-to-treat and per protocol analysis. The full trial protocol is published (Panman 2016) .Data for intention-to-treat analysis available in main paper, plus one conference abstract about the completed case analysis at three months (those with unsuccessful pessary fitting excluded).

\section{Risk of bias}

\begin{tabular}{lll}
\hline Bias & Authors' judgement & Support for judgement \\
\hline $\begin{array}{l}\text { Random sequence genera- } \\
\text { tion (selection bias) }\end{array}$ & Low risk & $\begin{array}{l}\text { Randomised in a 1:1 ratio using external (remotely accessed) computerised } \\
\text { system in variable block size }\end{array}$ \\
\hline $\begin{array}{l}\text { Allocation concealment } \\
\text { (selection bias) }\end{array}$ & Low risk & $\begin{array}{l}\text { Enrolling physician blind to block size and allocation sequence. Allocation us- } \\
\text { ing remotely accessed computer system. }\end{array}$ \\
\hline
\end{tabular}

Blinding of participants

High risk Patients and treating health professionals not blinded to treatment allocation. and personnel (performance bias)

All outcomes

$\begin{array}{lll}\text { Blinding of outcome as- } & \text { High risk } & \begin{array}{l}\text { Research physicians were not blinded to allocation and outcomes may have } \\ \text { sessment (detection bias) }\end{array} \\ \text { bll outcomes } & & \text { been influenced by their knowledge of allocation. }\end{array}$
All outcomes 
Panman 2016 (Continued)

Selective reporting (re- Low risk $\quad$ Data are presented across outcomes
porting bias)

Other bias Low risk None

GP: general practitioner

PFDI-20: Pelvic Floor Disability Index

PFIQ: Pelvic Floor Impact Questionnaire

PFMT: pelvic floor muscle training

POP: pelvic organ prolapse

POP-Q: Pelvic Organ Prolapse Quantification

$\mathrm{RCT}$ : randomised controlled trial

SD: standard deviation

SF36: Short Form 36

UDI: Urinary Distress Index

VAS: visual analogue scale

Characteristics of excluded studies [ordered by study ID]

\begin{tabular}{ll}
\hline Study & Reason for exclusion \\
\hline Chou 2013 & Ineligible comparison \\
\hline Cundiff 2007 & Ineligible study design (cross-over RCT) \\
\hline Danandeh 2019 & Ineligible study design (not RCT) \\
\hline Hagen 2011b & Ineligible comparison \\
\hline McDermott 2012 & Ineligible comparison \\
\hline Meriwether 2015 & $\begin{array}{l}\text { Not possible to separate data for women who had prolapse or prolapse plus incontinence from } \\
\text { women who had incontinence alone }\end{array}$ \\
\hline Propst 2015 & Ineligible comparison \\
\hline Sanker 2013 & Ineligible comparison \\
\hline Taege 2017 & $\begin{array}{l}\text { Not possible to separate data for women who had prolapse or prolapse plus incontinence from } \\
\text { women who had incontinence alone }\end{array}$ \\
\hline Tontivuthikul 2016 & Ineligible comparison \\
\hline Viravaidya 2012 & Ineligible intervention \\
\hline
\end{tabular}

$\mathrm{RCT}$ : randomised controlled trial

Characteristics of ongoing studies [ordered by study ID]

Cornish 2018

Study name Polyvinyl chloride ring pessary versus silicon irregular hexagon pessary for pelvic organ prolapse: a randomised trial comparing treatment success.

Methods Design: parallel RCT


Cornish 2018 (Continued)

Participants
The study aims to recruit 104 women.

Inclusion criteria: women who are at least 18 years of age with symptomatic pelvic organ prolapse, able to speak and read English, no previous use of a vaginal pessary for prolapse, at least stage II prolapse for any single compartment or multi-compartment prolapse, willing to use a ring pessary, willing and able to complete questionnaires and follow-up visits.

Exclusion criteria: refusal to participate, unable to speak or read English, women under 18 years of age, previous vaginal pessary use, prior prolapse surgery, contraindications to topical oestrogen therapy, unwilling to use a vaginal pessary, unable and unwilling to complete questionnaires and attend follow-up visits.
Group I: a silicon irregular hexagonal pessary

Group II: PVC ring pessary

Outcomes Primary outcome: treatment success (defined as retention of the pessary at 6 months and 12 months post randomisation)

Secondary outcomes: self-reported ability to self-care at 6 and 12 months; satisfaction with pessary treatment based on PFDI-20, PISQ 12 and EQ5D at 6 and 12 months; adverse events at 6 and 12 months.

\begin{tabular}{ll}
\hline Starting date & 2018 \\
\hline Contact information & chin.yong@thewomens.org.au \\
\hline Notes & This trial is ongoing. \\
\hline
\end{tabular}

van de Waarsenburg 2014

\begin{tabular}{ll}
\hline Study name & Pessary or prolapse surgery for symptomatic pelvic organ prolapse (PEOPLE) \\
\hline Methods & $\begin{array}{l}\text { Multicentre pragmatic cohort study with an embedded randomised controlled non-inferiority trial } \\
\text { comparing pessary therapy versus surgery including an economic evaluation }\end{array}$
\end{tabular}

Participants

The aim is to recruit 436 women.

Inclusion criteria: women with prolapse stage 2 or more, women with moderate to severe prolapse symptoms (score of $>33$ on PFDI-20), women with successful pessary fitting, written informed consent

Exclusion criteria: prior urogynaecological (prolapse or incontinence) surgery, probability of future childbearing, insufficient knowledge of Dutch language, comorbidity causing increased surgical risks (at surgeon discretion), major psychiatric illness, prior pessary use

Interventions

Group I: pessary

Group II: vaginal prolapse surgery

Outcomes
Primary outcome: global impression of improvement of prolapse symptoms at 24 months (PGI-I)

Secondary outcome: change in symptom bother and disease-specific quality of life at 12 and 24 months, changes in sexual function at 12 and 24 months, changes in general quality of life at 3,6, 12 and 24 months, adverse events/complications, development of prediction model to identify factors for failing of pessary and surgery, cost-effectiveness analysis 
van de Waarsenburg 2014 (Continued)

Starting date 2015

EQ-5D: EuroQol-5D

PFDI-20: Pelvic Floor Disability Index

PGI-I: Patient Global Impression of Improvement

PISQ-12: Pelvic Organ Prolapse/Urinary Incontinence Sexual Questionnaire

PVC: polyvinyl chloride

$\mathrm{RCT}$ : randomised controlled trial

\section{DATA AND ANALYSES}

\section{Comparison 1. Any pessary versus control, waiting list or no active treatment}

\begin{tabular}{|c|c|c|c|c|}
\hline Outcome or subgroup title & $\begin{array}{l}\text { No. of } \\
\text { studies }\end{array}$ & $\begin{array}{l}\text { No. of } \\
\text { partici- } \\
\text { pants }\end{array}$ & Statistical method & $\begin{array}{l}\text { Effect } \\
\text { size }\end{array}$ \\
\hline $\begin{array}{l}1.1 \text { Women's perceived improvement in prolapse symptoms: POP } \\
\text { score of Australian Pelvic Floor Questionnaire at } 12 \text { months (range } \\
0-10, \text { higher score = worse symptoms) }\end{array}$ & 1 & & $\begin{array}{l}\text { Mean Difference (IV, } \\
\text { Fixed, } 95 \% \mathrm{CI} \text { ) }\end{array}$ & $\begin{array}{l}\text { Totals not } \\
\text { selected }\end{array}$ \\
\hline $\begin{array}{l}\text { 1.2 Site-specific grading of prolapse - anterior - (measured with POP- } \\
\text { Q) at } 12 \text { months }\end{array}$ & 1 & & $\begin{array}{l}\text { Mean Difference (IV, } \\
\text { Fixed, } 95 \% \mathrm{CI} \text { ) }\end{array}$ & $\begin{array}{l}\text { Totals not } \\
\text { selected }\end{array}$ \\
\hline $\begin{array}{l}\text { 1.3 Site-specific grading of prolapse - posterior - (measured with } \\
\text { POP-Q) at } 12 \text { months }\end{array}$ & 1 & & $\begin{array}{l}\text { Mean Difference (IV, } \\
\text { Fixed, } 95 \% \mathrm{CI} \text { ) }\end{array}$ & $\begin{array}{l}\text { Totals not } \\
\text { selected }\end{array}$ \\
\hline $\begin{array}{l}1.4 \text { Cure or improvement of bladder problems at } 12 \text { months (mea- } \\
\text { sured with bladder score of Australian Pelvic Floor Questionnaire, } \\
\text { range } 0-10 \text {, higher score = worse symptoms) }\end{array}$ & 1 & & $\begin{array}{l}\text { Mean Difference (IV, } \\
\text { Fixed, } 95 \% \mathrm{CI} \text { ) }\end{array}$ & $\begin{array}{l}\text { Totals not } \\
\text { selected }\end{array}$ \\
\hline $\begin{array}{l}1.5 \text { Cure or improvement of bowel problems at } 12 \text { months (measured } \\
\text { with bowel score of Australian Pelvic Floor Questionnaire, range 0-10, } \\
\text { higher score = worse symptoms) }\end{array}$ & 1 & & $\begin{array}{l}\text { Mean Difference (IV, } \\
\text { Fixed, } 95 \% \mathrm{CI} \text { ) }\end{array}$ & $\begin{array}{l}\text { Totals not } \\
\text { selected }\end{array}$ \\
\hline $\begin{array}{l}\text { 1.6 Cure or improvement of sexual problems at } 12 \text { months (mea- } \\
\text { sured with sex score of Australian Pelvic Floor Questionnaire, range } \\
0-10 \text {, higher score = worse symptoms) }\end{array}$ & 1 & & $\begin{array}{l}\text { Mean Difference (IV, } \\
\text { Fixed, } 95 \% \mathrm{CI} \text { ) }\end{array}$ & $\begin{array}{l}\text { Totals not } \\
\text { selected }\end{array}$ \\
\hline
\end{tabular}


Analysis 1.1. Comparison 1: Any pessary versus control, waiting list or no active treatment, Outcome 1: Women's perceived improvement in prolapse symptoms: POP score of Australian Pelvic Floor Questionnaire at 12 months (range 0-10, higher score = worse symptoms)

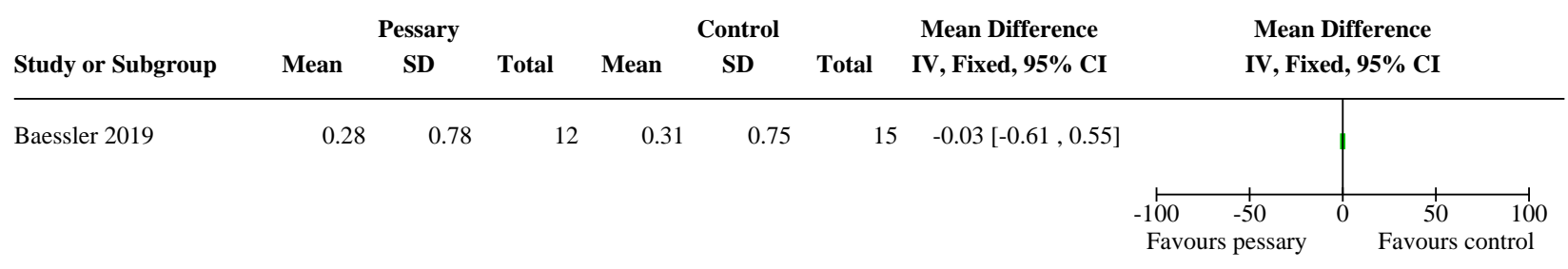

Analysis 1.2. Comparison 1: Any pessary versus control, waiting list or no active treatment, Outcome 2: Site-specific grading of prolapse - anterior - (measured with POP-Q) at 12 months

\begin{tabular}{|c|c|c|c|c|c|c|c|c|}
\hline & & Pessary & & & Control & & Mean Difference & Mean Difference \\
\hline Study or Subgroup & Mean & SD & Total & Mean & SD & Total & IV, Fixed, 95\% CI & IV, Fixed, $95 \%$ CI \\
\hline
\end{tabular}

\begin{tabular}{llllllll}
\hline Baessler 2019 & -1.2 & 1.1 & 12 & -1.3 & 1.1 & 15 & $0.10[-0.73,0.93]$
\end{tabular}

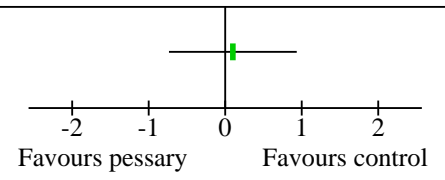

Analysis 1.3. Comparison 1: Any pessary versus control, waiting list or no active treatment, Outcome 3: Site-specific grading of prolapse - posterior - (measured with POP-Q) at 12 months

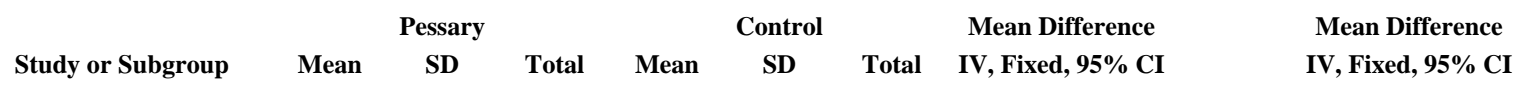

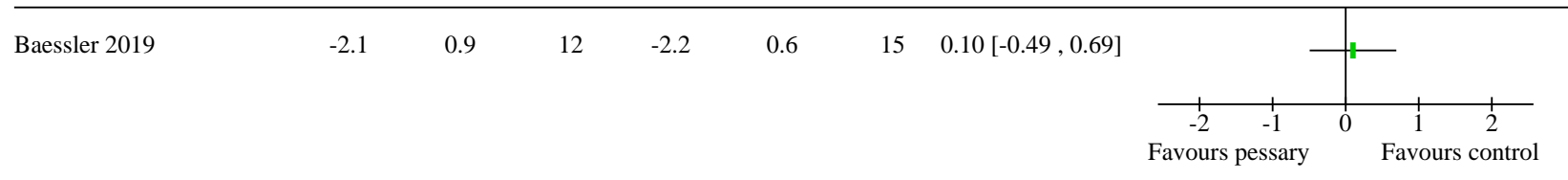

Analysis 1.4. Comparison 1: Any pessary versus control, waiting list or no active treatment, Outcome 4: Cure or improvement of bladder problems at 12 months (measured with bladder score of Australian Pelvic Floor Questionnaire, range $\mathbf{0 - 1 0}$, higher score = worse symptoms)

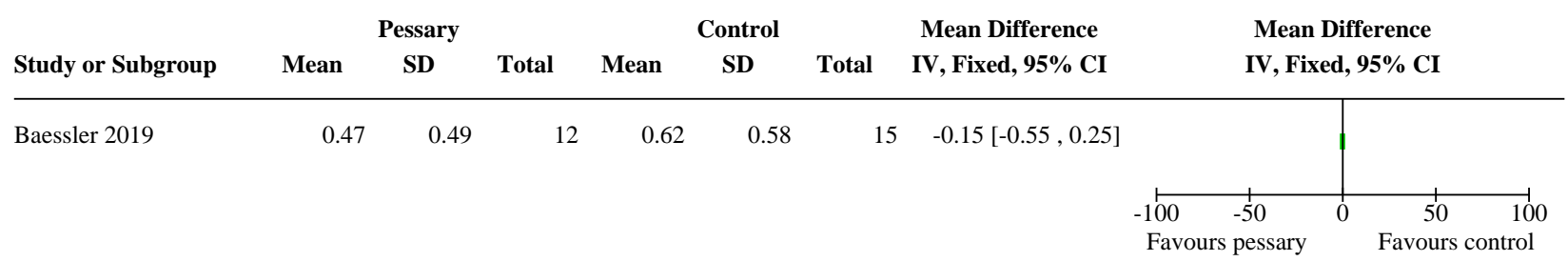


Analysis 1.5. Comparison 1: Any pessary versus control, waiting list or no active treatment, Outcome 5: Cure or improvement of bowel problems at 12 months (measured with bowel score of Australian Pelvic Floor Questionnaire, range 0-10, higher score = worse symptoms)

\begin{tabular}{|c|c|c|c|c|c|c|c|c|}
\hline & & Pessary & & & Control & & Mean Difference & Mean Difference \\
\hline Study or Subgroup & Mean & SD & Total & Mean & SD & Total & IV, Fixed, 95\% CI & IV, Fixed, $95 \%$ CI \\
\hline
\end{tabular}

$\begin{array}{llllllll}\text { Baessler } 2019 & 1.1 & 0.78 & 12 & 1.1 & 0.79 & 15 & 0.00[-0.60,0.60]\end{array}$

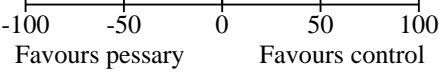

Analysis 1.6. Comparison 1: Any pessary versus control, waiting list or no active treatment,

Outcome 6: Cure or improvement of sexual problems at 12 months (measured with sex score of Australian Pelvic Floor Questionnaire, range 0-10, higher score = worse symptoms)

\begin{tabular}{|c|c|c|c|c|c|c|c|c|}
\hline & & Pessary & & & Control & & Mean Difference & Mean Difference \\
\hline Study or Subgroup & Mean & SD & Total & Mean & SD & Total & IV, Fixed, $95 \%$ CI & IV, Fixed, $95 \%$ CI \\
\hline
\end{tabular}

\begin{tabular}{llllllll}
\hline Baessler 2019 & 1.16 & 1.84 & 12 & 1.45 & 1.79 & 15 & $-0.29[-1.67,1.09]$
\end{tabular}

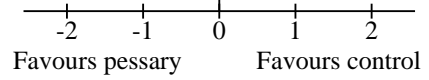

\section{Comparison 2. Any pessary versus PFMT}

\begin{tabular}{|c|c|c|c|c|}
\hline Outcome or subgroup title & $\begin{array}{l}\text { No. of } \\
\text { studies }\end{array}$ & $\begin{array}{l}\text { No. of } \\
\text { partici- } \\
\text { pants }\end{array}$ & Statistical method & $\begin{array}{l}\text { Effect } \\
\text { size }\end{array}$ \\
\hline $\begin{array}{l}2.1 \text { Women's perceived improvement of prolapse symptoms at } \\
12 \text { months (measured with PFDI-20; range: } 0-300 \text {, higher score = } \\
\text { worse symptoms) }\end{array}$ & 1 & & $\begin{array}{l}\text { Mean Difference (IV, } \\
\text { Fixed, } 95 \% \mathrm{Cl} \text { ) }\end{array}$ & $\begin{array}{l}\text { Totals not } \\
\text { selected }\end{array}$ \\
\hline $\begin{array}{l}2.2 \text { Women's perceived improvement of prolapse symptoms at } \\
24 \text { months (measured with PFDI-20; range: } 0-300 \text {, higher score = } \\
\text { worse symptoms) }\end{array}$ & 1 & & $\begin{array}{l}\text { Mean Difference (IV, } \\
\text { Fixed, } 95 \% \mathrm{Cl} \text { ) }\end{array}$ & $\begin{array}{l}\text { Totals not } \\
\text { selected }\end{array}$ \\
\hline $\begin{array}{l}2.3 \text { Women's perceived improvement of prolapse symptoms at } \\
12 \text { months (measured with POPDI-6; range: } 0-100 \text {, higher score = } \\
\text { worse symptoms) }\end{array}$ & 1 & & $\begin{array}{l}\text { Mean Difference (IV, } \\
\text { Fixed, } 95 \% \mathrm{Cl} \text { ) }\end{array}$ & $\begin{array}{l}\text { Totals not } \\
\text { selected }\end{array}$ \\
\hline $\begin{array}{l}\text { 2.4 Women's perceived improvement of prolapse symptoms at } \\
24 \text { months (POPDI-6; range: } 0-100 \text {, higher score = worse symp- } \\
\text { toms) }\end{array}$ & 1 & & $\begin{array}{l}\text { Mean Difference (IV, } \\
\text { Fixed, } 95 \% \mathrm{CI})\end{array}$ & $\begin{array}{l}\text { Totals not } \\
\text { selected }\end{array}$ \\
\hline $\begin{array}{l}2.5 \text { Women's perceived improvement of prolapse symptoms at } \\
24 \text { months }\end{array}$ & 1 & & $\begin{array}{l}\text { Risk Ratio }(M-H, \text { Fixed, } \\
95 \% \mathrm{Cl})\end{array}$ & $\begin{array}{l}\text { Totals not } \\
\text { selected }\end{array}$ \\
\hline $\begin{array}{l}\text { 2.6 Prolapse-specific quality of life at } 12 \text { months (measured with } \\
\text { PFIQ-7, range: } 0-300 \text {, higher score = worse QoL) }\end{array}$ & 1 & & $\begin{array}{l}\text { Mean Difference (IV, } \\
\text { Fixed, } 95 \% \mathrm{CI} \text { ) }\end{array}$ & $\begin{array}{l}\text { Totals not } \\
\text { selected }\end{array}$ \\
\hline $\begin{array}{l}\text { 2.7 Prolapse-specific quality of life at } 24 \text { months (measured with } \\
\text { PFIQ-7, range: } 0-300 \text {, higher score = worse QoL) }\end{array}$ & 1 & & $\begin{array}{l}\text { Mean Difference (IV, } \\
\text { Fixed, } 95 \% \mathrm{CI})\end{array}$ & $\begin{array}{l}\text { Totals not } \\
\text { selected }\end{array}$ \\
\hline
\end{tabular}




\begin{tabular}{|c|c|c|c|c|}
\hline Outcome or subgroup title & $\begin{array}{l}\text { No. of } \\
\text { studies }\end{array}$ & $\begin{array}{l}\text { No. of } \\
\text { partici- } \\
\text { pants }\end{array}$ & Statistical method & $\begin{array}{l}\text { Effect } \\
\text { size }\end{array}$ \\
\hline $\begin{array}{l}\text { 2.8 Quality of life at } 12 \text { months (measured with PCS-12, range: } \\
0-100 \text {, higher score = better health status) }\end{array}$ & 1 & & $\begin{array}{l}\text { Mean Difference (IV, } \\
\text { Fixed, } 95 \% \mathrm{CI} \text { ) }\end{array}$ & $\begin{array}{l}\text { Totals not } \\
\text { selected }\end{array}$ \\
\hline $\begin{array}{l}2.9 \text { Quality of life at } 24 \text { months (measures with PCS-12, range: } \\
0-100 \text {, higher score = better health status) }\end{array}$ & 1 & & $\begin{array}{l}\text { Mean Difference (IV, } \\
\text { Fixed, } 95 \% \mathrm{CI} \text { ) }\end{array}$ & $\begin{array}{l}\text { Totals not } \\
\text { selected }\end{array}$ \\
\hline $\begin{array}{l}2.10 \text { Quality of life at } 12 \text { months (measured with MCS-12, range: } \\
0-100 \text {, higher score = better health status) }\end{array}$ & 1 & & $\begin{array}{l}\text { Mean Difference (IV, } \\
\text { Fixed, } 95 \% \mathrm{CI} \text { ) }\end{array}$ & $\begin{array}{l}\text { Totals not } \\
\text { selected }\end{array}$ \\
\hline $\begin{array}{l}2.11 \text { Quality of life at } 24 \text { months (measured with MCS-12, range: } \\
0-100 \text {, higher score = better health status) }\end{array}$ & 1 & & $\begin{array}{l}\text { Mean Difference (IV, } \\
\text { Fixed, } 95 \% \mathrm{CI} \text { ) }\end{array}$ & $\begin{array}{l}\text { Totals not } \\
\text { selected }\end{array}$ \\
\hline $\begin{array}{l}\text { 2.12 Cure or improvement of bladder problems at } 12 \text { months } \\
\text { (measured with UDI-6, range: } 0-100 \text {, higher score = worse symp- } \\
\text { toms) }\end{array}$ & 1 & & $\begin{array}{l}\text { Mean Difference (IV, } \\
\text { Fixed, } 95 \% \mathrm{CI} \text { ) }\end{array}$ & $\begin{array}{l}\text { Totals not } \\
\text { selected }\end{array}$ \\
\hline $\begin{array}{l}2.13 \text { Cure or improvement of bladder problems at } 24 \text { month } \\
\text { (measured with UDI-6, range: } 0-100 \text {, higher score = worse symp- } \\
\text { toms) }\end{array}$ & 1 & & $\begin{array}{l}\text { Mean Difference (IV, } \\
\text { Fixed, } 95 \% \mathrm{CI} \text { ) }\end{array}$ & $\begin{array}{l}\text { Totals not } \\
\text { selected }\end{array}$ \\
\hline $\begin{array}{l}\text { 2.14 Cure or improvement of bowel problems at } 12 \text { months } \\
\text { (measured with CRADI- } 8 \text {, range: } 0-100 \text {, higher score = worse } \\
\text { symptoms) }\end{array}$ & 1 & & $\begin{array}{l}\text { Mean Difference (IV, } \\
\text { Fixed, } 95 \% \mathrm{CI} \text { ) }\end{array}$ & $\begin{array}{l}\text { Totals not } \\
\text { selected }\end{array}$ \\
\hline $\begin{array}{l}2.15 \text { Cure or improvement of bowel problems at } 24 \text { months } \\
\text { (measured with CRADI- } 8 \text {, range: } 0-100 \text {, higher score = worse } \\
\text { symptoms) }\end{array}$ & 1 & & $\begin{array}{l}\text { Mean Difference (IV, } \\
\text { Fixed, } 95 \% \mathrm{CI} \text { ) }\end{array}$ & $\begin{array}{l}\text { Totals not } \\
\text { selected }\end{array}$ \\
\hline $\begin{array}{l}\text { 2.16 Cure or improvement of sexual problems at } 12 \text { months } \\
\text { (measured with PISQ-12, range: } 0-48 \text {, higher score = better sexual } \\
\text { functioning) }\end{array}$ & 1 & & $\begin{array}{l}\text { Mean Difference (IV, } \\
\text { Fixed, } 95 \% \mathrm{Cl} \text { ) }\end{array}$ & $\begin{array}{l}\text { Totals not } \\
\text { selected }\end{array}$ \\
\hline $\begin{array}{l}\text { 2.17 Cure or improvement of sexual problems at } 24 \text { months } \\
\text { (measured with PISQ-12, range: } 0-48 \text {, higher score = better sexual } \\
\text { functioning) }\end{array}$ & 1 & & $\begin{array}{l}\text { Mean Difference (IV, } \\
\text { Fixed, } 95 \% \mathrm{CI} \text { ) }\end{array}$ & $\begin{array}{l}\text { Totals not } \\
\text { selected }\end{array}$ \\
\hline 2.18 Number of women with adverse events & 1 & 97 & $\begin{array}{l}\text { Risk Ratio (M-H, Fixed, } \\
95 \% \mathrm{Cl})\end{array}$ & $\begin{array}{l}75.25 \\
{[4.70} \\
1205.45]\end{array}$ \\
\hline
\end{tabular}

\section{Analysis 2.1. Comparison 2: Any pessary versus PFMT, Outcome 1: Women's perceived improvement of prolapse symptoms at 12 months (measured with PFDI-20; range: 0-300, higher score = worse symptoms)}

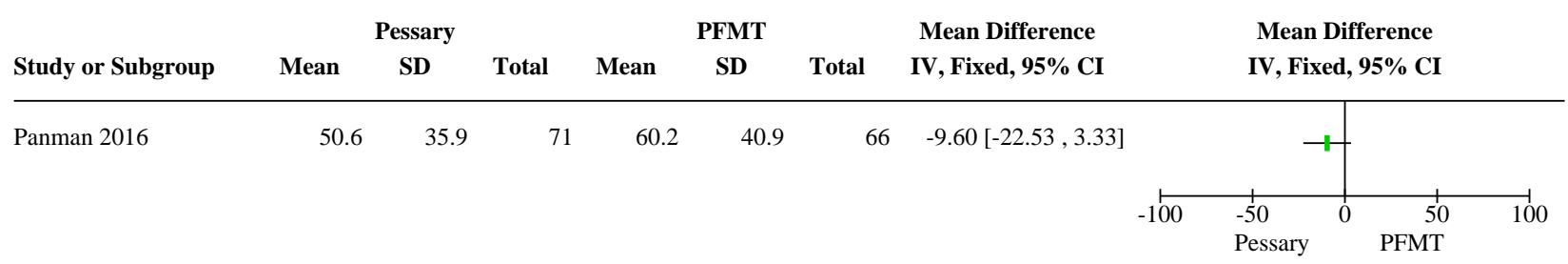


Analysis 2.2. Comparison 2: Any pessary versus PFMT, Outcome 2: Women's perceived improvement of prolapse symptoms at 24 months (measured with PFDI-20; range: 0-300, higher score = worse symptoms)

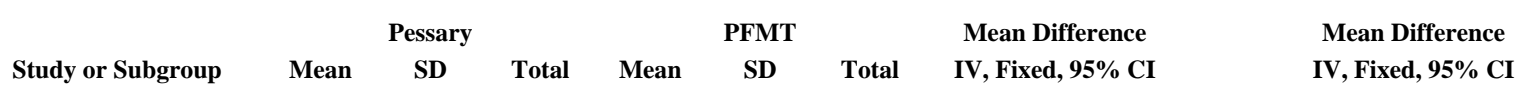

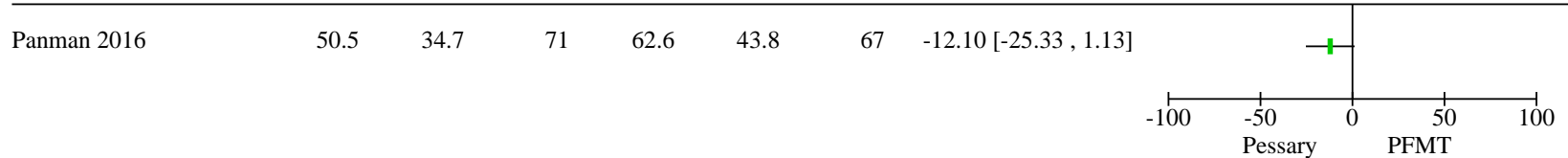

Analysis 2.3. Comparison 2: Any pessary versus PFMT, Outcome 3: Women's perceived improvement of prolapse symptoms at 12 months (measured with POPDI-6; range: 0-100, higher score $=$ worse symptoms)

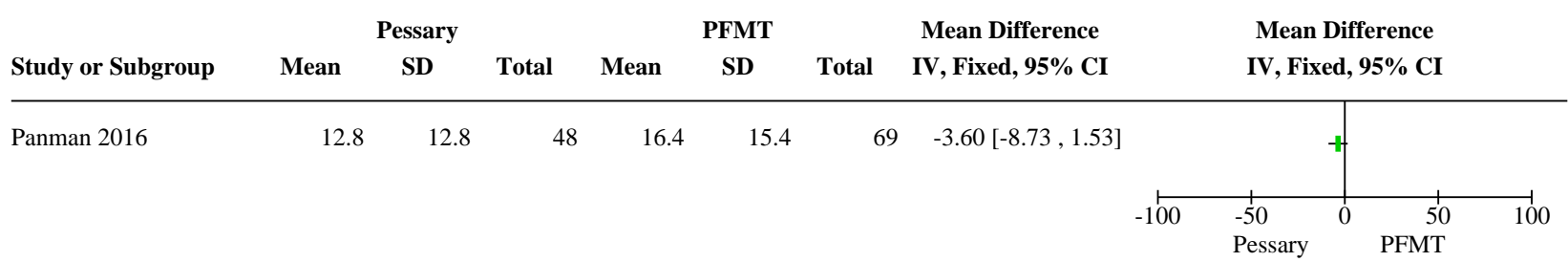

Analysis 2.4. Comparison 2: Any pessary versus PFMT, Outcome 4: Women's perceived improvement of prolapse symptoms at 24 months (POPDI-6; range: 0-100, higher score = worse symptoms)

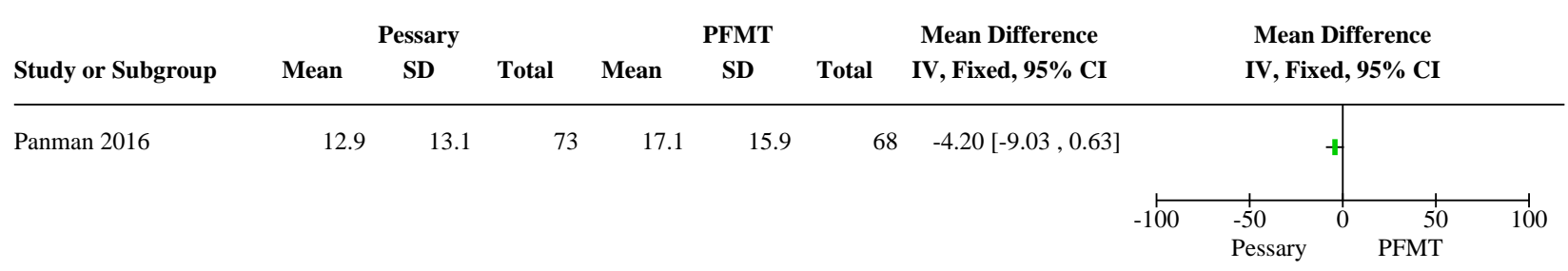

Analysis 2.5. Comparison 2: Any pessary versus PFMT, Outcome 5: Women's perceived improvement of prolapse symptoms at 24 months

\begin{tabular}{|c|c|c|c|c|c|c|}
\hline \multirow[b]{2}{*}{ Study or Subgroup } & \multicolumn{2}{|c|}{ Pessary } & \multicolumn{2}{|c|}{ PFMT } & Risk Ratio & Risk Ratio \\
\hline & Events & Total & Events & Total & M-H, Fixed, 95\% C & M-H, Fixed, 95\% CI \\
\hline
\end{tabular}

\begin{tabular}{|c|c|c|c|c|c|c|c|}
\hline \multirow{2}{*}{ Panman 2016} & 25 & 72 & 24 & 70 & $1.01[0.64,1.59]$ & 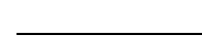 & $\longrightarrow$ \\
\hline & & & & & & $\begin{array}{cc}0.7 & 0.85 \\
\text { Favours } & \text { PFMT }\end{array}$ & $\begin{array}{cc}1.2 & 1.5 \\
\text { Favours pessary }\end{array}$ \\
\hline
\end{tabular}


Analysis 2.6. Comparison 2: Any pessary versus PFMT, Outcome 6: Prolapse-specific quality of life at 12 months (measured with PFIQ-7, range: 0-300, higher score = worse QoL)

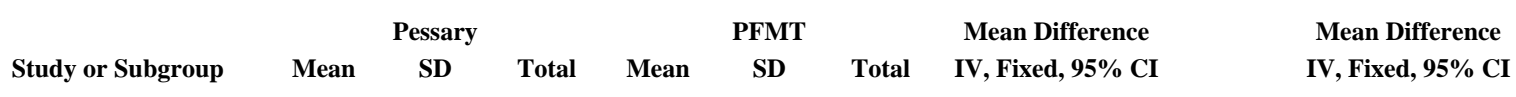

\begin{tabular}{llllllll}
\hline Panman 2016 & 19.1 & 36.9 & 50 & 15.8 & 26 & 66 & $3.30[-8.70,15.30]$
\end{tabular}

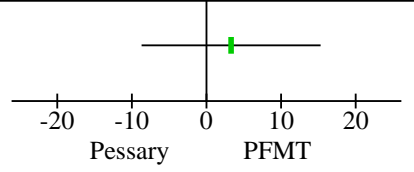

Analysis 2.7. Comparison 2: Any pessary versus PFMT, Outcome 7: Prolapse-specific quality of life at 24 months (measured with PFIQ-7, range: 0-300, higher score = worse QoL)

\begin{tabular}{|c|c|c|c|c|c|c|c|}
\hline & & essary & & & PFMT & Mean Difference & Mean Difference \\
\hline Study or Subgroup & Mean & SD & Total & Mean & SD & IV, Fixed, 95\% CI & IV, Fixed, $95 \%$ CI \\
\hline
\end{tabular}

Panman 2016

$16 \quad 28.7$

$67 \quad 19$

$66-3.00[-12.72,6.72]$

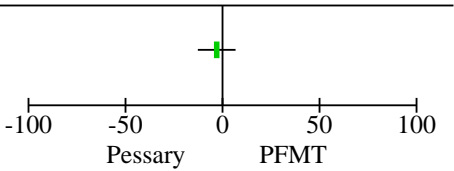

Analysis 2.8. Comparison 2: Any pessary versus PFMT, Outcome 8: Quality of life at 12 months (measured with PCS-12, range: 0-100, higher score = better health status)

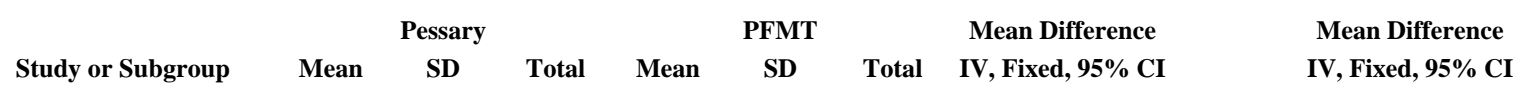

\begin{tabular}{|c|c|c|c|c|c|c|c|c|c|}
\hline \multirow{2}{*}{ Panman 2016} & 47.2 & 8.8 & 43 & 46 & 10.4 & 65 & $1.20[-2.45,4.85]$ & & t \\
\hline & & & & & & & -100 & $\begin{array}{l}-50 \\
\text { Pessary }\end{array}$ & $\begin{array}{lr}0 & 50 \\
& \text { PFMT }\end{array}$ \\
\hline
\end{tabular}

Analysis 2.9. Comparison 2: Any pessary versus PFMT, Outcome 9: Quality of life at 24 months (measures with PCS-12, range: 0-100, higher score = better health status)

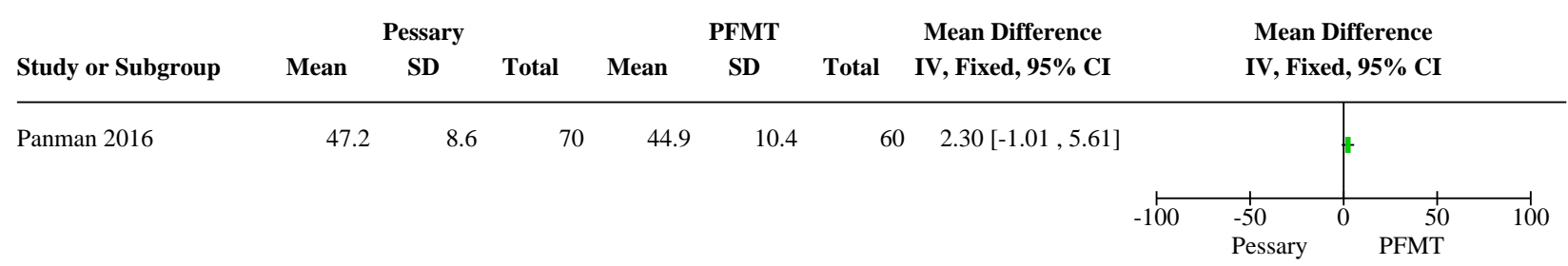


Analysis 2.10. Comparison 2: Any pessary versus PFMT, Outcome 10: Quality of life at 12 months (measured with MCS-12, range: 0-100, higher score = better health status)

\begin{tabular}{|c|c|c|c|c|c|c|c|c|c|c|}
\hline Study or Subgroup & Mean & $\begin{array}{l}\text { essary } \\
\text { SD }\end{array}$ & Total & Mean & $\begin{array}{l}\text { PFMT } \\
\text { SD }\end{array}$ & Total & $\begin{array}{c}\text { Mean Difference } \\
\text { IV, Fixed, } 95 \% \text { CI }\end{array}$ & $\begin{array}{r}\text { Mean } \\
\text { IV, Fix }\end{array}$ & $\begin{array}{l}\text { Difference } \\
\text { ed, } 95 \% \text { CI }\end{array}$ & \\
\hline \multirow[t]{2}{*}{ Panman 2016} & 51.6 & 10.3 & 43 & 53.5 & 8.3 & 65 & $-1.90[-5.58,1.78]$ & & + & \\
\hline & & & & & & & -100 & $\begin{array}{l}1 \\
-50 \\
\text { Pessary }\end{array}$ & $\begin{array}{rr}1 & 1 \\
0 & 50 \\
& \text { PFMT }\end{array}$ & $\overrightarrow{100}$ \\
\hline
\end{tabular}

Analysis 2.11. Comparison 2: Any pessary versus PFMT, Outcome 11: Quality of life at 24 months (measured with MCS-12, range: 0-100, higher score = better health status)

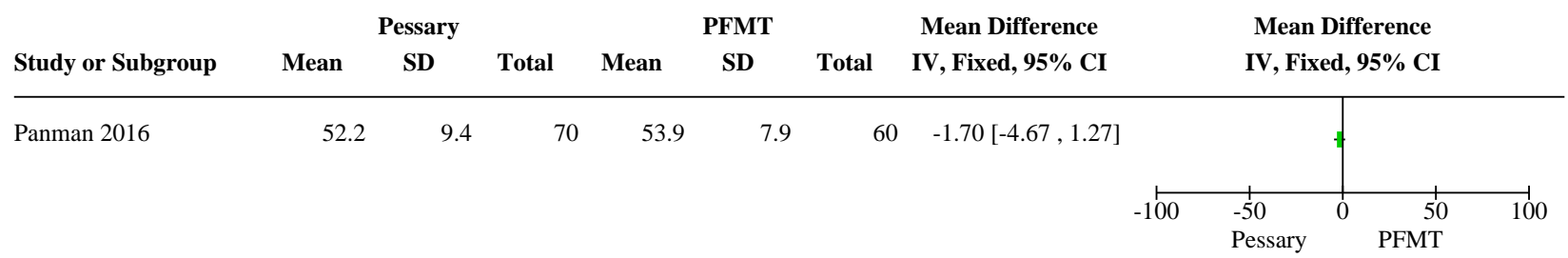

Analysis 2.12. Comparison 2: Any pessary versus PFMT, Outcome 12: Cure or improvement of bladder problems at 12 months (measured with UDI-6, range: 0-100, higher score = worse symptoms)

\begin{tabular}{|c|c|c|c|c|c|c|c|c|}
\hline & & Pessary & & & PFMT & & Mean Difference & Mean Difference \\
\hline Study or Subgroup & Mean & SD & Total & Mean & SD & Total & IV, Fixed, $95 \%$ CI & IV, Fixed, $95 \%$ CI \\
\hline
\end{tabular}

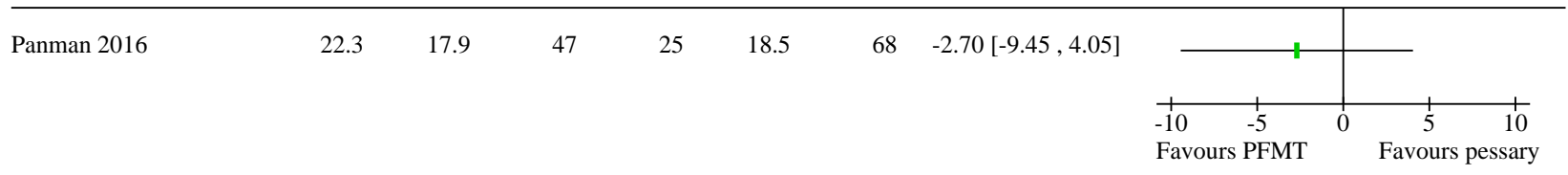

Analysis 2.13. Comparison 2: Any pessary versus PFMT, Outcome 13: Cure or improvement of bladder problems at 24 month (measured with UDI-6, range: 0-100, higher score = worse symptoms)

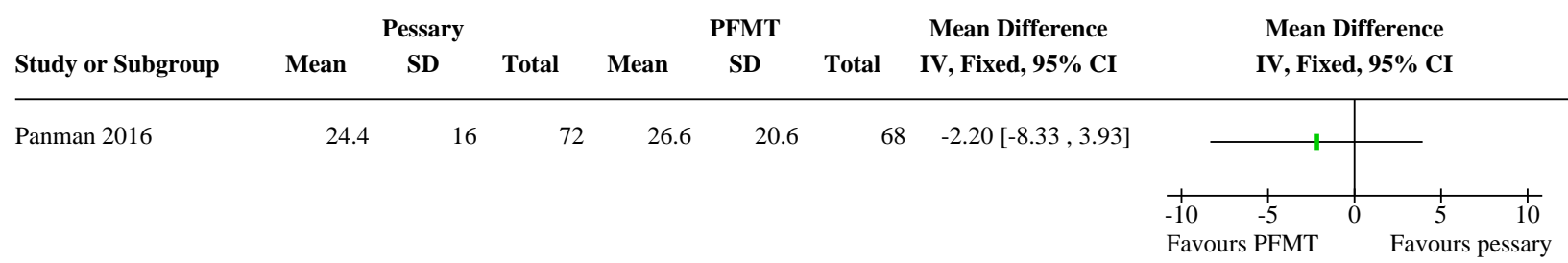


Analysis 2.14. Comparison 2: Any pessary versus PFMT, Outcome 14: Cure or improvement of bowel problems at 12 months (measured with CRADI-8, range: 0-100, higher score = worse symptoms)

\begin{tabular}{|c|c|c|c|c|c|c|c|c|}
\hline & & Pessary & & & PFMT & & Mean Difference & Mean Difference \\
\hline Study or Subgroup & Mean & SD & Total & Mean & SD & Total & IV, Fixed, $95 \%$ CI & IV, Fixed, 95\% C \\
\hline
\end{tabular}

$\begin{array}{llllllll}\text { Panman } 2016 & 14.2 & 12.3 & 48 & 17.7 & 15.5 & 66 & -3.50[-8.61,1.61]\end{array}$

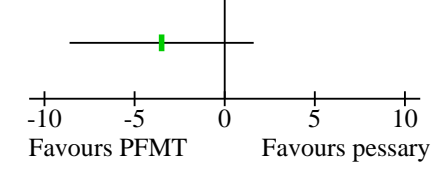

Analysis 2.15. Comparison 2: Any pessary versus PFMT, Outcome 15: Cure or improvement of bowel problems at 24 months (measured with CRADI-8, range: 0-100, higher score = worse symptoms)

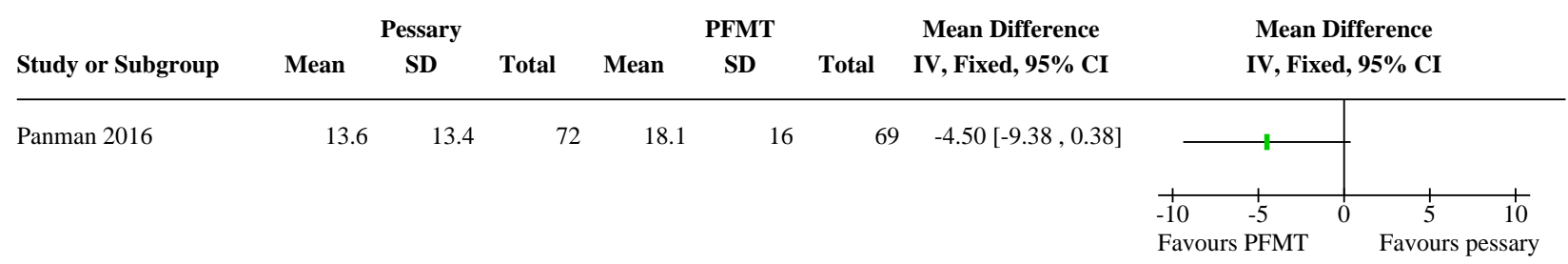

Analysis 2.16. Comparison 2: Any pessary versus PFMT, Outcome 16: Cure or improvement of sexual problems at 12 months (measured with PISQ-12, range: 0-48, higher score = better sexual functioning)

\begin{tabular}{|c|c|c|c|c|c|c|c|c|}
\hline & & Pessary & & & PFMT & & Mean Difference & Mean Difference \\
\hline Study or Subgroup & Mean & SD & Total & Mean & SD & Total & IV, Fixed, 95\% CI & IV, Fixed, 95\% CI \\
\hline
\end{tabular}

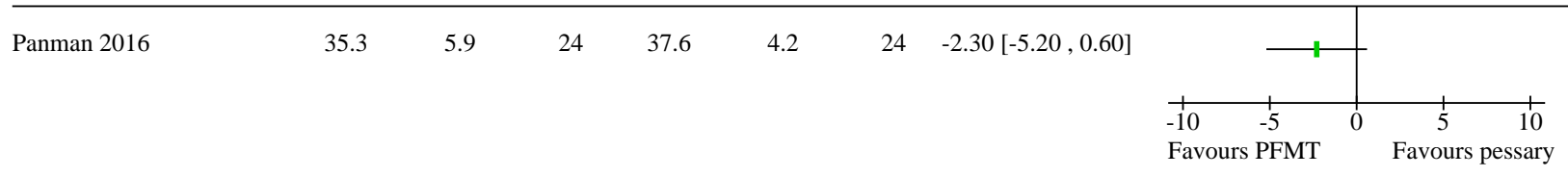

Analysis 2.17. Comparison 2: Any pessary versus PFMT, Outcome 17: Cure or improvement of sexual problems at 24 months (measured with PISQ-12, range: 0-48, higher score = better sexual functioning)

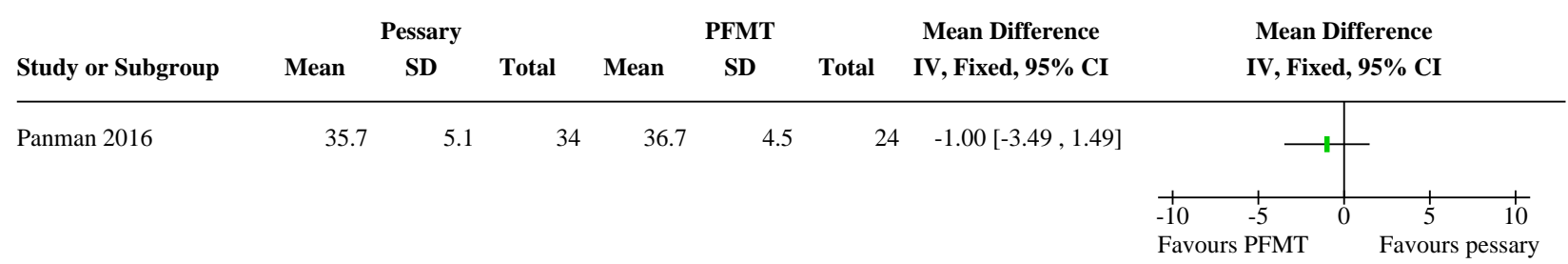


Analysis 2.18. Comparison 2: Any pessary versus PFMT, Outcome 18: Number of women with adverse events

\begin{tabular}{|c|c|c|c|c|c|c|c|c|c|}
\hline \multirow[b]{2}{*}{ Study or Subgroup } & \multicolumn{2}{|c|}{ Pessary } & \multicolumn{2}{|c|}{ PFMT } & \multirow[b]{2}{*}{ Weight } & \multirow{2}{*}{$\begin{array}{c}\text { Risk Ratio } \\
\text { M-H, Fixed, 95\% CI }\end{array}$} & \multirow{2}{*}{\multicolumn{3}{|c|}{$\begin{array}{c}\text { Risk Ratio } \\
\text { M-H, Fixed, 95\% CI }\end{array}$}} \\
\hline & Events & Total & Events & Total & & & & & \\
\hline Panman 2016 & 21 & 35 & 0 & 62 & $100.0 \%$ & $75.25[4.70,1205.45]$ & & & \\
\hline Total $(95 \%$ CI $)$ & & 35 & & 62 & $100.0 \%$ & $75.25[4.70,1205.45]$ & & & \\
\hline Total events: & 21 & & 0 & & & & & & \\
\hline Heterogeneity: Not ap & able & & & & & & 0.02 & 0.1 & 10 \\
\hline Test for overall effect & $=3.05(\mathrm{P}=$ & $0.002)$ & & & & & & PFMT & Pessary \\
\hline
\end{tabular}

Test for subgroup differences: Not applicable

\section{Comparison 3. Any pessary plus PFMT versus PFMT alone}

\begin{tabular}{lllll}
\hline Outcome or subgroup title & $\begin{array}{l}\text { No. of } \\
\text { studies }\end{array}$ & $\begin{array}{l}\text { No. of } \\
\text { partici- } \\
\text { pants }\end{array}$ & Statistical method & Effect size \\
\hline $\begin{array}{l}\text { 3.1 Perceived improvement of prolapse symp- } \\
\text { toms at } 12 \text { months }\end{array}$ & 1 & Risk Ratio (M-H, Fixed, 95\% Cl) & $\begin{array}{l}\text { Totals not select- } \\
\text { ed }\end{array}$ \\
\hline $\begin{array}{l}\text { 3.2 Cure or improvement of bladder problems - } \\
\text { SUI }\end{array}$ & 1 & Risk Ratio (M-H, Fixed, 95\% Cl) & $\begin{array}{l}\text { Totals not select- } \\
\text { ed }\end{array}$ \\
\hline $\begin{array}{l}\text { 3.3 Cure or improvement of bladder problems - } \\
\text { UUl }\end{array}$ & 1 & Risk Ratio (M-H, Fixed, 95\% Cl) & Totals not select- \\
\hline $\begin{array}{l}\text { 3.4 Cure or improvement of bladder problems - } \\
\text { voiding difficulty }\end{array}$ & 1 & Risk Ratio (M-H, Fixed, 95\% Cl) & Totals not select- \\
\hline $\begin{array}{l}\text { 3.5 Number of women with adverse events - ab- } \\
\text { normal vaginal bleeding }\end{array}$ & 1 & Risk Ratio (M-H, Fixed, 95\% Cl) & Subtotals only \\
\hline $\begin{array}{l}\text { 3.6 Number of women with adverse events - de } \\
\text { novo voiding difficulty }\end{array}$ & 1 & Risk Ratio (M-H, Fixed, 95\% Cl) & Subtotals only \\
\hline
\end{tabular}

Analysis 3.1. Comparison 3: Any pessary plus PFMT versus PFMT alone, Outcome 1: Perceived improvement of prolapse symptoms at 12 months

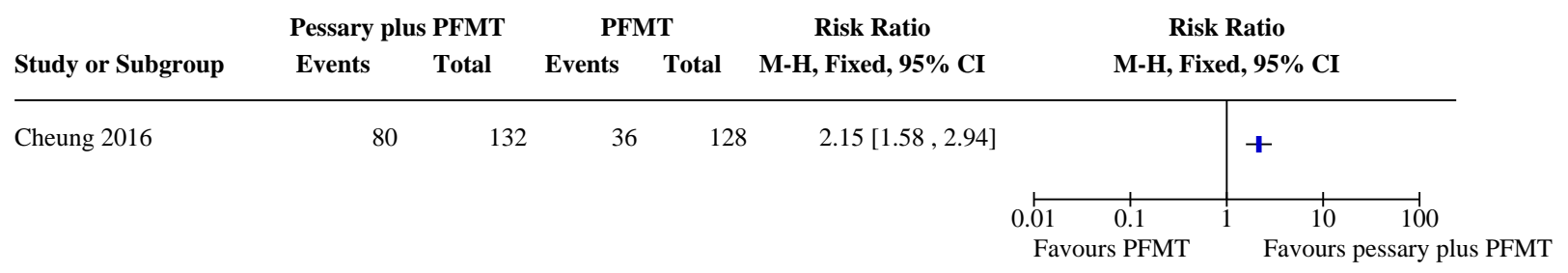


Analysis 3.2. Comparison 3: Any pessary plus PFMT versus PFMT alone, Outcome 2: Cure or improvement of bladder problems - SUI

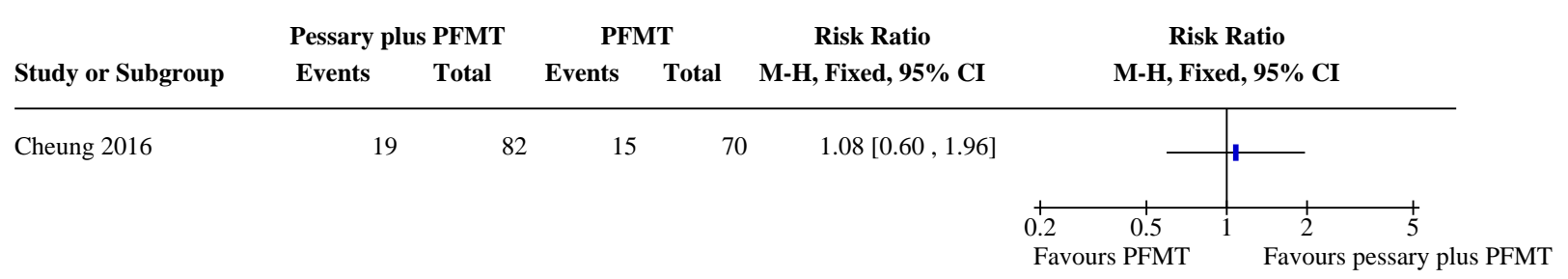

Analysis 3.3. Comparison 3: Any pessary plus PFMT versus PFMT alone, Outcome 3: Cure or improvement of bladder problems - UUI

\begin{tabular}{|c|c|c|c|c|}
\hline & Pessary plus PFMT & PFMT & Risk Ratio & Risk Ratio \\
\hline Study or Subgroup & Events & Events & M-H, Fixed, 95\% CI & M-H Fixed $95^{\circ}$ \\
\hline
\end{tabular}

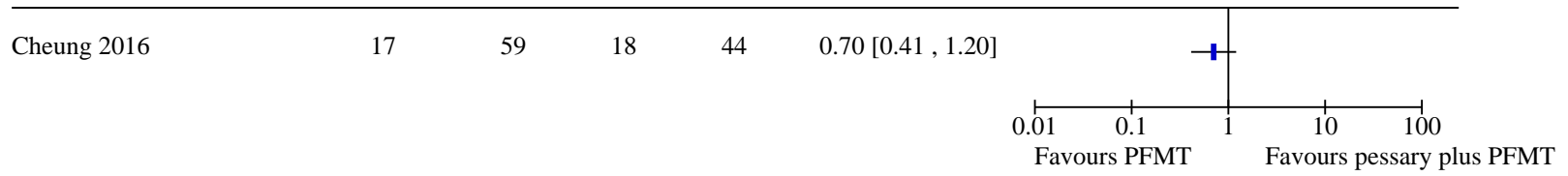

Analysis 3.4. Comparison 3: Any pessary plus PFMT versus PFMT alone, Outcome 4: Cure or improvement of bladder problems - voiding difficulty

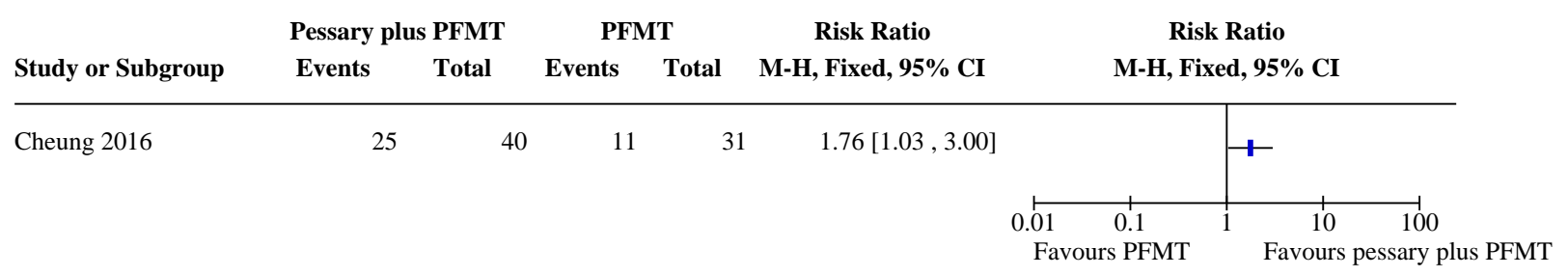

Analysis 3.5. Comparison 3: Any pessary plus PFMT versus PFMT alone, Outcome 5: Number of women with adverse events - abnormal vaginal bleeding

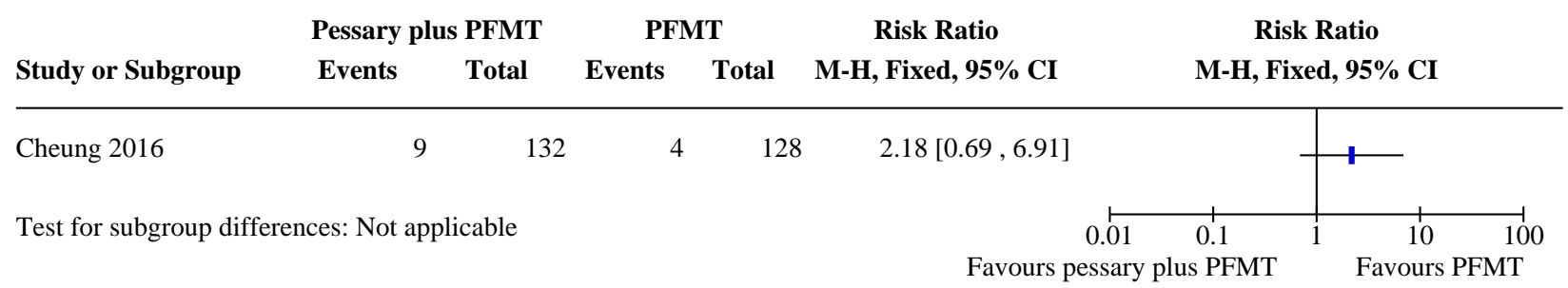


Analysis 3.6. Comparison 3: Any pessary plus PFMT versus PFMT alone, Outcome 6: Number of women with adverse events - de novo voiding difficulty

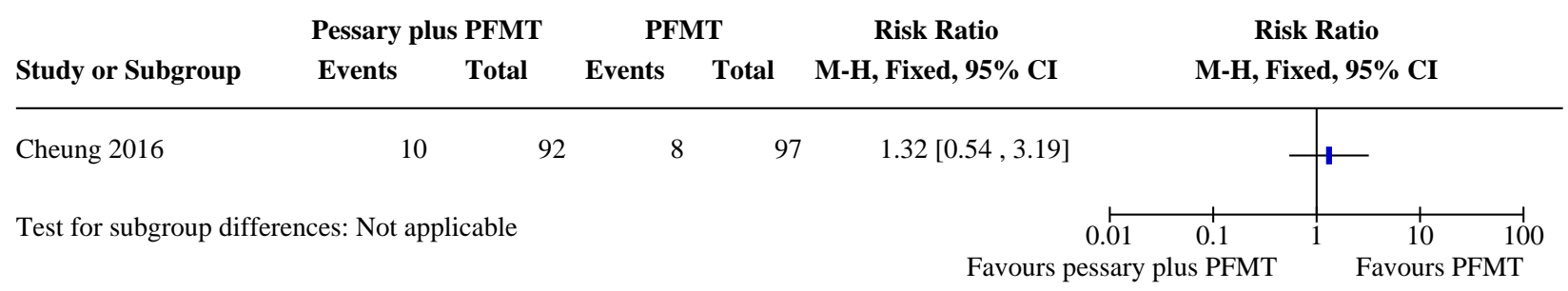

\section{APPENDICES}

\section{Appendix 1. Search of the Cochrane Incontinence Specialised Register}

The search terms used to search the Cochrane Incontinence Specialised Register are given below:

((design.cct $\left.{ }^{\star}\right)$ OR (design.rct $\left.\left.{ }^{\star}\right)\right)$

AND

topic.prolapse*

AND

intvent.mech*

All searches were of the keywords field of EndNote 2018.

\section{Appendix 2. Search methods and strategies for the extra specific searches conducted for some of the previous versions of this review}

\section{Electronic databases}

MEDLINE (January 1966 to Week 5 August 2005) was searched on 14 September 2005 and PREMEDLINE (15 September 2005) was searched on 19 September 2005, both on OVID, using the following search terms:

1.prolapse/

2.uterine prolapse/

3.Rectocele/

4. (prolaps\$ adj5 (pelvi\$ or vagin\$ or genit\$ or uter\$ or vault\$ or apical or urethr\$ or segment\$ or wall\$)).tw.

5.cystoc?ele\$.tw.

6.rectoc?ele\$.tw.

7.urethroc?ele\$.tw.

8.enteroc?ele\$.tw.

9.proctoc?ele\$.tw.

10.sigmoidoc?ele\$.tw.

11.(pelvi\$ adj3 dysfunct\$).tw.

12.(pelvi\$ adj3 (disorder\$ or relax\$)).tw.

13. (vagin\$ adj3 defect\$).tw.

14.(urogenital adj5 prolaps\$).tw.

15.(cervi\$ adj5 prolaps\$).tw.

16.or/1-15

This set of terms was combined with the first two parts of the Cochrane Highly Sensitive Search Strategy for randomised controlled trials (Appendix 5b.2, Cochrane Handbook, version 4.2, March 2003) using the Boolean operator 'AND'.

Embase (January 1996 to Week 43 2005) was searched on 25 October 2005, on OVID, using the following search terms:

1.pelvic adj5 prolaps\$.tw.

2.uterus prolapse/

3.rectocele/

4.vagina prolapse/

5.cystocele/

$6.0 \mathrm{r} / 1-5$ 
7.randomised controlled trial/

8.controlled study/

9.clinical study/

10.major clinical study/

11.prospective study/

12.meta analysis/

13.exp clinical trial/

14.randomisation/

15.crossover procedure/ or double blind procedure/ or parallel design/ or single blind procedure/

16.placebo/

17.latin square design/

18.exp comparative study/

19.follow up/

20.pilot study/

21.family study/ or feasibility study/ or study/

22.placebo\$.tw.

23.random\$.tw.

24.(clin\$ adj25 trial\$).tw.

25.((singl\$ or doubl\$ or trebl\$ or tripl\$) adj25 (blind\$ or mask\$)).tw.

26.factorial.tw.

27.crossover.tw.

28.latin square.tw.

29.(balance\$ adj2 block\$).tw.

30.or/7-29

31.(nonhuman not human).sh.

32.30 not 31

33.6 and 32

CINAHL (January 1982 to February Week 4 2003) was searched on 13 March 2003, on OVID, using the following search terms:

1.exp pelvic organ prolapse/

2.genital diseases, female/

3.prolapse/

4.uterine prolapse/

5.Rectocele/

6.(prolaps\$ adj5 (pelvi\$ or vagin\$ or genit\$ or uter\$ or vault\$ or apical or urethr\$ or segment\$ or wall\$)).tw.

7.cystoc?ele\$.tw.

8.rectoc?ele\$.tw.

9.urethroc?ele\$.tw.

10.enteroc?ele\$.tw.

11.proctoc?ele\$.tw.

12.sigmoidoc?ele\$.tw.

13. (pelvi\$ adj3 dysfunct\$).tw.

14.(pelvi\$ adj3 (disorder\$ or relax\$)).tw.

15.(vagin $\$$ adj3 defect\$).tw.

16.(urogenital adj5 prolaps\$).tw.

17. (cervi\$ adj5 prolaps\$).tw.

18.((descen\$ adj2 (uter\$ or genit\$ or pelv\$)).tw.

19.procident\$.tw.

20.(vagin\$ adj2 (eversion\$ or evert\$)).tw.

21.(hernia $\$$ adj2 (bladder $\$$ or cystic or vesico $\$)$ ).tw.

22. (bladder\$ adj2 protru\$).tw.

23. (viscer\$ adj2 prolap\$).tw.

24.hysteropex\$.tw.

25.or/1-2

26.placebo\$.tw.

27.random\$.tw.

28.(clin\$ adj25 trial\$).tw.

29.((singl\$ or doubl\$ or trebl\$ or tripl\$) adj25 (blind\$ or mask\$)).tw.

30.factorial.tw.

31.crossover.tw.

32.latin square.tw. 
33.(balance\$ adj2 block\$).tw.

34.or/26-33

35.25 and 34

PEDro (the Physiotherapy Evidence Database) (url: www.pedro.fhs.usyd.edu.au) produced by the Centre for Evidence-Based Physiotherapy (CEBP), University of Sydney, Australia was searched on 13 October 2003 using the search term "prolapse".

The UK National Research Register (Issue 3, 2003), Controlled Clinical Trials (April 2003) and ZETOC database of conference abstracts (April 2003) were searched using the search terms cystocele, urethrocele, rectocele, vault prolapse, uterine prolapse, vaginal prolapse, pelvic organ prolapse, pelvic floor.

The reference lists of relevant articles were searched for other possibly relevant trials.

We did not impose any language or other restrictions on any of the searches.

\section{Appendix 3. Search methods for the brief economic commentary (BEC)}

We performed searches for the brief economic commentary (BEC). We searched:

- The NHS Economic Evaluation Database (NHS EED) on the Centre for Reviews and Dissemination (CRD) website (covering from the earliest record in NHS EED, dating from 1968, up to and including 31 December 2014 when their coverage ended). Date of search: 13 February 2020.

As NHS EED is no longer actively updated we performed additional searches of the following databases to identify eligible studies added to these databases from 1 January 2015 onwards (date of search: 13 February 2020):

- MEDLINE on OvidSP (covering 1 January 1946 to January February 12020 ); and

- Embase (on OvidSP) (covering 1 January 1974 to 2020 Week 06).

The economic evaluation search filters applied to our MEDLINE and Embase search strategies were those formerly used by the CRD to identify published reports of full economic evaluations for indexing on NHS EED. These economic evaluation search filters remain freely available on the CRD Database web-pages (CRD 2015). The other search lines in the MEDLINE and Embase search strategies were adapted from the electronic search strategies run for our Cochrane Incontinence Specialised Register along with additional terms for this population developed specifically for this review. Similarly, our NHS EED search strategy was adapted from search strategies run for our Specialised Register and based on textword and MeSH terms (capturing relevant P-I-C concepts) used to identify eligible studies of intervention effects. We followed the current economic methods guidance (Shemilt 2019).

Ovid MEDLINE(R) on OvidSP covering 1 January 1946 to January February 12020 was searched on 13 February 2020 using the following search strategy:

1. Economics/

2. exp "costs and cost analysis"/

3. Economics, Dental/

4. exp economics, hospital/

5. Economics, Medical/

6. Economics, Nursing/

7. Economics, Pharmaceutical/

8. (economic\$ or cost or costs or costly or costing or price or prices or pricing or pharmacoeconomic\$).ti,ab.

9. (expenditure\$ not energy).ti,ab.

10. value for money.ti,ab.

11. budget\$.ti,ab.

12. or/1-11

13. ((energy or oxygen) adj cost).ti,ab.

14. (metabolic adj cost).ti,ab.

Pessaries (mechanical devices) for managing pelvic organ prolapse in women (Review) 
15. ((energy or oxygen) adj expenditure).ti,ab.

16. or $/ 13-15$

17. 12 not 16

18. letter.pt.

19. editorial.pt.

20. historical article.pt.

21. or/18-20

22. 17 not 21

23. exp animals/ not humans/

24. 22 not 23

25. prolapse/

26. uterine prolapse/

27. Rectocele/

28. (prolaps\$ adj5 (pelvi\$ or vagin\$ or genit\$ or uter\$ or vault\$ or apical or urethr\$ or segment\$ or wall\$)).tw.

29. cystoc?ele\$.tw.

30. rectoc?ele\$.tw.

31. urethroc?ele\$.tw.

32. enteroc?ele\$.tw.

33. proctoc?ele\$.tw.

34. sigmoidoc?ele\$.tw.

35. (pelvi\$ adj3 dysfunct\$).tw.

36. (pelvi\$ adj3 (disorder\$ or relax\$)).tw.

37. (vagin\$ adj3 defect\$).tw.

38. (urogen[SW1] ital adj5 prolaps\$).tw.

39. (cervi\$ adj5 prolaps\$).tw.

40. exp Pelvic Organ Prolapse/

41. Pelvic Floor/

42. Pelvic Floor Disorders/

43. (pelvi\$ adj2 floor[SW2] ).tw.

44. perineomet\$.tw.

45. (prolaps\$ adj5 rect\$).tw.

46. or $/ 25-45$

47.24 and 46

Embase on OvidSP covering 1 January 1974 to 2020 Week 06 was searched on 13 February 2020 using the following search strategy:

1. Health Economics/

Pessaries (mechanical devices) for managing pelvic organ prolapse in women (Review) 
2. exp Economic Evaluation/

3. exp Health Care Cost/

4. pharmacoeconomics/

5. (econom\$ or cost or costs or costly or costing or price or prices or pricing or pharmacoeconomic\$).ti,ab.

6. (expenditure\$ not energy).ti,ab.

7. (value adj2 money).ti,ab.

8. budget\$̣.ti,ab.

9. or/1-8

10. letter.pt.

11. editorial.pt.

12. note.pt.

13. or $/ 10-12$

14. 9 not 13

15. (metabolic adj cost).ti,ab.

16. ((energy or oxygen) adj cost).ti,ab.

17. ((energy or oxygen) adj expenditure).ti,ab.

18. 15 or 16 or 17

19. 14 not 18

20. animal/

21. exp animal experiment/

22. nonhuman/

23. (rat or rats or mouse or mice or hamster or hamsters or animal or animals or dog or dogs or cat or cats or bovine or sheep).ti,ab,sh.

24. 20 or 21 or 22 or 23

25. exp human/

26. human experiment/

27. 25 or 26

28. 24 not (24 and 27)

29. 19 not 28

30. conference abstract.pt.

31.29 not 30

32. Uterus Prolapse/

33. Rectocele/

34. Vagina Prolapse/ or Cystocele/ or enterocele/

35. prolapse/ or pelvic floor prolapse/ or exp pelvic organ prolapse/ or perineal descent/ or exp visceral prolapse/

36. (prolaps\$ adj5 (pelvi\$ or vagin\$ or genit\$ or uter\$ or vault\$ or apical or urethr\$ or segment\$ or wall\$)).tw.

Pessaries (mechanical devices) for managing pelvic organ prolapse in women (Review) 
37. (prolaps\$ adj5 rect\$).tw.

38. cystoc?ele\$.tw.

39. rectoc?ele\$.tw.

40. urethroc?ele\$.tw.

41. enteroc?ele\$.tw.

42. proctoc?ele\$.tw.

43. sigmoidoc?ele\$.tw.

44. (pelvi\$ adj3 dysfunct\$).tw.

45. (pelvi\$ adj3 (disorder\$ or relax\$)).tw.

46. (vagin\$ adj3 defect\$).tw.

47. (urogenital adj5 prolaps\$).tw.

48. (cervi\$ adj5 prolaps\$).tw.

49. (pelvi\$ adj2 floor).tw.

50. perineomet\$.tw.

51. pelvis floor/

52. or $/ 32-51$

53. 31 and 52

NHS EED on the Centre for Reviews and Dissemination (CRD) website (covering from the earliest record in NHS EED, dating from 1968, up to and including 31 December 2014 when their coverage ended). Date of search: 13 February 2020. The search strategy used is given below.

\begin{tabular}{|c|c|}
\hline Search & Hits \\
\hline 1 & (MeSH DESCRIPTOR Prolapse EXPLODE ALL TREES) IN NHSEED \\
\hline 2 & (MeSH DESCRIPTOR Cystocele EXPLODE ALL TREES) IN NHSEED \\
\hline 3 & (MeSH DESCRIPTOR Pelvic Organ Prolapse EXPLODE ALL TREES) IN NHSEED \\
\hline 4 & (MeSH DESCRIPTOR Rectal Prolapse EXPLODE ALL TREES) IN NHSEED \\
\hline 5 & (MeSH DESCRIPTOR Uterine Prolapse EXPLODE ALL TREES) IN NHSEED \\
\hline 6 & (MeSH DESCRIPTOR Visceral Prolapse EXPLODE ALL TREES) IN NHSEED \\
\hline 7 & (MeSH DESCRIPTOR Rectocele EXPLODE ALL TREES) IN NHSEED \\
\hline 8 & (MeSH DESCRIPTOR Pelvic Floor EXPLODE ALL TREES) IN NHSEED \\
\hline 9 & (MeSH DESCRIPTOR Pelvic Floor Disorders EXPLODE ALL TREES) IN NHSEED \\
\hline 10 & ((pelvi* ADJ5 prolaps $\left.\left.{ }^{\star}\right)\right)$ OR ((prolaps* ADJ5 pelvi*)) IN NHSEED \\
\hline 11 & $\left(\left(\right.\right.$ vagin $^{\star}$ ADJ5 prolaps $\left.\left.{ }^{\star}\right)\right)$ OR ((prolaps* ADJ5 vagin*)) IN NHSEED \\
\hline
\end{tabular}




12 ((genit* ADJ5 prolaps $\left.\left.{ }^{\star}\right)\right)$ OR ((prolaps* ADJ5 genit* $\left.)\right)$ IN NHSEED

\begin{tabular}{|c|c|}
\hline 13 & ((uter* ADJ5 prolaps*)) OR ((prolaps* ADJ5 uter*)) IN NHSEED \\
\hline 14 & $\left(\left(\right.\right.$ vault $^{\star}$ ADJ5 prolaps $\left.\left.{ }^{\star}\right)\right)$ OR ((prolaps ${ }^{\star}$ ADJ5 vault $\left.\left.{ }^{\star}\right)\right)$ IN NHSEED \\
\hline 15 & ((apical ADJ5 prolaps*)) OR ((prolaps* ADJ5 apical)) IN NHSEED \\
\hline 16 & ((urethr* ADJ5 prolaps*)) OR ((prolaps* ADJ5 urethr*)) IN NHSEED \\
\hline 17 & $\left(\left(\right.\right.$ segment ${ }^{\star}$ ADJ5 prolaps $\left.\left.{ }^{\star}\right)\right)$ OR ((prolaps ${ }^{\star}$ ADJ5 segment $\left.\left.{ }^{\star}\right)\right)$ IN NHSEED \\
\hline 18 & $\left(\left(\right.\right.$ wall $^{\star}$ ADJ5 prolaps*)) OR ((prolaps* ADJ5 wall*)) IN NHSEED \\
\hline 19 & $\left(\left(\right.\right.$ rect $^{\star}$ ADJ5 prolaps $\left.\left.{ }^{\star}\right)\right)$ OR $\left(\left(\right.\right.$ prolaps $^{\star}$ ADJ5 rect $\left.\left.{ }^{\star}\right)\right)$ IN NHSEED \\
\hline 20 & $(($ urogen* ADJ5 prolaps*)) OR ((prolaps* ADJ5 urogen*)) IN NHSEED \\
\hline 21 & $\left(\left(\right.\right.$ cervi $^{\star}$ ADJ5 prolaps $\left.\left.{ }^{\star}\right)\right)$ OR ((prolaps* ADJ5 cervi $\left.\left.{ }^{\star}\right)\right)$ IN NHSEED \\
\hline 22 & $\left(\left(\right.\right.$ pelvi ${ }^{\star}$ ADJ5 dysfunct $\left.\left.{ }^{\star}\right)\right)$ OR ((dysfunct* ADJ5 pelvi^)) IN NHSEED \\
\hline 23 & $\left(\left(\right.\right.$ pelvi $^{\star}$ ADJ5 disorder $\left.\left.{ }^{\star}\right)\right)$ OR ((disorder ${ }^{\star}$ ADJ5 pelvi $\left.\left.{ }^{\star}\right)\right)$ IN NHSEED \\
\hline 24 & $\left(\left(\right.\right.$ pelvi $^{\star}$ ADJ5 relax $\left.\left.^{\star}\right)\right)$ OR ((relax* ADJ5 pelvi*)) IN NHSEED \\
\hline 25 & $\left(\left(\right.\right.$ pelvi $^{\star}$ ADJ5 floor $\left.\left.{ }^{\star}\right)\right)$ OR $\left(\left(\right.\right.$ floor $^{\star}$ ADJ5 pelvi $\left.\left.{ }^{\star}\right)\right)$ IN NHSEED \\
\hline 26 & $\left(\left(\right.\right.$ vagin $^{\star}$ ADJ5 defect $\left.\left.{ }^{\star}\right)\right)$ OR ((defect* ADJ5 vagin*)) IN NHSEED \\
\hline 27 & (perineomet $^{\star}$ ) IN NHSEED \\
\hline 28 & 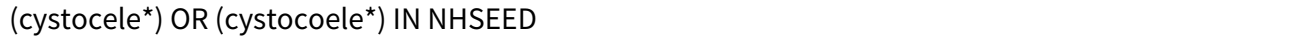 \\
\hline 29 & $(\text { rectocele*})^{*}$ OR (rectocoele*) IN NHSEED \\
\hline 30 & (urethrocele*) OR (urethrocoele*) IN NHSEED \\
\hline 31 & (enterocele*) OR (enterocoele ${ }^{\star}$ ) IN NHSEED \\
\hline 32 & (proctocele*) OR (proctocoele*) IN NHSEED \\
\hline 33 & (sigmoidocele*) OR (sigmoidocoele*) IN NHSEED \\
\hline 34 & $\begin{array}{l}\# 1 \text { OR \#2 OR \#3 OR \#4 OR \#5 OR \#6 OR \#7 OR \#8 OR \#9 OR \#10 OR \#11 OR \#12 OR \#13 OR \#14 OR \#15 } \\
\text { OR \#16 OR \#17 OR \#18 OR \#19 OR \#20 OR \#21 OR \#22 OR \#23 OR \#24 OR \#25 OR \#26 OR \#27 OR \#28 } \\
\text { OR \#29 OR \#30 OR \#31 OR \#32 OR \#33 }\end{array}$ \\
\hline
\end{tabular}

WHAT'S NEW

\begin{tabular}{lll}
\hline Date & Event & Description \\
\hline 3 November 2020 & New search has been performed & $\begin{array}{l}\text { The following changes were made for this update, published in } \\
2020 .\end{array}$ \\
& &
\end{tabular}




\begin{tabular}{lll}
\hline Date Event Description &
\end{tabular}

1. We updated the search to January 2020 and included a total of four trials (Baessler 2019; Cheung 2016; Coolen 2018; Panman 2016). The crossover study included in the previous version of the review has been excluded due to concerns about carry-over data with this study design.

2. We amended the outcomes to reflect those that are most important to women and to clinical decision-makers. We presented separate outcomes for resolution of prolapse symptoms and improvement in prolapse and we also included as an outcome the number of women with adverse events.

3. We removed two comparisons due to their lack of contribution to the evidence base regarding the effectiveness of pessaries as a treatment: pessary plus another treatment versus pessary alone; and differing frequencies of pessary device review or device change.

4. We conducted and included a brief economic commentary to summarise the principal findings of full economic evaluations that compared pessaries with alternative treatment interventions for pelvic organ prolapse in women.

5 . We substantially modified the methodology of the review in accordance with current Cochrane guidance, including adding 'Summary of findings' tables and assessing the certainty of the body of evidence using the GRADE approach.

6. The authorship of the review has changed.

3 November 2020
New citation required and conclusions have changed
1. This version of the review includes four RCTs, leading to the following conclusions: We are uncertain if pessaries improve pelvic organ prolapse symptoms for women compared with no treatment or PFMT but pessaries in addition to PFMT probably improve women's pelvic organ prolapse symptoms and prolapse-specific quality of life. However, there may be an increased risk of adverse events with pessaries compared to PFMT.

\section{H I S T O RY}

Protocol first published: Issue 1, 2003

Review first published: Issue 2, 2004

\begin{tabular}{lll}
\hline Date & Event & Description \\
\hline 7 August 2008 & Amended & Converted to new review format. \\
\hline 26 January 2006 & New search has been performed & $\begin{array}{l}\text { Minor update: 26/01/06 New studies sought but none found: } \\
26 / 10 / 05\end{array}$ \\
\hline 25 February 2004 & $\begin{array}{l}\text { New citation required and conclusions } \\
\text { have changed }\end{array}$ & Review first published \\
\hline
\end{tabular}

\section{CONTRIBUTIONS OF AUTHORS}

CB: reviewed abstracts, extracted data and produced the final review.

EJA: contributed to writing the final review and arbitrated on inclusion/extraction decisions.

DG: reviewed abstracts and contributed to writing the final review.

FS: supported abstract review and data extraction and contributed to writing the final review. 
MD: reviewed abstracts and extracted data and contributed to writing the final review

PS: conducted the brief economic commentary

RK: extracted data and contributed to writing the final review.

\section{DECLARATIONS OF INTEREST}

In accordance with Cochrane's Commercial Sponsorship Policy, the following interests are declared.

CB: none known

EJA: none known

DG: Travel and accomodation expenses provided by Boston Scientific to attend the International Urogynaecology Association's annual conference in Lisbon in 2011. Expenses were paid into the Urogynaecology Department Endowment Fund at the Central Manchester University Hospitals NHS Foundation Trust.

FS: none known

MD: none known

PS: none known

RK: none known

\section{SOURCES OF SUPPORT}

\section{Internal sources}

- No sources of support supplied

\section{External sources}

- National Institute of Health Research, UK

This project was supported by the National Institute for Health Research, via Cochrane Infrastructure funding to Cochrane Incontinence. The views and opinions expressed therein are those of the authors and do not necessarily reflect those of the Evidence Synthesis Programme, the NIHR, NHS or the Department of Health and Social Care.

\section{DIFFERENCES BETWEEN PROTOCOLANDREVIEW}

For this update, published in 2020, we made the following changes.

1. We updated the search to January 2020 and included a total of four trials (Baessler 2019; Cheung 2016; Coolen 2018; Panman 2016). The crossover study included in the previous version of the review (Bugge 2013b) has been excluded due to concerns about carry-over data with this study design.

2. We amended the outcomes to reflect those that are most important to women and to clinical decision-makers. We presented separate outcomes for resolution of prolapse symptoms and improvement in prolapse and we also included as an outcome the number of women with adverse events.

3. We removed two comparisons due to their lack of contribution to the evidence base regarding the effectiveness of pessaries as a treatment: pessary plus another treatment versus pessary alone; and differing frequencies of pessary device review or device change.

4. We conducted and included a brief economic commentary to summarise the principal findings of full economic evaluations that compared pessaries with alternative treatment interventions for pelvic organ prolapse in women.

5. We substantially modified the methodology of the review in accordance with current Cochrane guidance, including adding 'Summary of findings' tables and assessing the certainty of the body of evidence using the GRADE approach.

\section{N DEX TERMS}

\section{Medical Subject Headings (MeSH)}

Pelvic Organ Prolapse [*therapy]; ${ }^{\star}$ Pessaries; Randomized Controlled Trials as Topic; Rectal Prolapse [ ${ }^{\star}$ therapy]; Urethral Diseases [therapy]; Urinary Bladder Diseases [therapy]; Uterine Prolapse [therapy]

\section{MeSH check words}

Female; Humans 